University of South Florida

DIGITAL COMMONS

Digital Commons @ University of

@ UNIVERSITY OF SOUTH FLORIDA

South Florida

\title{
Using Microtransit Electric Low Speed Vehicles as a Means for Improving Quality of Life in Miami-Dade County
}

CUTR

Follow this and additional works at: https://digitalcommons.usf.edu/cutr_nctr

\section{Scholar Commons Citation}

CUTR, "Using Microtransit Electric Low Speed Vehicles as a Means for Improving Quality of Life in MiamiDade County" (2020). Research Reports. 255.

https://digitalcommons.usf.edu/cutr_nctr/255

This Technical Report is brought to you for free and open access by the National Center for Transit Research (NCTR) Archive (2000-2020) at Digital Commons @ University of South Florida. It has been accepted for inclusion in Research Reports by an authorized administrator of Digital Commons @ University of South Florida. For more information, please contact digitalcommons@usf.edu. 
Final Report CUTR-2020-25

\title{
Using Microtransit Electric Low Speed Vehicles as a Means for Improving Quality of Life in Miami-Dade County
}

\author{
Project Number \\ CUTR-NCTR-RR-2020-25
}

Fabian Cevallos, Ph.D.

Florida International University (FIU)

Prepared For

National Center for Transit Research

August 2020

\section{CUTR.USF.EDU \& SOUTH FLORIDA}




\title{
Using Microtransit Electric Low Speed Vehicles as a Means for Improving Quality of Life in Miami-Dade County
}

\author{
Submitted by: \\ Fabian Cevallos, Ph.D. \\ Transit Program Director \\ Lehman Center for Transportation Research (LCTR) \\ Florida International University (FIU) \\ 10555 West Flagler Street, EC 3609 \\ Miami, FL 33174 \\ Phone: (305) 348-3144 \\ Email: fabian.cevallos@fiu.edu
}

\author{
Submitted to: \\ Robert Bertini, Director \\ National Center for Transit Research \\ Center for Urban Transportation Research \\ University of South Florida \\ 4202 E. Fowler Avenue, CUT 100 \\ Tampa, FL 33620 \\ Phone: (813) 974-9797 \\ Email: rbertini@usf.edu
}

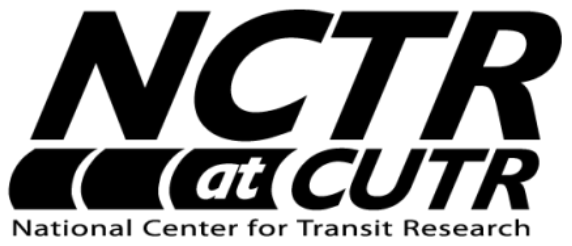

August 2020

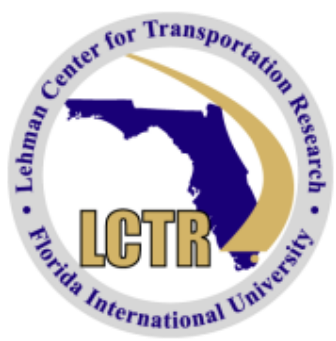




\section{Disclaimer}

The contents of this report reflect the views of the authors, who are responsible for the facts and the accuracy of the information presented herein. This document is disseminated under the sponsorship of the U.S. Department of Transportation's University Transportation Centers Program, in the interest of information exchange. The U.S. Government assumes no liability for the contents or use thereof. 


\section{Acknowledgment}

The project team is grateful to Mr. Robert Pearsall, Senior Research Associate at the Lehman Center for Transportation Research (LCTR), for his participation and invaluable comments. Special thanks must go to Ms. Lilibeth Turino, student assistant from the Department of Civil and Environmental Engineering at Florida International University (FIU), for her dependable assistance throughout this project.

The project team would also like to thank Mr. Jason Spiegel, Managing Partner at Freebee, for providing the microtransit data needed for this project and for providing answers to all our questions.

This work was supported by the National Center for Transit Research, a program of the Center for Urban Transportation Research at the University of South Florida and funded by the U.S. Department of Transportation. 


\section{LIST OF FIGURES}

Figure 1. U.S. DOT Definition of Microtransit..................................................................... 20

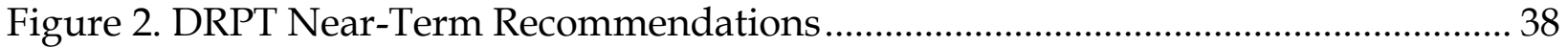

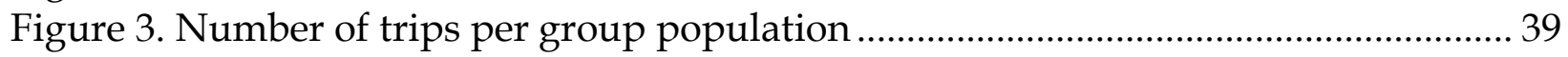

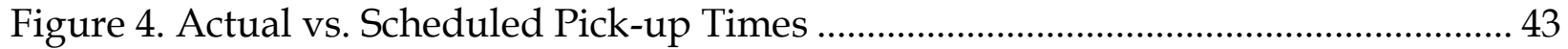

Figure 5. Actual vs. Scheduled Drop-off Times................................................................. 43

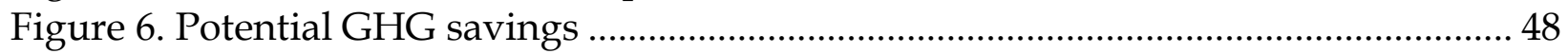

Figure 7 Freebee Microtransit Vehicles............................................................................ 50

Figure 8 Coral Gables Microtransit Ridership ………....................................................... 58

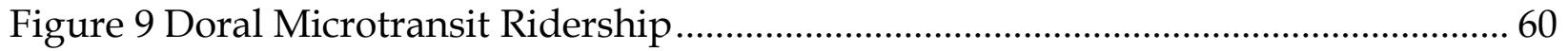

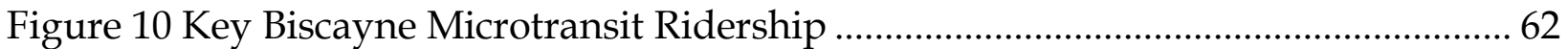

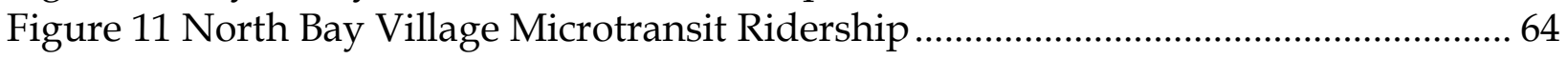

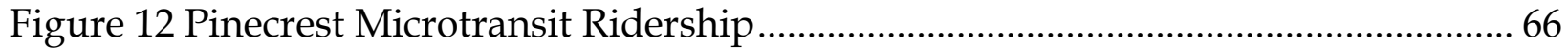




\section{LIST OF TABLES}

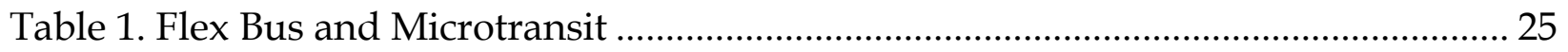

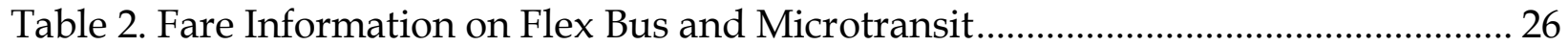

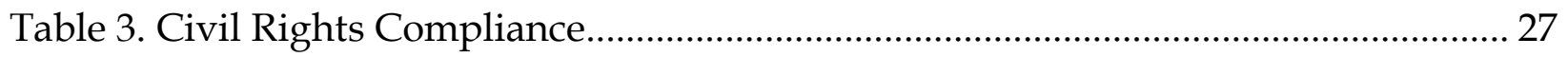

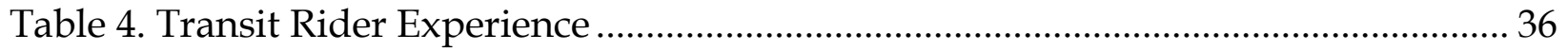

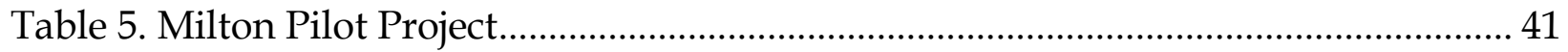

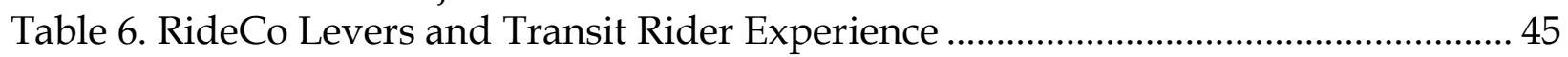

Table 7. Microtransit Use Cases in GTHA and Greater Montréal ....................................... 48

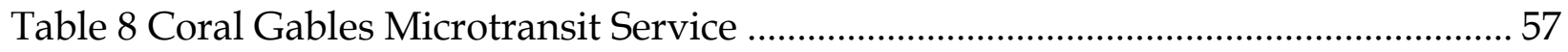

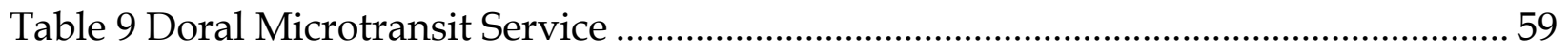

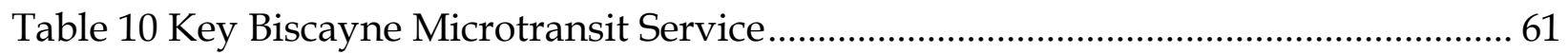

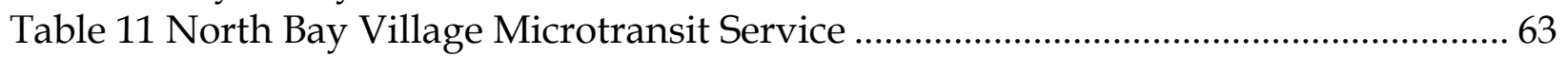

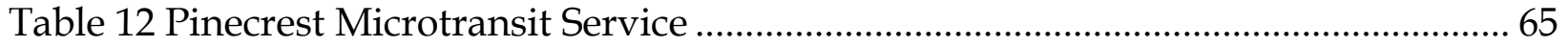




\section{TABLE OF CONTENTS}

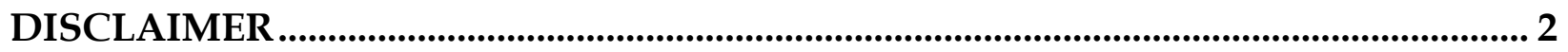

ACKNOWLEDGMENT ................................................................................................... 3

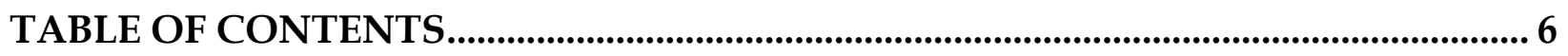

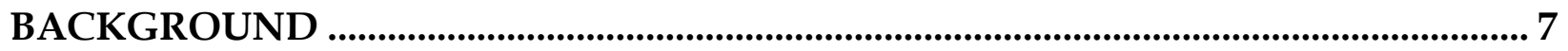

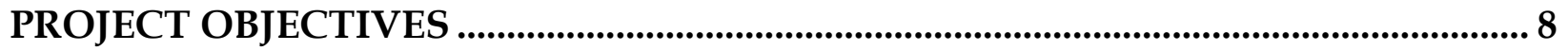

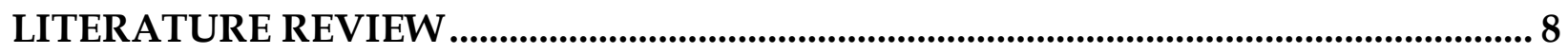

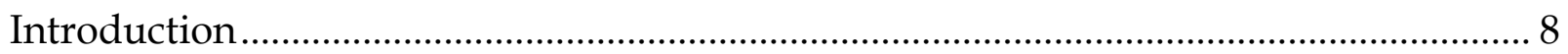

Transportation Modes ................................................................................................. 9

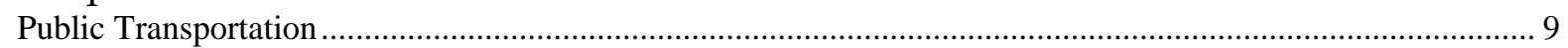

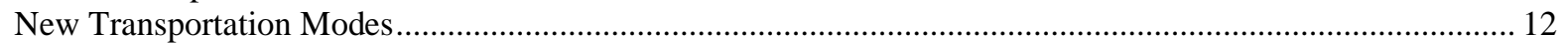

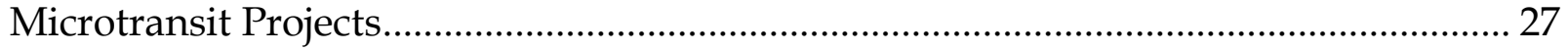

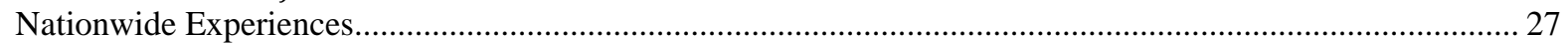

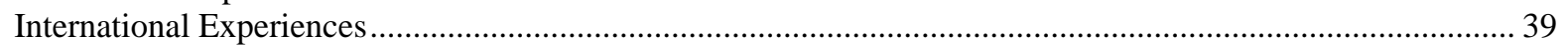

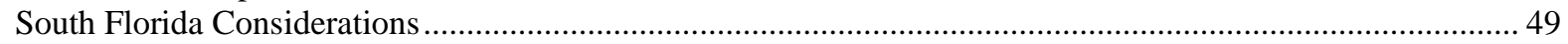

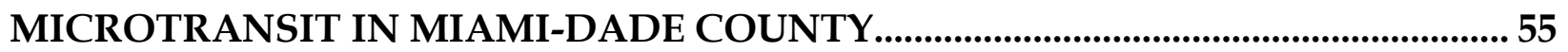

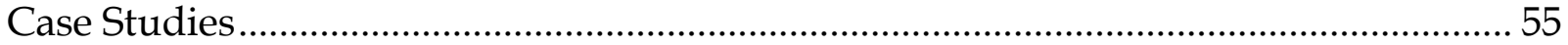

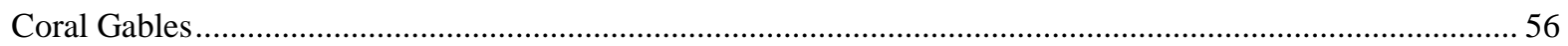

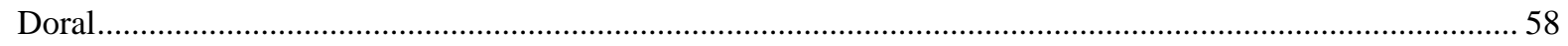

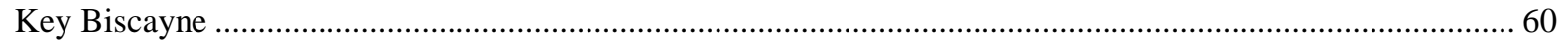

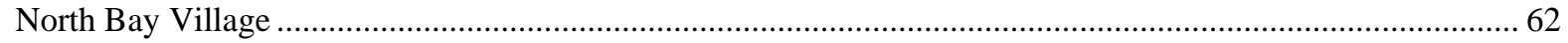

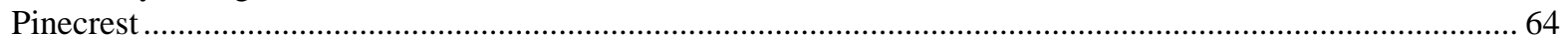

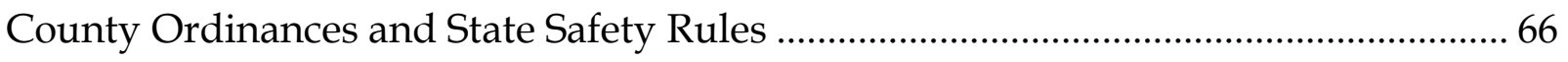

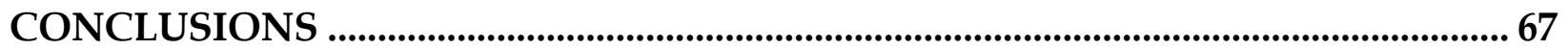

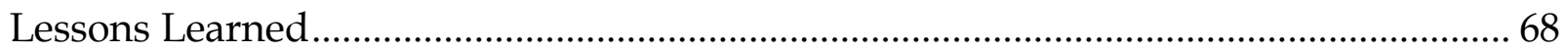

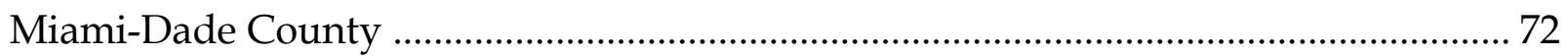

Future Considerations............................................................................................... 72

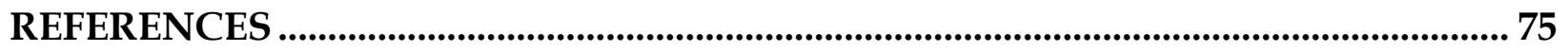

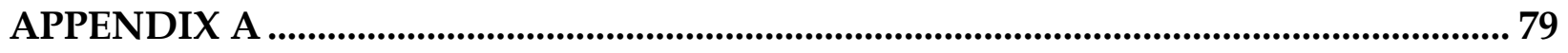

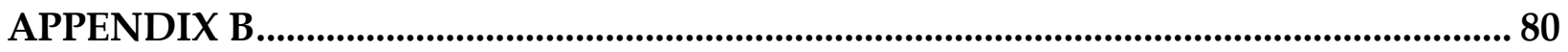




\section{BACKGROUND}

The services provided by public transportation systems increase the mobility and accessibility options of a community. In addition, transit improvements are one of the transportation demand strategies for enhancing community livability, as they offer affordable transportation alternatives and help reduce traffic congestion. Public transportation can provide access to employment, health, educational, and other services that improve the livability of communities. Therefore, implementing additional public transportation services will foster economic development and offer residents, workers, and visitors a full range of transportation choices that will result in an improved quality of life.

The transportation services provided by local communities help in the creation of livable communities. They help transport people daily to jobs, affordable housing, schools, shopping, and health care facilities. In Miami-Dade County, local services are provided by trolleys, community buses, and shuttles that are supported by a major regional transit system that includes rail and bus services. Other transportation services used by the local communities include services from Transportation Network Companies (TNCs) like Uber or Lyft and microtransit service providers such as Freebee or U-Ride which serve areas not well covered by fixed-route transportation services.

This study concentrates on the microtransit services in Miami-Dade operated with electric lowspeed vehicles used within several local communities. Lessons learned from these systems will be documented to assess their impact on quality of life of the communities they serve. Microtransit has been defined as private multi-passenger transportation service that provides transit-like service, but with smaller vehicles. Microtransit can provide service as fixed-route or on-demand and typically relies on technology and dynamic routing. This mode of transportation can fit somewhere between private and public transportation to cover areas that are not effectively serviced by public transit. In addition, microtransit can be useful to address both the first mile/last mile problem and fill the gap of providing mobility to areas not reached by conventional public transportation.

These microtransit services in Miami-Dade County appear to be well accepted with the increasing ridership. It is also expected that the number of microtransit vehicles and overall service will increase in the future as more municipalities in Miami-Dade explore this relatively new transportation service. The service is commonly offered to a community free of charge to passengers, which provides a viable transportation option that improves the quality of life.

This research study includes background information that describes the goal of this project in terms of the impact that this transportation service has on the quality of life. As part of the literature review, existing papers, articles, and reports are reviewed and summarized to gain a better understanding of this subject. This study is enhanced by collecting data and information from the 
current microtransit services to evaluate the effectiveness of the service and their community impact. The data and information were processed and analyzed to identify the key success elements and challenges in the operation of microtransit in Miami-Dade. The document concludes with a summary discussion of lessons learned and suggestions for future research.

\section{PROJECT OBJECTIVES}

The main objective of this scope of work is to conduct a study of microtransit service using electric low-speed vehicles in Miami-Dade County and the impact they have on the quality of life of in the community. To achieve this, the FIU research team proposes a series of work tasks that include developing a work plan, conducting a literature review, data collection, data analysis, and preparing the final report.

\section{LITERATURE REVIEW}

This section focuses mainly on the literature review of microtransit services based on the information available. This includes existing reports, papers, and articles on the subject. A complementary examination of the literature on how these services impact the quality of life and livability of communities is also included to support this effort. The literature review provides information about the successful elements, items of interest, and challenges that need to be taken into consideration in the subsequent tasks of this project. It is expected that the outcome of the literature review will help the team gain enough information for a better understanding of microtransit services and its impact on the quality of life.

\section{Introduction}

According to the Eno Foundation (2018), the transportation system in the United States needs a transformation to efficiently address people's needs and demands. Transportation agencies should make it a priority to identify existing problems in order to provide better solutions of customers' needs. In the case of public transportation, it can be improved with the use of mobility options such as new on-demand services.

Public transportation should provide mobility and enhanced quality of life for those who are unable to provide their own mobility. It should be a resource for efficiently moving people, stimulating economic development, and influencing land use. These should be the main elements to focus on to attract people to public transportation. Stakeholders should remain engaged in public transit to continue addressing any number of public concerns. By doing this, the change in public transportation will be accepted as a positive impact and people will be more inclined to invest in the future, rather than keep the transportation system as it is (Polzin S., 2018). 
New transportation options are being created to offer people alternative means of mobility. This occurs despite of the reluctance of many transit agencies to let go of the institutional structures, systems, and services that exist today. New developments related to public transportation seem inevitable. People are willing to experiment with new transit services, other than the current fixedroute systems, as they look for solutions to their growing demands. This is discussed in Just Around the Corner: The Future of U.S. Public Transportation (Polzin S., 2018). In addition, changes in technology applied to transportation may influence the magnitude and value of economic development associated with transportation investment. For example, self-driving vehicles can decrease traffic on the streets, drones are being used to do deliveries, and society can change land construction patterns to create more or free-up parking spaces. Indisputably, improving the transportation system will result in a series of changes, along with time and money savings, that will have an impact on economic activity and the quality of life.

\section{Transportation Modes}

This section presents the current transportation modes available to the local communities for their mobility. The presence of these modes, in a way, measures the quality of life in a community. That is, a community that has good access to efficient and affordable transportation options is likely to be a vibrant, socially inclusive, economically sound, and environmental conscientious community that offers many opportunities to its residents and visitors.

\section{Public Transportation}

Public transportation is a crucial component of our transportation system. According to APTA, public transportation services offer many benefits. Below is a list of some of the public transportation benefits (APTA, 2010):

- The increase of transportation services is stimulating the economy by supporting sustainable employment and economic activity.

- It gives people the option of using public transportation rather than purchasing a costly and less environmentally friendly car.

- It helps to reduce the dependence on foreign oil.

- Public transportation is an excellent alternative to lower air pollution and carbon footprint.

- It helps relieve traffic congestion and reduce traffic accidents.

- It provides transportation alternatives that improves the quality of life.

- Provide services to older adults and people with disabilities helping them to maintain a healthier and independent life.

In this section, the most relevant transit modes are briefly described, as they relate to microtransit. This includes fixed-route, paratransit, and community bus services. 


\section{Fixed-Route Service}

This is transit service provided along a specific route with a fixed schedule where vehicles stop to pick up and drop off passengers. To provide efficient service, transit agencies must have the resources in place for planning, implementing, and executing services and programs. For this service to be efficient, agencies need reliable equipment and adequate resources to operate and manage the transit fleet. It is also worth mentioning that, among potential transit service improvements, more frequent service was deemed to be the most likely measure to increase ridership (Cevallos F. et al., 2010).

Nevertheless, monitoring and maintaining good on-time performance can be a cost-efficient measure to improve customer satisfaction. Fixed-route service is best suited to provide transit service along main roads or arterials. The main purpose is to provide mobility to people along corridors that connect people to employment, shopping, health, and recreational services.

\section{Paratransit Service}

Transit agencies that provide fixed-route services are required, to comply with the ADA, to provide complementary paratransit services to individuals living within $3 / 4$ of a mile from a fixed route and during concurrent hours of operation. The paratransit service is usually available to the elderly and people with disabilities who are unable to use fixed-route transit. Most paratransit systems require that requests for rides be made in advance, to manage this service which requires demand scheduling and routing strategies. Therefore, the cost of providing a responsive paratransit service requires a considerable subsidy by the government agencies (Cevallos F. et al., 2010).

Paratransit fulfills an important need of the elderly and people with disabilities, but it is an expensive service and it is occasionally abused by individuals who are capable of using regular transit service. As the transit industry improves their services, it opens new opportunities to this segment of the population (Cevallos F. et al., 2010).

\section{Community Bus Service}

Public transportation is crucial to improve the quality of the community. The community bus service is usually provided by municipalities, neighborhoods, and institutions to meet specific needs of their residents. For the community bus service to be effective, they should provide connections to other existing local and regional transit services. It is important that they connect with major transit stations, activity centers, and residential areas.

The services community buses provide are often similar to fixed routes, but they usually serve a smaller area and use smaller vehicles. Community buses connect with fixed-route transit and allow more people to access regular fixed-route services. In other situations, they can attract transit riders from underperforming fixed routes and trips from paratransit services. These community bus 
services can be beneficial to the elderly, because they are designed to travel through the neighborhoods and close to residences and trip destinations (Cevallos F. et al., 2010).

\section{Concerns with Public Transportation}

In regard to the transportation service provided by transit agencies, users are generally concerned about the reliability, the frequency, and the days and hours of operation. In addition, they would like services that meet their trips needs, are comfortable, and desire door to door services. Further, better transit services can open new opportunities for those considering a transportation service, including choice riders. To address these concerns, the $5 \mathrm{~A}$ 's developed by the Beverly Foundation in 2001 can be applied and although the concept is mostly used for an older adult context, they can be relevant to anyone. The 5 A's, as discussed below, are Availability, Accessibility, Affordability, Acceptability, and Adaptability.

- Availability deals with the options people have for using public transit. Research shows that people would use transit service if more options were readily available within their neighborhoods.

- Accessibility deals with the easiness to use public transportation. Transit requires that people navigate the walking environment that includes sidewalks, crosswalks, and streets. However, there are places that are inaccessible or difficult to access which makes transit difficult to use. This is a critical element for people with disabilities.

- Affordability deals with the cost of riding public transit. For instance, many of the elderly require financial assistance for transportation. So, focusing on transit services that are responsive to their needs at a reasonable cost is an important part of enhancing their mobility.

- Acceptability deals with the quality of service provided. It measures the service level, safety standards, and vehicle comfort. Public transportation can be available, but potential riders may believe that the services are unacceptable. The perception that transit is not safe and the belief that services are unreliable and uncomfortable discourage people from using public transit.

- Adaptability deals with the necessary adjustments to meet the needs of the riders. It questions if the transit services are appropriate. Therefore, transit providers should take this into consideration, focus on the needs of its current users and potential riders and adapt accordingly.

Improving public transit services can make the service more attractive to the general public. Potential benefits of improving transit service can also help improve mobility, reduce costs, 
decrease energy use, diminish the environmental impacts, and provide a better quality of life. There are many strategies in the short-run and long-run that agencies can apply to achieve this. Below is a list of few strategies that can be used to improve transit services (Cevallos F. et al., 2010):

- Improve schedule reliability.

- Provide real-time arrival/departure information using advanced technologies.

- Find ways for attracting people who are not familiar with using transit.

- Provide a variety of services, offered at different prices.

- Offer shared-ride and on-demand services.

\section{New Transportation Modes}

As the demand for new and more efficient transportation modes increases, this section presents two relatively new modes of transportation, namely TNCs and Microtransit. Transportation Network Companies (TNC) are mobility service and ridesharing providers that match passengers with vehicles via mobile apps and websites. Transit agencies around the country are looking for solutions to enhance the current transportation system. Partnerships are being created with private mobility companies such as TNC and Microtransit. Pilots are being implemented in many cities showing than partnerships with Microtransit have higher probabilities of being a successful program than with TNC.

\section{TNCs}

The technology revolution is making a big difference on transportation services such as: ridesharing, car sharing, bike sharing, and microtransit. It is creating innovative ways to make the mobility options easier and more reachable for the people. With the growth of transportation network companies (TNCs), many questions about the safety of the passengers, accessibility to the services, and employment issues have been raised bringing about the change of policies and regulations of long-time established services like taxis and limousines (National Academies of Sciences, 2016). These new services vary upon the geographical area of where they are implemented. Most large cities with sizeable street-hail markets extensively regulate taxis, while smaller cities where dispatch service is the norm tend to have lighter regulation (The National Academy of Sciences, Engineering and Medicine, 2016). This situation has caught the attention of the policymakers because the fair treatment would be that both services, taxis and TNCs, have the same policy and regulations that best serve their riders.

There are still many unresolved issues associated with TNCs such as compliance with ADA when offering service to people with disabilities or addressing the fact that this new mobility service has created more full-time and part-time jobs. TNC drivers and most taxi drivers are classified by their companies as independent contractors, which limits their access to benefits tied to employment 
(National Academies of Sciences, 2016). Another characteristic of these services is that people should be tech savvy and have a credit card available in order to request and pay for the services.

Popularity of TNCs services are negatively impacting taxi ridership and also limiting the availability of affordable transportation for low income families and of disabled people. To best serve the people's needs, transportation planning bodies should develop methods for incorporating shared mobility into transportation planning initiatives and promote collaboration between publicand private-sector transportation providers (National Academies of Sciences, 2016)

According to Weinreich (2020), municipalities and transit agencies across the country are quickly developing an innovative new mode of public transit based on the same technology that has facilitated the advent of Transportation Network Companies (TNCs) like Uber and Lyft. Appbased, on-demand transportation services that connect user and driver play an important role in providing a more efficient and personalized transportation service. This revolution in public transportation is due to the inability of fixed-route transit to address the increasing number of customers' demands. This is particularly critical for people who live in those areas with no fixedroute service or areas with poor transit services.

TNC services could be the complement to fixed-route transit. Although it is unclear of the results of that collaboration, many transportation planners are taking into consideration the use of these on demand services to cover those gaps to improve the transportation service. TNCs could cover the first and last mile of people trips but in order to provide a solution to this issue, they should integrate with fixed-route transit system and design a system that works for both services.

However, a number of elements of fixed-route services have been identified showing they do not integrate well across many transit systems, including physical infrastructure like stations and signage; scheduling; fare payment systems, machines, payment cards, transfer discounts; information and data sharing; and special event/emergency planning (Weinreich, 2020). There will be many challenges that these new services would have to face, but the goal should be serving the community with the best transportation systems to enhance people lives.

Transportation Network Companies (TNC) are providing on-demand service to communities which are becoming popular among the people. It is software based which provides comfort to their customers allowing them to request services without following a bus schedule or walking a certain distance to the nearest bus stop, which saves time. However, many have begun to question the effectiveness TNCs are having on the cities where they operate, including public transit ridership, single-occupancy vehicle (SOV) trips, and traffic congestion (Feigon, S. and C. Murphy, 2018). These concerns are fed by the situation of fixed-route bus service declines during the last few years. This leads to another big question on how much this new type of mobility is changing people's perspectives related to public transportation. 
As per TCRP Research Report 195 report, many key findings were highlighted to address these questions in several cities like Chicago, Los Angeles, Nashville, Seattle, and Washington, D.C. (Feigon, S., and C. Murphy, 2018):

1. According to this study, the heaviest TNC use is during evening hours and weekends.

2. Most TNC trips in the study regions are short and concentrated in downtown core neighborhoods.

3. There is no clear relationship between the level of peak-hour TNC use and longer-term changes of public transit usage in the study regions.

4. Among survey respondents, people who use transit or commute by driving solo do so as part of a routine; TNCs are used on a more occasional basis.

5. Transit travel and wait times were major concerns of survey respondents who replaced transit trips with TNC trips.

6. TNC usage takes place in communities of all income levels.

7. TNC use is associated with decreases in respondents' vehicle ownership and SOV trips.

The report also provides a range of guidance to help inform public transit agencies and other public entities of large, midsized and smaller urban areas with their attempts to engage with TNC services. This guidance includes the following items:

- Transit agencies in large urban areas should continue to prioritize rail, bus rapid transit, bus-only lanes, and other transit-centered approaches that move large numbers of people efficiently and effectively. For transit agencies that wish to partner with a TNC company, it is recommended that curb space or other specific locations for pickups and drop-offs be identified to minimize the conflict with near transit stops or stations. In addition, costsavings public-private partnerships should be pursued for late night, call-and-ride, and paratransit services.

- Transit agencies in midsized urban areas may want to explore first mile/last mile partnership opportunities with TNCs to help attract new riders and increase the utility of public transit in lower-density areas.

- Transit agencies in smaller urban areas often have challenges beyond the fare box when it comes to providing frequent and full coverage of their service areas, and thus may be interested in partnering with TNCs to provide alternatives to unproductive routes or provide service across greater time spans or geographic areas.

A profound analysis should be made to study the advantages and disadvantages of an integration of public transit agencies and TNC companies so measurement and policies could be written and implemented for both parties to follow. The main priority is to meet customers' needs while at the same time complementing each other to increase mobility, reduce traffic congestion, mitigate carbon emissions, and increase access to underserved communities (Feigon, S. and C. Murphy, 2018). 
In the report titled Between Public and Private Mobility Examining the Rise of TechnologyEnabled Transportation Services, Kortum, K. (2016) states that the rapid innovation and growth in technology-enabled mobility services has raised many policy issues. The new on-demand service is welcome among the people who are willing to experiment with a new mobility form, however, it has created public concerns related to the safety, accessibility and employment. TNCs are the most controversial new services, disrupting the regulated for-hire taxi industry and posing a series of challenges to transportation policy makers and regulators. The main issue is creating policies and regulations for both transit forms yet focusing on customers' needs as the main goal.

It is important to address these challenges before the on-demand services continuing growing within the transportation sector to not only improve the mobility of people but also making the new transit environmentally friendly by decreasing the traffic and pollution on the streets. Definitive statements are premature, but the potential benefits and risks of shared mobility services are an important topic for exploration. This report highlights the following findings (Kortum, K., 2016):

- Innovative mobility services are expanding travel choices and are being widely embraced by millions of travelers.

- Although TNC services have the potential to enhance mobility for low-income and older adults, the continued expansion of TNCs threatens to worsen the divide among users.

- Regulated taxi service offers important transportation services to people with disabilities. However, in the absence of public policy response, TNCs fueled a decline in taxi services that could affect the availability of vehicle-for-hire services to a substantial number of travelers with disabilities.

- Public safety is a public policy concern with the new shared mobility services.

- TNC drivers, like most taxi drivers, are classified by their companies as independent contractors, not as employees. This status limits their access to benefits that are currently tied to employment.

- The main differences in the scale of TNCs compared with taxi services raise new considerations for regulators.

- Innovations in shared mobility services have the potential to impact travel and land use patterns.

Innovative mobility services are already enhancing mobility for millions of people and have the potential to generate even greater benefits and help with other social goals. Below are recommendations to the many questions formulated with the rapid development of TNC services for the policy makers (Kortum, K., 2016):

1. Policy makers and regulators should formulate public policies and regulations designed to steer the development of innovative services to improve mobility, safety, and sustainability. 
2. Policy makers, planners, and regulators should obtain the necessary information to set policies to regulate mobility services.

3. Policy makers and regulators should carefully examine and consider the pros and cons of employment classifications for TNC and taxi drivers.

4. Policy makers and regulators should seek to integrate the features of TNCs and other innovative shared mobility services into transportation systems and services in ways that leverage the new services' strengths and features.

Transportation will continue to grow over the years. For that reason, it is important to face the potential challenges that will appear and look for answers with the objective of keeping focused on what it is important, the public interest. Lack of flexible services provided by the public transportation system could be a problem for people wishing for services like TNCs. To address this issue, transportation network companies like Uber and Lyft can be a convenient travel mode, because they can provide flexible services available at any time. Therefore, building a partnership relationship with TNCs could solve many transportation problems and increase the mobility options to older adults and people with disabilities.

There are many ideas on how to improve the public transportation system to offer a more efficient and customer-driven service. TNCs can assist public transit in the customers' origin-destination trips and a replacement to low productive fixed-route services. Currently, there are barriers in order to provide an efficient public transit service such as:

- Lack of sidewalks and curb-cuts to reach fixed-route transit stops or area destinations.

- Limited or no TNCs or taxi service available in the area.

- Lack of wheelchair-accessible vehicles from TNCs or taxis.

- Limited or no transit service available in the area.

- Difficulty in navigating roadways, transit schedules, and technology.

TNC partnerships could offer some answers to some of the many problems when providing transportation services. Below are important points to have in consideration when implementing a TNC service (Hansen, T., 2019):

- Data can provide meaningful information on the role of TNCs and inform decision making. Data-sharing agreements have not been common due to privacy concerns.

- Cost per passenger is not capable of telling the whole story of the service provided by TNCs. For this, there is a need to develop metrics to measure the cost and service quality.

- Outreach and training are critical for the adoption of pilot TNC services. This should include some education efforts at the beginning of the pilot project.

- Specialized software for dispatch and routing has the potential to be more efficient than traditional demand-response models. 
- Transit agencies must ensure that enough drivers are available to meet the demand for requested TNC trips.

- Exploration of additional funding opportunities is critical to continue, improve, and expand the TNC services.

- Transit agencies must understand the capabilities of the rapidly evolving innovation of TNCs and adjust accordingly.

Many transit agencies around the country are embracing the idea that greater collaboration between transportation network companies and transit services can enhance mobility (Schwieterman, J., et al., 2018). They expect to solve many transportation problems the system has as a result of these partnerships. Extensive research found that TNCs, instead of occupying the competence of the fixed-routed buses, are functioning more as a complement to serve areas where buses do not reach such as the first and last mile of customers' trips. It has been also noted that people are willing to experiment with the idea of ridesharing services like Uber or Lyft, as success stories have been reported in other areas.

One of the problems that partnerships with TNCs can solve is to provide transportation services in cities where public transportation is deficient or nonexistent. A study by the University of South California shows that ridesharing can also help resolve inequities created by the uneven distribution of taxicabs, particularly by servicing disadvantaged communities in which taxicabs rarely operate. As reported by Schwieterman, J., et al. (2018), most partnerships fit into one of these five groups:

1. Incentives to broadly encourage connections between ridesharing and transit service or to fill gaps in the transit system through discounts and other financial incentives.

2. Development of smartphone trip planning applications that encourage combining ridesharing and transit options on the same trip.

3. Efforts to mitigate parking shortages or anticipate the need for investments in parking lots in downtown districts, areas of public assembly, transit stations, and other locations.

4. Programs to promote mobility for travelers with impairments, including the elderly and disabled, that serve as alternatives to conventional paratransit service.

5. Specialty programs that indirectly promote transit use or the improvement of transit service that considers a variety of initiatives to promote exchanging data to guaranteed ride home programs for commuters using alternative transportation methods.

These partnerships could make a big difference covering customer's needs and demands because the goal is to enhance the already established transit system to improve and enlarge the capacity of move people around. However, the introduction of this new method of transportation can carry many consequences to the cities if they do not follow certain regulations. Some of the main problems have been highlighted and grouped into different sections so the people responsible of making the changes can address them (Schaller, B., 2018): 
Current transportation systems require changes because people's need and demand are growing every day. New mobility methods like Transportation Network Companies (TNCs), microtransit companies such as Via and Chariot, and more recently bikeshare and electric scooters are appearing and offering other mobility options which are becoming popular among people. TNCs are providing an innovative way of transportation that many prefer due to the convenience, flexibility and on-demand technology that characterizes these services. They play a role in providing improved mobility. TNCs and microtransit can be valuable extensions for fixed-route public transit. However, implementation of these services must be within the policy and regulations of the fixed-route buses to guarantee they are serving the goals of mobility, safety, equity, and environmental sustainability (Schaller, B., 2018).

Municipalities and transit agencies across the country are rapidly innovating the development of a new mode of public transit, based on the same technology that has facilitated the advent of Transportation Network Companies (TNCs) like Uber and Lyft. Texas has been a national leader in this regard with app-based, on-demand transportation services that connect user and driver. This revolution in public transportation is due to the inability of fixed-route transit to cover the customer's demands which are increasing every day. This deficiency could create numerous geographical service gaps, disfavoring the people who live in those areas due to the lack of transit services coordination (Weinreich, D. et al., 2020).

TNC services could be the complement to fixed-route transit. Although it is unclear of the results of that collaboration, many transportation planners are taking in consideration the use of these on demand services to cover gaps that improve the transportation service. TNCs can also cover the first and last mile of passenger trips but to provide a solution to this issue. Planners should integrate with fixed-route transit system to design a system that works for both services. However, a number of elements of fixed-route services have been identified that they do not integrate well across many transit systems, including physical infrastructure like stations and signage. Other challenges of integrating the systems includes scheduling; fare payment structures, fareboxes, payment cards, transfer discounts; information and data sharing; and special event/emergency planning (Weinreich, D. et al., 2020). There will be many challenges both services will have to face, but the goal should be the same which is serving the community with the best transportation system to enhance people's lives.

With the development of new technology, the transportation system has also been affected by these new changes. Transportation network companies have appeared offering new mobility options to the people, and even though this is not a new concept, the technology expansion has made it possible to put it into practice options that are diminishing the use of the fixed-route buses. Several research projects have been completed that study how to coordinate TNCs and fixed-route buses while keeping in mind that the main goal is to meet the customers' need. A new design of the transportation system is recommended where it includes both services to complement each other. 


\section{Microtransit}

Microtransit is a relatively new concept offering innovative ways of mobility to people. Nevertheless, there are already some definitions of what microtransit is. Figure 1 shows a microtransit definition by the U.S. Department of Transportation (U.S. DOT), as presented the Eno Foundation 2018 report UpRouted: Exploring Microtransit in the United States. U.S. DOT defines microtransit as "a privately owned and operated shared transportation system that can offer fixed routes and schedules, as well as flexible routes and on-demand scheduling. The vehicles generally include vans and buses." The capability to use a phone application for requesting and paying for this service is changing the way people conceive and use transportation. The microtransit on-demand service is becoming very popular these days, sometimes leaving the fixedroute bus service as an obsolete way of moving around the city.

As microtransit is still a vague term and sometimes even applied to nearly any shared ride service in vehicles larger than a sedan but smaller than a bus (Nelson\Nygaard, 2019). It can use small vehicles with a dynamic routing and scheduling for curb-to-curb transit (KFH Group, 2019). Programs are being designed to either replace an entire route in a low ridership area or to complement fixed-route buses. Many challenges can confront microtransit and if the goals and objectives are not well set, these partnerships can be shut down. Microtransit is still a developing concept that has caught the attention of transit agencies to provide a solution to the problems that current transportation systems are facing. It is still in a probationary phase but so far, the results are promising on how microtransit can be implemented to enhance public transit services and attract more riders (NelsonlNygaard, 2019).

An obstacle to using public transportation is that it is not always accessible for the beginning and end of a person's trip. This dilemma, when the distance to or from a public transit stop or station exceeds a person's comfortable walking distance, is commonly referred to as the First Mile/Last Mile problem. In general, most transit riders and potential transit riders are willing to walk up to $1 / 4$ of a mile at the start or end of their trip. Distances greater than $1 / 4$ of a mile, poor weather, or walking surfaces in poor condition can make it a challenge to use public transportation. An emerging solution to the First Mile/Last Mile problem is Microtransit, which is a multi-passenger transportation service with smaller vehicles (LCTR, 2019).

Many public agencies are considering adapting microtransit to replace fixed-route service in low demand, low-density areas, serving as a first mile-last mile connection to transit hubs and key community destinations. This service can be requested and paid through smartphone applications making it affordable and accessible to customers. Typically, microtransit providers charge a fixed fee to passengers when they book a ride. This fee may vary depending on time-of-day, distance, and current demand, and is generally higher than public transit and lower than ride hailing (around \$3-6 per trip). Companies, such as Via, are approved for use with commuter cards. Others, such as Transdev Link, operated in partnership with existing transit services (NelsonlNygaard, 2019). 


\section{Defining Microtransit}

The U.S. Department of Transportation (U.S. DOT) defines microtransit as "a privately owned and operated shared transportation system that can offer fixed routes and schedules, as well as flexible routes and on-demand scheduling. The vehicles generally include vans and buses."9

Microtransit can be operated on a fixed or flexible route, and by a preset schedule or on-demand schedule. There are several potential configurations as illustrated below. This paper focuses exclusively on flexible route/on demand schedule microtransit, the bottom right quadrant.

\section{Fixed Route/Fixed Schedule}

While routing and arrival/departure times of the shared vehicles are fixed, new and adjusted routes can be "crowd sourced" (i.e., users request origindestination points on a tech-enabled platform that can inform the operators of which routes to introduce). This configuration most closely mirrors public transit.

\section{Fixed Route/On Demand Schedule}

Users request shared vehicles in real time through a tech-enabled application along a predetermined route. Alignment of routes can be "crowd sourced."

\section{Flexible Route/Fixed Schedule}

Users request shared vehicles in real time through a tech-enabled application, but the arrival and departure times of the shared vehicles are fixed. Routes can be fully dynamic and adjusted in real time based on traffic and demand or can change over the span of a few days.

\section{Flexible Route/On Demand Schedule}

Users request shared vehicles through a tech-enabled application, and the vehicle will deviate from its route to somewhere within walking distance of the requester. Routes can be fully dynamic and adjusted in real time based on traffic and demand or can change over the span of a few days.

Figure 1. U.S. DOT Definition of Microtransit

As the transportation system in the United States needs a change to efficiently address people's needs and demands, microtransit offers a new way of mobility. As interest in this service grows, it is critical for public transportation agencies and departments of transportation to understand the benefits and challenges of incorporating components of these innovations into publicly funded services (The Eno Foundation, 2018). 
The experiences of several public transportation providers reveal important lessons to be applied to the future public operation of flexible route, on-demand microtransit (The Eno Foundation, 2018):

1. Agencies seeking to test microtransit need to prioritize customers' needs ahead of the novelty of new technology and think critically about how to design, develop, and implement a pilot that puts the customer first.

2. Agencies should utilize a contracting mechanism that empowers those most familiar with the pilot project to make quick decisions outside of the standard processes, in order to react quickly to potential issues.

3. The success or failure of the application should be determined based on performance metrics that go beyond ridership changes and farebox recovery, such as improved mobility, increased safety, and enhanced customer experience.

4. Agencies should establish their goals up-front and work with potential technology vendors to design a microtransit project within those parameters.

5. Agencies should invest in robust marketing and outreach in order to ensure that all current and potential customers understand how to use the service.

Public transportation can be improved with the use of the microtransit on-demand services as an additional mobility option. Agencies should complete a study to identify their existing transportation problems in order to provide better solutions while keeping the needs of customers as a priority. Transportation services like microtransit that are being provided in many communities seem to the filling the gap of existing public transportation services. As microtransit gets accepted as a new transportation mode, the definition of what is exactly microtransit is likely to evolve.

Microtransit describes the types of services offered by private sector transportation service companies. Its name can vary from one community to another. For instance, it can be referred as Flex service, call n'ride, dial-a-ride, on-demand service, and on call service. This type of service is mainly used in areas not fully covered by fixed-route transit. They can be more expensive than fixed-route service, but less than paratransit. It is more convenient in less dense cities rather than crowded metropolitan areas because in big cities the fixed-route services are usually more efficient. When microtransit is provided and funded by the private sector, its services are usually offered in dense cities with nonexistent fixed-route transit service (National Academies of Sciences, 2019).

With the advancement of technology, transit services have reduced their services tremendously in the past years while demand-responsive transport (DRT) have gained more popularity among the population. Many customers nowadays prefer more personalized service rather than trying to locate a public bus. Technology also brings them comfort from their homes with their smartphones which can request, track or cancel a service. However, for on-demand service to be efficient, transit 
agencies need to engage in serious planning by analyzing travel patterns, identifying trip attractors and generators, and understanding the transportation consumer markets in the lower demand areas to enable moving as many passengers as possible on each route (National Academies of Sciences, 2019).

Microtransit, sometimes referred to as DRT, is enjoying increased attention and throughout the country many transit agencies of all sizes are issuing requests for proposals for services in their areas (National Academies of Sciences, 2019). However, adequate ways of communication and marketing need to be studied in order to promote on-demand services to the general public. Transit agencies report that using the same fares rates as fixed routes could minimize confusion. Also, extensive community outreach needs to be implemented to help people to familiarize with the new changes and learn the basics of using this transit service. Even though the ridership is less than the public fixed-route services, this kind of service offers a variety of service options. But before analyzing the demand-responsive transport operation, it is necessary to understand the essential characteristics of the system under consideration by analyzing the following five aspects of the demand-responsive transport system (Alonso-Gonzalez, M. J., et al., 2018):

1. Coverage and routing. Defined by the operating area and the degree of flexibility in the operation. The latter can range from a fully flexible door-to-door service to more rigid configurations in which only partial deviations from a planned route are possible.

2. Operating hours. Equivalent to the service span considered for fixed-route transit.

3. Vehicle characteristics. DRT fleets often consist of minibus vehicles with previous research suggesting that a vehicle capacity of eight is the preferred vehicle size. Fleet size is also a key design variable of DRT systems as it will determine the different routes that can be covered simultaneously by the system.

4. Booking system. The system can allow for instant bookings in real-time or require advanced bookings or allow for both options. Traditionally, dial-a ride schemes relied on telephone reservations, but large-scale real-time DRT systems require Internet connection to perform the bookings in an efficient manner.

5. Request acceptance criteria. Time required to the pick-up point or vehicle availability are the often-used criteria in deciding whether a request is accepted or rejected.

There are a few factors that have contributed to the interest of implementing demand-response public transit service by transit agencies (National Academies of Sciences, 2019), as presented below:

- Ridership has decreased for most transit agencies since 2014. There are many reasons for this trend, including the competition from transportation network companies that provide an attractive and convenient form of personal demand-response mobility service for those who can afford it. 
- Suburban development continues to grow, but these areas cannot be easily or economically served by fixed-route transit services.

- Transit agencies want to address issues of political or jurisdictional nature by providing some form of service and socioeconomic equity for all areas that support transit through taxes.

- New ridesharing technology in the form of real time route optimizing software, mobile hardware, and communications capabilities are now available to transit agencies. This gives transit agencies the opportunity to potentially provide demand-response service to the general public in a more economical and dynamic fashion than ever before.

- While transit agencies have always tried to be accessible and serve as many people as possible, they have historically been supply-oriented, focusing on their operations and requiring people to adjust to the service they provide. Nowadays, the public expectations are a lot higher. With the advance of technology, as used by DRT or microtransit services, the transit vehicle can easily find the person instead of the person finding the transit service.

Entrepreneurs, referring to microtransit, talk about "first-mile/last-mile transit" all the time (Mackie, P., 2018). However, it is not clear if they really know what the term means to people or the actual distance people have to walk to reach a public transportation service. Some of the microtransit companies are not operating on specific routes where their services are required. They are going wherever the clients request of them, without control of their rides and places. So, they cannot answer if their companies are covering the first mile to public transit. This presents some concerns about the main principles for these companies to operate. Immediate answers to these problems are needed. Whether microtransit services are going to compete or complement with existing transit services is an important piece of information that planners, city leaders, businesses, and the public need to know.

In the editorial board of the Los Angeles Times, Mackie, P., 2018 describes the ambitious goal of the Los Angeles County Metropolitan Transportation Authority to triple the number of commuters who regularly use public transit at a time when subway and bus ridership is actually moving in the other direction. For this, the City of Los Angeles is looking for partnership between microtransit companies and public transit agencies to provide a better service to the community, to have all vehicles ADA accessible, and to think of ways to serve people who do not have a smartphone or credit card. Mackie, P. (2018) states that some companies are probably going to fail, but if they work together with the data and technology available for the entire people-moving and routing processes, there's no reason not to be successful (Mackie, P., 2018).

Another example is Bridj that was an on-demand service that was put into practice in some cities including Kansas City, Boston and Austin. The service was managed by a private company without any affiliation to any transit agency and it was supposed to show the world "what happens when ride-hailing really meets public transit" (Bliss, L.). However the results of the pilot programs were not as expected in Kansas City where the ridership projection was short; and even though the 
company was having great results in Boston, due to the failure in Kansas City, the company abandoned the program after a potential buyer dropped out from extended ownership talks (Bliss, L., 2017). As per the "Bridj Is Dead, But Microtransit Isn't" article, the story is an affirmation of where such on-demand flexible shuttle services really belong in partnering with transportation agencies. The service Bridj offer was no different to the ones implemented nowadays, an ondemand service using a customized software so clients can request and pay for the service. Unfortunately, since it was not associated with a transit agency and the cities being served had insufficient density, the service did not have a positive impact in the community.

Microtransit, on the other hand, is relying on transportation agencies' subsidies. For that reason, using a microtransit service is like a shared taxi service, except the fares on the services have been competitive with those on buses (Bliss, L., 2017). Even though Bridj failed to deliver the message, that Microtransit is the answer for replacing the current transportation system operating big buses that are not moving people to their places, then it is going to be inevitable that in the future we will hear more about it. So, it is crucial to put in practice more pilot programs to figure what people are expecting from their transportation system and what really works for them. Bridj may not have had found the right recipe, but someone probably will (Bliss, L., 2017).

It is important to point out that although microtransit or TNCs were originally thought as transportation options that could address the first mile/last mile problem, currently they go beyond this initial concept. They actually provide a comprehensive and efficient on-demand transportation service for not only connecting to existing transit services (first mile/last mile), but most importantly for providing general transportation service to the local communities.

The following tables present interesting observations based on the case studies in the Demand Response Transit / Microtransit: A Guide for Implementing Flexible Transportation Services report by the KFH Group (2019). Table 1 presents a comparison between Flex Bus and Microtransit. It provides information on a group of transit variables for AC Transit, CapMetro, and Dart under Flex Bus and Hart, the City of Arlington, and the City of West Sacramento under Microtransit. The variables for each of the transit agencies include service area, square miles, bus stops, walking distance, service days and hours, reservations, wait times, and first mile-last mile connections. 
Table 1. Flex Bus and Microtransit

\begin{tabular}{|c|c|c|c|c|c|c|}
\hline \multirow[b]{2}{*}{ Variable } & \multicolumn{3}{|c|}{ Publicly Regulated e-Hailing Flex Bus } & \multicolumn{3}{|c|}{ Publicly Regulated Microtransit } \\
\hline & $\begin{array}{l}\text { AC Transit } \\
\text { FLEX }\end{array}$ & $\begin{array}{l}\text { CapMetro } \\
\text { Pickup }\end{array}$ & $\begin{array}{l}\text { DART } \\
\text { GoLink }\end{array}$ & $\begin{array}{l}\text { HART } \\
\text { HyperLINK }\end{array}$ & $\begin{array}{c}\text { City of } \\
\text { Arlington } \\
\text { Via } \\
\text { Rideshare }\end{array}$ & $\begin{array}{l}\text { City of West } \\
\text { Sacramento } \\
\text { Via On-Demand } \\
\text { Rideshare }\end{array}$ \\
\hline Service area & $\begin{array}{l}2 \text { zones } \\
\text { Newark } \\
\text { Castro Valley }\end{array}$ & Izone & 6 zones & $\begin{array}{l}4 \text { zones } \\
\text { Brandon (2) } \\
\text { Temple Terrace } \\
\text { University }\end{array}$ & $\begin{array}{l}1 \text { zone } \\
\text { TRe Commuter } \\
\text { Prawi Station }\end{array}$ & Chywide \\
\hline Square miles & $\begin{array}{l}\text { Newark } 5.4 \\
\text { Castro Valley. } 42\end{array}$ & 7 & Data unsvailable & 3 & 25 & 21 \\
\hline Bus stops & Designated & Virtual & Virtual & $\begin{array}{l}\text { Designated } \\
\text { Virtual }\end{array}$ & Virtual & Virtual \\
\hline Walking distance & $\begin{array}{l}\text { Min: Curb } \\
\text { Max } 2 \text { blocks }\end{array}$ & $\begin{array}{l}\text { Min: Curb } \\
\text { Max: Curb }\end{array}$ & $\begin{array}{l}\text { Minc Curb } \\
\text { Mac } 2 \text { blocks }\end{array}$ & $\begin{array}{l}\text { Min: Curb } \\
\text { Max: } 2 \text { blocks }\end{array}$ & $\begin{array}{l}\text { Min: Door } \\
\text { Max } 2 \text { blocks }\end{array}$ & $\begin{array}{l}\text { Min: Door } \\
\text { Max } 2 \text { blocks }\end{array}$ \\
\hline Service days/ hours & $\begin{array}{l}\text { Weekdays } \\
\text { 6am-8pm }\end{array}$ & $\begin{array}{l}\text { Weelodays } \\
7 \text { am-7pm } \\
\text { Saturdays } \\
\text { 10am-5pm }\end{array}$ & $\begin{array}{l}\text { Weekdays } \\
\text { Sam8spm }\end{array}$ & $\begin{array}{l}\text { Daily } \\
\text { 5:30am-10:30pm }\end{array}$ & $\begin{array}{l}\text { Weekdays } \\
6 \text { am-9pm } \\
\text { Saturdays } \\
9 a m-9 p m\end{array}$ & $\begin{array}{l}\text { Weekdays } \\
\text { 7am-10pm } \\
\text { Saturdays } \\
\text { 9am-10pm }\end{array}$ \\
\hline Reservations & AC Transit website & Pickup app & Golink app & HyperLiNK app & Via app & Via app \\
\hline Wait times (minutes) & $15 \min \max$ & $15 \min \max$ & Data unsvailable & Data unavailable & $12 \min \max$ & $15 \min \max$ \\
\hline $\begin{array}{l}\text { First Mile-Last Mile } \\
\text { Connections }\end{array}$ & $\begin{array}{l}\text { - } 2 \text { Heavy Rail stations } \\
\text { : Park \& Ride } \\
: \text { Amtrak } \\
\text { - } 9 \text { major trip } \\
\text { generators }\end{array}$ & $\begin{array}{l}\text { - } 1 \text { Light Rail } \\
\text { Station } \\
\text { - } 6 \text { major trip } \\
\text { generators }\end{array}$ & $\begin{array}{l}\text { Each connect to a } \\
\text { Light Rail station }\end{array}$ & $\begin{array}{l}\text { - Connect local } \\
\text { and express bus } \\
\text { - } 2 \text { Transit Centers } \\
\text { - } 7 \text { major trip } \\
\text { generators }\end{array}$ & $\begin{array}{l}1 \text { Commuter } \\
\text { Rail station } \\
10 \text { major trip } \\
\text { generators }\end{array}$ & $\begin{array}{l}1 \text { Transit Center } \\
\text { - } 9 \text { major trip } \\
\text { generators }\end{array}$ \\
\hline
\end{tabular}

Table 2 provides information for agencies that provide Flex Bus and Microtransit services based on the following variables: fare policy, special fares, transfer policy, regional fare integration, and payment method. The agencies under Flex Bus are AC Transit, CapMetro, and Dart and the ones under Microtransit are HART, the City of Arlington, and the City of West Sacramento for Microtransit (KFH Group, 2019). 
Table 2. Fare Information on Flex Bus and Microtransit

\begin{tabular}{|c|c|c|c|c|c|c|}
\hline \multirow[b]{2}{*}{ Variable } & \multicolumn{3}{|c|}{ Publicly Regulated e-Hailing Flex Bus } & \multicolumn{3}{|c|}{$\begin{array}{l}\text { Publicly Regulated and Privately Operated } \\
\text { Microtransit }\end{array}$} \\
\hline & $\begin{array}{l}\text { AC Transit } \\
\text { FLEX }\end{array}$ & $\begin{array}{l}\text { CapMetro } \\
\text { Pickup }\end{array}$ & $\begin{array}{l}\text { DART } \\
\text { GoLink }\end{array}$ & $\begin{array}{c}\text { HART } \\
\text { HyperLINK }\end{array}$ & $\begin{array}{c}\text { City of } \\
\text { Arlington } \\
\text { Via } \\
\text { Rideshare }\end{array}$ & $\begin{array}{l}\text { City of West } \\
\text { Sacramento } \\
\text { Via On-Demand } \\
\text { Rideshare }\end{array}$ \\
\hline Fare Policy & Same as local fare & Free & Same as local fare & $\begin{array}{l}\text { Bus base: } \$ 2.00 \\
-\$ 1 \text { to/from } \\
\text { designated stops } \\
-\$ 3 \text { to/from } \\
\text { anywhere in zone }\end{array}$ & $\begin{array}{l}\text { Bus base: } \$ 2.50 \\
-\$ 3.00\end{array}$ & $\begin{array}{c}\text { Bus base: } \$ 2.75 \\
-\$ 3.50\end{array}$ \\
\hline Special fares & Free 1st month & None & None & First 5 trips free & $\begin{array}{l}\text { ViaPass: } \$ 15 / \\
\text { week (4 trips per } \\
\text { day) }\end{array}$ & $\begin{array}{l}\text {-ViaPass: } \$ 15 \text { ( } \$ 7.50 \\
\text { seniors disabled)/ week (4 } \\
\text { trips per day) } \\
\text {-1st time riders: 1st two } \\
\text { rides free } \\
\text { - Referral promo: } \$ 10 \\
\text { credit for a friend who } \\
\text { rides }\end{array}$ \\
\hline Transfer Policy & None & None & Yes & None & None & None \\
\hline $\begin{array}{c}\text { Regional fare } \\
\text { integration }\end{array}$ & No & No & $\begin{array}{l}\text { GoPass app } \\
\text { GoLink app }\end{array}$ & No & No & No \\
\hline Payment & $\begin{array}{c}\text { Cash } \\
\text { AC Transit pass } \\
\text { Clipper card } \\
\text { (smartcard) }\end{array}$ & Pickup app & $\begin{array}{l}\text { GoPass app } \\
\text { GoLink app }\end{array}$ & HyperUINK app & Via app & Via app \\
\hline
\end{tabular}

Table 3 shows a comparison of Flex Bus and Microtransit services based on Title VI, reduced fares, customers with no internet or smartphone access, limited English proficiency, unbanked customers, vehicles, and ADA capabilities. The agencies under Flex Bus are AC Transit, CapMetro, and Dart and the ones under Microtransit are HART, the City of Arlington, and the City of West Sacramento for Microtransit (KFH Group, 2019). 


\begin{tabular}{|c|c|c|c|c|c|c|}
\hline \multirow[b]{2}{*}{ Variable } & \multicolumn{3}{|c|}{ Publicly Regulated e-Hailing Flex Bus } & \multicolumn{3}{|c|}{ Publicly Regulated Microtransit } \\
\hline & $\begin{array}{l}\text { AC Transit } \\
\text { FLEX }\end{array}$ & $\begin{array}{l}\text { CapMetro } \\
\text { Pickup }\end{array}$ & $\begin{array}{l}\text { DART } \\
\text { GoLink }\end{array}$ & $\begin{array}{l}\text { HART } \\
\text { HyperLINK }\end{array}$ & $\begin{array}{l}\text { City of } \\
\text { Arlington } \\
\text { Via } \\
\text { Rideshare }\end{array}$ & $\begin{array}{l}\text { City of West } \\
\text { Sacramento } \\
\text { Via On- } \\
\text { Demand } \\
\text { Rideshare }\end{array}$ \\
\hline Title VI analysis & Service Equity Analysis & NA & NA & NA & NA & NA \\
\hline Reduced fares & $\begin{array}{c}\text { Youth: } \angle 54 \% \\
\text { Senior: } \angle 54 \% \\
\text { Disabled: }<54 \%\end{array}$ & NA (free) & $\begin{array}{c}\text { Same } \\
\text { populations as } \\
\text { fare policy }\end{array}$ & None & $\begin{array}{l}1.75 \text { senior/ } \\
\text { disabled }\end{array}$ & $\begin{array}{l}\text { Senior: }<50 \% \\
\text { Disabled: }<50 \%\end{array}$ \\
\hline $\begin{array}{l}\text { Customers with } \\
\text { no smartphone or } \\
\text { internet access }\end{array}$ & $\begin{array}{l}\text {-AC Transit Customer Call Center } \\
\text {-Customers board at BART } \\
\text { stations without }\end{array}$ & $\begin{array}{l}\text { CapMetro call } \\
\text { center }\end{array}$ & $\begin{array}{l}\text { DART call } \\
\text { center }\end{array}$ & $\begin{array}{l}\text { Transdev Call } \\
\text { center }\end{array}$ & $\begin{array}{l}\text { Via Customer } \\
\text { Call Center }\end{array}$ & $\begin{array}{l}\text { Via Customer } \\
\text { Call Center }\end{array}$ \\
\hline $\begin{array}{l}\text { Unbanked } \\
\text { customers }\end{array}$ & $\begin{array}{l}\text { Pay cash onboard vehicle } \\
\text { AC Transit pass } \\
\text { Clipper card (smartcard) }\end{array}$ & $\begin{array}{c}\text { Pay cash } \\
\text { onboard vehicle }\end{array}$ & $\begin{array}{l}\text { Pay cash when } \\
\text { board }\end{array}$ & $\begin{array}{l}\text { Pay cash when } \\
\text { board }\end{array}$ & Cashless & Cashless \\
\hline $\begin{array}{l}\text { Limited English } \\
\text { Proficiency }\end{array}$ & $\begin{array}{l}\text {-AC Transit Customer Call Center } \\
\text { interpretation service } \\
\text {-Website reservation \& } \\
\text { notification software in Spanish \& } \\
\text { Chinese } \\
\text {-Google translate }\end{array}$ & $\begin{array}{l}\text { CapMetro call } \\
\text { center }\end{array}$ & $\begin{array}{c}\text { Data } \\
\text { unavallable }\end{array}$ & Data unavailable & Data unavailable & $\begin{array}{c}\text {-Google } \\
\text { translate } \\
\text {-Staff available } \\
\text { at City Hall }\end{array}$ \\
\hline Vehicles & $\begin{array}{l}\text { Cutaway } 26^{\prime} \\
\text { (14 passenger) }\end{array}$ & $\begin{array}{c}\text { Cutaway } 26^{\prime}(12 \\
\text { passenger) }\end{array}$ & $\begin{array}{l}\text { Cutaway } 26^{\prime} \\
\text { (14 passenger) }\end{array}$ & $\begin{array}{l}\text { Vans (5 passenger) } \\
\text { MV-1 (4 passenger) }\end{array}$ & $\begin{array}{l}\text { Mercedes- } \\
\text { Benz Metris (6 } \\
\text { passenger) }\end{array}$ & $\begin{array}{l}\text { Mercedes- } \\
\text { Benz Metris (6 } \\
\text { Dassenger) }\end{array}$ \\
\hline ADA & $\begin{array}{l}\text { Wheekchair accessible (all } \\
\text { vehicles) }\end{array}$ & $\begin{array}{l}\text { Wheelchair } \\
\text { accessible (all } \\
\text { vehicles) }\end{array}$ & $\begin{array}{l}\text { Wheelchair } \\
\text { accessible (all } \\
\text { vehicles) }\end{array}$ & Vans only & 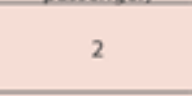 & $\begin{array}{l}\text { Wheelchair } \\
\text { accessible -1 }\end{array}$ \\
\hline Blind/Deaf & Data unavailable & Data unavailable & $\begin{array}{c}\text { Data } \\
\text { unavallable }\end{array}$ & Data unavailable & Data unavailable & None \\
\hline
\end{tabular}

\section{Microtransit Projects}

This section presents selected microtransit projects that, in most cases, are making a positive impact to the communities they serve. As there are many agencies across the country that have implemented, are in the process of implementing, or are considering the implementation of microtransit services, included is a selection of case studies presenting three different groups: Nationwide, International, and South Florida experiences. The case studies are sorted by name and not necessarily by importance.

\section{$\underline{\text { Nationwide Experiences }}$}

\section{Anaheim}

The Anaheim Transportation Network (ATN) and the City of Anaheim's Community Development Department have a common interest in creating a microtransit service for CtrCity Anaheim (Center City in Downtown Anaheim, CA). This project is consistent with city goals of economic prosperity and the positive impacts of developments on parking spaces, traffic congestion, and gas emissions. 
They realized the importance of creating new ways of mobility to provide access to different places as the main element for the city to continue progressing. Microtransit is significant because it represents the first indication of private sector interest in providing transit service since the late 1950s. The transportation industry is experiencing significant growth within the cities due to the wide range of services that it provides such as: conventional fixed-route transit, taxicabs, car sharing, bike sharing, car and vanpooling, pedestrian facilities and parking. Most microtransit companies are offering their services in areas with a high activity and population to alleviate traffic demand and provide service that fixed-route services cannot reach effectively.

Microtransit service could operate as a sub-system of the Anaheim Resort Transportation (ART) and provide the connectivity to the entire ART network, including the Anaheim Resort, Platinum Triangle and ARTIC. Three service alternatives are being considered: On-demand service; fixedroute shuttle; and flexibly-route shuttle (ART, 2017).

ART is a public transportation system of the Anaheim Transportation Network (ATN) and provides service for the residents, employees and visitors of the City of Anaheim and the greater Anaheim resort area, including the cities of Garden Grove, Santa Ana, Costa Mesa and Orange. It has 22 interchangeable routes providing access and convenient transportation service between 72 employment establishments, lodging and resort areas, local destinations, and attractions, convention facilities, sporting venues, and multi-modal transportation facilities. However, ART is looking for a new method to expand their services to areas where fixed-route buses cannot reach providing residents a new way of mobility and connection.

The microtransit service will provide the connectivity to the entire ART network and are considering the following delivery concepts (ART, 2017; ART, 2018):

- e-Hailing. The microtransit service should operate as demand-response transit, where passengers can request a ride from one place to another at a particular time. The vehicles providing this service would not follow a fixed route, but rather they would travel throughout the community transporting passengers according to their specific requests. Direct hailing (e-hailing) would take the form of real-time or dynamic ridesharing where shared rides can be requested in a short-time notice. The system will make use of three technological elements: GPS, smartphones, and social networks.

- Flex Route Service. This service will incorporate some elements of a fixed-route and demand responsive services. A "point deviation" along the route component will allow accommodation of e-hailed trip requests.

To ensure that the system meets requirements of the Americans with Disabilities Act (ADA), microtransit reservations and e-hailing applications will include requests for special services. If passengers do not have access to smart phones or mobile applications, they can request rides over 
the phone using an optional Interactive Voice Response (IVR) system. In addition, according to ART, since 2018, ATN has included two ADA complaint vehicles in the purchase of the ten Electric Low Speed Vehicles (LSV). These vehicles meet federal safety standards and are equipped with windshield glass, safety belts, turn signals, mirrors, and other safety features.

\section{Central Florida}

Central Florida Regional Transportation Authority (LYNX) provides transit service in Orlando, Florida serving a population of approximately 2.4 million people. In 2008, they implemented an on-demand service for the following reasons (National Academies of Sciences, Engineering, and Medicine, 2019):

- To replace inefficient fixed-route buses in low density areas with a less expensive alternative.

- To help transition paratransit customers to fixed-route service and reduce paratransit demand and costs. The on-demand service would transport customers to the nearest transfer point of a fixed-route service.

- To provide access to customers who were unable to access fixed-route services due to various reasons: physical barriers, canals, limited streetlights, or an inadequate sidewalk system.

- To offer connectivity to fixed-route services and local destinations for people in the outskirts of the transit service area.

To address the concerns of the community regarding the service changes, LYNX staff met with community stakeholders. It was determined that the main concerns were with commuters traveling locally and those who needed transfers to fixed route to complete their trips. Staff used historical data to generate the potential service demand for the new service; community stakeholders also provided additional feedback. LYNX planning and operations staff determined that to satisfy the community demand, smaller vehicles would be needed, and the hours of service would be from 5:30 a.m. to 7:30 p.m., Monday through Saturday. In addition, staff created new flex zones of approximately 5 to 7 square miles where the on-demand service would be provided. They expected that one vehicle could accommodate up to six passengers within a zone of that size.

The on-demand service ended up being called "NeighborLink". As this was designed to improve transit service, LYNX believes that the on-demand service is a crucial element of their transit network. Initially, people were hesitant to use the service, but over time they valued the convenience of the service. The agency was able to discontinue fixed routes with low ridership and reduce costs by converting to a less expensive service that met the demand that exists in many communities in the outer portions of their wide service area. Several lessons were learned through the implementation of the microtransit on-demand service such as (National Academies of Sciences, 2019): 
- Involve the community. Effective communication with the community is critical to ensure that they know about the microtransit services and how to use them. Marketing strategies can also help with this effort.

- Agreements with TNCs may be needed when the microtransit service cannot accommodate the passenger demand.

- Use technology to efficiently operate the transit services provided.

- To reduce confusion, use the same fare structure and fare media as fixed-route services.

- The service areas need to be of an acceptable size to meet customers' and agency's expectations, in particular, when only one vehicle provides service to a zone, the service area should be smaller.

- Time connections with fixed routes need to be met.

- Provide travel training for customers who are transitioning from paratransit.

- A transit agency can use less expensive modes to replace low performing routes.

\section{Denver}

With a service area of more than 3 million people, the Denver Regional Transportation District (RTD) provides transit service to the entire city. Denver is a very dynamic city and it continues to grow. Nevertheless, there are areas of low density that RTD needed to deal with. Below are some of the RTD strategies to deal with this issue (National Academies of Sciences, 2019):

- Providing public services to lower density areas where public transportation services are inexistent.

- Providing fixed-route buses services to areas with scattered travel patterns and noncontinuous streets.

- Addressing issues concerning with areas that pay taxes, but do not receive public transit services.

- Complementing the current transit system with new services to make better connections.

RTD completed an extensive study in order to identify the areas that need on-demand service. The study included the service area, travel patterns, trip generators, population and employment density, street layout, traffic generators, community service area, and transit network connections (National Academies of Sciences, 2019). The service was designed to serve destinations too dispersed in the region for which a fixed-route service was deemed impractical.

To provide better transit service, RTD implemented a new service called Call-n-Ride (now called FlexRide: https://www.rtd-denver.com/services/flexride) in the city of Brighton replacing the almost inexistent circulator route buses. The service had great acceptance in this community, and due to this success, Call-n-Ride has considered implementation in other areas with similar transportation characteristics to help with the first and last mile of the transit trips. 
The service used a comprehensive technology platform where customers can book a ride online through their phones, computers, or onboard the vehicles at scheduled locations. The Call-n-Ride service used minivans provided by RTD. The vehicles are lift equipped and the service complies with ADA requirements. Fares were the same as fixed-route buses and reviews from customers were 4.5 on a 5-point scale. The funding sources for the RTD's demand-response services include RTD tax revenue, transit fares, and other matching funds (National Academies of Sciences, 2019).

There are several lessons that were learned from the implementation of the Call-n-Ride on- demand service that can help other agencies considering the implementation of similar services. Lessons learned are presented, as follows (National Academies of Sciences, 2019):

- Establish clear and measurable objectives.

- Plan for the market to be served.

- Assess potential ridership, customer characteristics, and service area characteristics.

- Research the travel patterns of potential riders and configure the service to meet their needs.

- Consider the use of service policies and standards to measure the outcomes.

- Use marketing strategies to promote the service, considering that they can be more difficult than the strategies used for fixed-route services.

\section{Hall County}

Hall County, Georgia, conducted a study on the feasibility of microtransit to analyze the condition for a possible implementation of these on-demand services as the city is constantly growing. The following items are the different element considered in the study (Georgia Planning Association, 2019):

- Service Area

- Entire Hall County (400 square miles)

- Gainesville urbanized area (130 square miles)

- Gainesville City Limits (35 square miles)

- Hours of operation

- Quality of service

- Replace or supplement existing Gainesville Connection and/or Dial-A-Ride

The feasibility study consisted of three steps (Georgia Planning Association, 2019):

1. Identifying opportunities for microtransit

2. Projecting demand

3. Simulating scenarios to determine a microtransit configuration that meets the goals of Hall Area Transit (HAT) 
As a result of this study, many opportunities were identified where microtransit can play an important role in society development, such as:

- Provide transit in previously underserved areas (transit deserts)

- Provide suburban mobility

- Provide first and last mile connections to fixed-route services

- Mitigate traffic congestion

- Reduce parking congestion

- Upgrade a paratransit offering

- Upgrade existing Dial-A-Ride service

- Replace under-performing fixed-route services

\section{Houston}

Houston is a city of four million people and the regional transit provider, Houston METRO, needs to be creative when designing public transportation services to accommodate all residents. Because the city has lower density areas, it has been difficult to take public transit to those regions, affecting mainly the people who live in these regions. For this reason, METRO decided to experiment with providing general public demand-response transit service to replace the poor performing fixedroute bus services. The primary goals of establishing On-Demand Transit (DRT) were (National Academies of Sciences, 2019):

- Offering public transit services to regions where fixed-route buses were ineffective.

- Replacing fixed-route buses with a less expensive alternative.

- Study other areas that can be potentially eligible for DRT due to ineffective transit service.

Houston METRO completed an analysis of different areas that were eligible for DRT service based on the following: low ridership of fixed-route buses, high concentrations of older seniors, low income families, circuitous and disconnected street patterns making it difficult to maneuver fixedroute transit, poor pedestrian environment, and areas near connections to other transportation services. The DRT project started in March 2015 using minibuses with 12 seats.

The DRT service was software based giving the commodity to customers to request their trips online, but they also can board the minibuses at two anchor locations. The customers can also make their trip reservations through phones calls. METRO's demand-responsive transit reflects low utilization and high costs, but the main problem was to maintain the poor-performing fixedroute buses in the same area as the DRT. Even though the fixed-route buses were operating in the DRT Flex zones, customers response from the DRT service was higher than the fixed-route buses. 
One of the many lessons METRO learned from the implementation of a DRT service was to offer a pilot demonstration, so that skeptics and critics had the opportunity to examine the concept in the field. The second lesson was to discontinue fixed-route bus service while the DRT was operating (National Academies of Sciences, 2019). This allowed better collection of data that could be used for further analysis of the pilot project.

\section{Los Angeles}

In 2017, through a forum, Los Angeles County Metropolitan Transportation Authority (LA Metro) encouraged other agencies to join them in this effort. If the agency qualifies, they will be selected to work in planning, design, implementation, and evaluation services for the MicroTransit Pilot project for LA Metro. The main focus of LA Metro is to improve the transportation experience of its residents by offering an on-demand service covering the first and last mile of their trips. This service will connect more people to desired destinations. The service can be requested through a Smartphone application where clients can track their rides. This is expected to be more convenient that using fixed-route buses. In the "2017 Industry Forum on Micro Transit Pilot Project", it is stated that the new public transportation service will be called "MicroTransit," because the service will be used for short trips (under 20 minutes) and will use smaller vehicles than the regular transit vehicles (LA Metro, 2017).

With the advances in technology, customers have new tools and higher expectations on how to plan for trips, pay for services, and travel in general. Therefore, the LA Metro Microtransit application will be designed to be customer friendly to bring a positive experience and attract as many customers as possible. By integrating new transportation technology into their service, LA Metro aims to improve the customer experience by providing a range of benefits to Metro customers, such as (LA Metro, 2017):

- Real-time pickup and drop-off data

- Demand responsive service

- Managed and reduced overall wait times and in-vehicle time

- Faster overall trip times

- Reduced distance to transit access

- Dynamically routed trips

- Reduced number of transfers

- Improved experience when transferring across LA Metro services

- Point-to-point service to and from LA Metro's fixed-route transit system

- Point-to-point service locally within pre-defined service areas

- An alternative to single-occupancy vehicle use for short trips

- Meeting or exceeding ADA requirement 
If the LA Metro Microtransit project is successful, not only will it improve their transportation system, but also will increment the use of the current and new transit routes and will encourage people to use public transportation rather than single-occupancy vehicles alleviating area traffic and reducing the gas emission into the atmosphere. Now, in 2020, LA Metro continues its special interest of the Microtransit Pilot Project to improve the transportation system in Los Angeles County. If implemented, as per their website (https://www.metro.net/projects/microtransit/), this would be the largest microtransit operation in the country run by a public transit agency.

\section{Sacramento}

The Sacramento Regional Transit District (SacRT) announced that it is expanding its on-demand microtransit service to six additional communities. According to SacRT, this makes them the largest microtransit provider in the country with 42 shuttles (Sacramento Regional Transit, 2020). General Manager and CEO Henry Li stated they are committed to provide better mobility options to their residents and since they have seen the success of this type of mobility, they decided to expand the service to other communities. In addition, Sacramento's Board Chair and SacRT Board Chair Patrick Kennedy said that SacRT is truly embracing the future of mobility by providing a more comfortable, convenient, and affordable way to move around their community (Sacramento Regional Transit, 2020).

To request the microtransit service, SmaRT Ride, a smartphone application powered by Via is used. The application uses an algorithm designed for customers to share a vehicle in an efficient manner, as it assigns the closest shuttle for pickups and drop-offs based on customer and vehicle locations. Riders can be picked up and dropped off along the flexible route meanwhile the software continuously updates to provide the rider wait times and trip destination arrival times. The predictions are subject to change based on unforeseen circumstances as traffic conditions, delays caused by passengers like no shows, and/or traffic accidents. The technology behind this type of service utilizes a scheduling software algorithm that finds flexible routing and/or scheduling of vehicles to provide rideshare transportation in a given area (Sacramento Regional Transit, 2020).

The goal of this partnership between Via's technology and SacRT is to make Sacramento an example that microtransit can enhance the public transportation system. The service relies on small, neighborhood-friendly shuttle buses to easily maneuver on residential streets, and they conveniently accommodate people with disabilities. They also cover the first and last miles of their riders by picking and drop them off within a block or two from their locations (Sacramento Regional Transit, 2020).

Microtransit is a new method of transportation where customers can request and pay for their services through applications. SacRT is trying to implement on-demand microtransit services in the City of Citrus Heights to offer their residents other mobility options like Uber or Lyft. SacRT's 
new SmaRT Ride service leveraged innovative app-based technology created by TransLōc, a leader in agency-owned flexible microtransit, for a seamless transit experience. Similar to other ride-hailing models, a shuttle will pick up riders wherever they are and take them where they want to go in the designated service area (Li, H., 2018).

The new microtransit project includes the following attributes (Li, H., 2018):

- Curb-to-curb service to any destination within the boundaries of the city and to medical centers just outside the city boundaries.

- The service is provided with 30-foot cutaway style vehicles that are wheelchair-lift equipped.

- $\quad$ Service hours are currently Monday through Friday, 7 am to $7 \mathrm{pm}$.

- Customers can track their ride in real-time using a computer or a smartphone using a free app from the App Store or Google Play Store.

The cost to ride is only $\$ 2.75$ per trip, $\$ 1.35$ for those eligible for discount fare (seniors, students, and persons with disabilities) or riders can use their SacRT monthly pass. The low-cost makes SacRT's new on-demand service much more affordable than a traditional ride-hailing service, which could cost riders more than five times the amount (Li, H., 2018). Other transit agencies around the country have reached SacRT offices to learn about the new program due to its success. Some of their interest topics related with the program include the funding, operations, usage, experience, labor issues and lessons learned. Even though microtransit is relatively a new ondemand method of transportation, it is becoming more popular throughout the country.

\section{San Antonio}

The City of San Antonio, Texas, is one of the fastest growing cities in the U.S by population. This growth has significant transportation implications. To help with this, San Antonio is looking for innovative partnerships with microtransit companies to enhance and prepare their transit system for the future.

San Antonio plans to conduct a pilot project to use on demand services with vans or shuttles that will replace existing buses. They identified specific innovation zones in the City of San Antonio with low-density suburban routes or routes serving outlying cities with poor ridership, mainly due to long travel times or limited access to transit. San Antonio is also looking for options to the first mile last mile problem. The idea is turning the problem into an opportunity by implementing improved mobility options in these innovation zones.

The project will include a specific zone with 83,569 residents and 25,228 jobs. Currently, this area is served by three bus routes that run at a frequency of every hour, but there are areas not covered 
by this service. Further, riders may have to walk long distances to get to a bus stop and may have to transfer to another bus route to reach their destination. The average ridership is around 1,000 rides per day and the average operating cost to the city is approximately $\$ 7.50$ per passenger ride.

The analysis conducted by the RideCo scientists has led to a recommendation to create approximately 400 virtual stops in this innovation zone. This should increase the area cover by transit and reduce the needs to transfer to another route. The service will be provided using a small fleet that would be dynamically adjusted based on demand. The used vehicles would be five-seater vans from a local transportation company. As far as technology, the project will use the RideCo app to book the rides. The RideCo software application is available for Apple and Android devices.

The anticipated savings to San Antonio is estimated to be over $\$ 250,000$ annually for this innovative zone alone. Table 4 shows the key elements of this project (RideCo., 2019).

\section{Table 4. Transit Rider Experience}

\begin{tabular}{|l|l|l|}
\hline \multicolumn{1}{|c|}{ Levers } & \multicolumn{1}{c}{$\begin{array}{c}\text { Current transit rider } \\
\text { experience }\end{array}$} & $\begin{array}{c}\text { New transit rider experience } \\
\text { with RideCo }\end{array}$ \\
\hline $\begin{array}{l}\text { Frequency of pickups } \\
\text { and drop offs }\end{array}$ & $\begin{array}{l}\text { Buses are scheduled to run every } \\
\text { hour which can result in long wait } \\
\text { times at the bus stop. }\end{array}$ & $\begin{array}{l}\text { Pickups are available every 20 } \\
\text { minutes at the virtual stops. }\end{array}$ \\
\hline $\begin{array}{l}\text { Distance to the } \\
\text { virtual stop or use of } \\
\text { door step }\end{array}$ & $\begin{array}{l}\text { Bus stops are spread out and } \\
\text { require a walk of 15 minutes or } \\
\text { more depending on location. }\end{array}$ & $\begin{array}{l}\text { The 400+ virtual stops are } \\
\text { strategically located for an average } \\
\text { walk of 4 minutes. }\end{array}$ \\
\hline $\begin{array}{l}\text { Travel Delay versus } \\
\text { driving directly alone }\end{array}$ & $\begin{array}{l}\text { The use of different routes within } \\
\text { the zone may require transfers to } \\
\text { get to destination. }\end{array}$ & $\begin{array}{l}\text { Ridesharing means an extra 5 } \\
\text { minutes spent in transit versus } \\
\text { driving directly to destination. }\end{array}$ \\
\hline $\begin{array}{l}\text { Vehicle Type with } \\
\text { the number of seats }\end{array}$ & $\begin{array}{l}\text { Uses municipal buses with the } \\
\text { possibility of not getting a seat, } \\
\text { depending on ridership. }\end{array}$ & $\begin{array}{l}\text { Use 5-seater vans and rides are } \\
\text { only confirmed when seats are } \\
\text { available. }\end{array}$ \\
\hline $\begin{array}{l}\text { Vehicle Quantity in } \\
\text { the fleet }\end{array}$ & $\begin{array}{l}\text { Three total buses are used to cover } \\
\text { the different routes which limits } \\
\text { service. }\end{array}$ & $\begin{array}{l}\text { A fleet of five to eight vans from a } \\
\text { local transportation company are } \\
\text { used to maximize availability. }\end{array}$ \\
\hline
\end{tabular}




\section{San Mateo County}

San Mateo County Transit District (SamTRans) in California has launched a pilot project that started in May of 2019 replacing the FLX Pacifica services in San Mateo county. The new SamTrans OnDemand service was created to improve mobility in the area and to determine whether an on-demand service can provide a more convenient alternative to customers, while encouraging new riders to use the SamTRans transit system (SamTrans, (n.d.)).

The SamTrans OnDemand service makes use of software to allow customers to request their trips through a smartphone app where they can pay and track their rides. For clients who don't have smartphones, they can call customer service to book their rides. Vehicles used by the on-demand service will have 18 seats and can accommodate up to two bikes and two wheelchairs complying with ADA requirements. Fares will vary from $\$ 2.25$ for adults, $\$ 1.10$ for youth, and seniors 65 years and older are eligible for a discounted fare (SamTrans, (n.d.)).

Unfortunately, it has been decided that starting in May 2020, the SamTrans On Demand pilot program will revert back to the original FLX Pacifica route. The project ended after one year of testing. The decision was made based on an analysis conducted by staff that indicated that the ondemand service has been underperforming compared to the previous Pacifica fixed-route service. The following are the key items from this on demand pilot project experience:

- Served fewer passengers

- Operated more vehicle revenue miles

- Generated more customer complaints

- Required higher operating costs

- It was neither effective for school service nor for first/last mile trips

The lessons learned from the on-demand pilot project will assist SamTrans in providing better service for their customers and identifying potential opportunities to improve public transportation throughout San Mateo County (SamTrans, (n.d.)).

\section{Virginia}

In Virginia, the Department of Rail and Public Transportation (DRPT) is launching a Statewide Integrated Mobility Initiative to assist the department and its partner agencies to deal with the rapidly changing mobility landscape. As new transportation alternatives that use technology and include shared modes, become available new travel opportunities are offered to people. These include on-demand TNCs, microtransit, carsharing, and scooters. In addition, it has been observed a transit ridership decline not only in the Commonwealth of Virginia, but also nationwide. DRPT plans to do the following as part of the statewide initiative (Kimley-Horn and IBI Group, 2019): 
- Explore what is happening in Virginia, the U.S., and around the world with the integration of shared mobility and transit.

- Utilize technology to measure, improve, and adapt transit operations to the evolving mobility landscape.

- Identify the positive and negative impacts of shared mobility on the transit industry in Virginia.

- Document existing and planned technology projects at the Virginia transit agencies, including those involving shared mobility providers.

After analyzing these factors, DRPT provided recommendations to the transit agencies on how to provide better transportation service to the community. Figure 2 presents the near-term recommendations from the DRPT Statewide Integrated Mobility Initiative that include program development, statewide contracts and platforms, and local projects. These recommendations will require some investments to cover for DRPT staff time and external vendor or consultant support (Kimley-Horn and IBI Group, 2019).

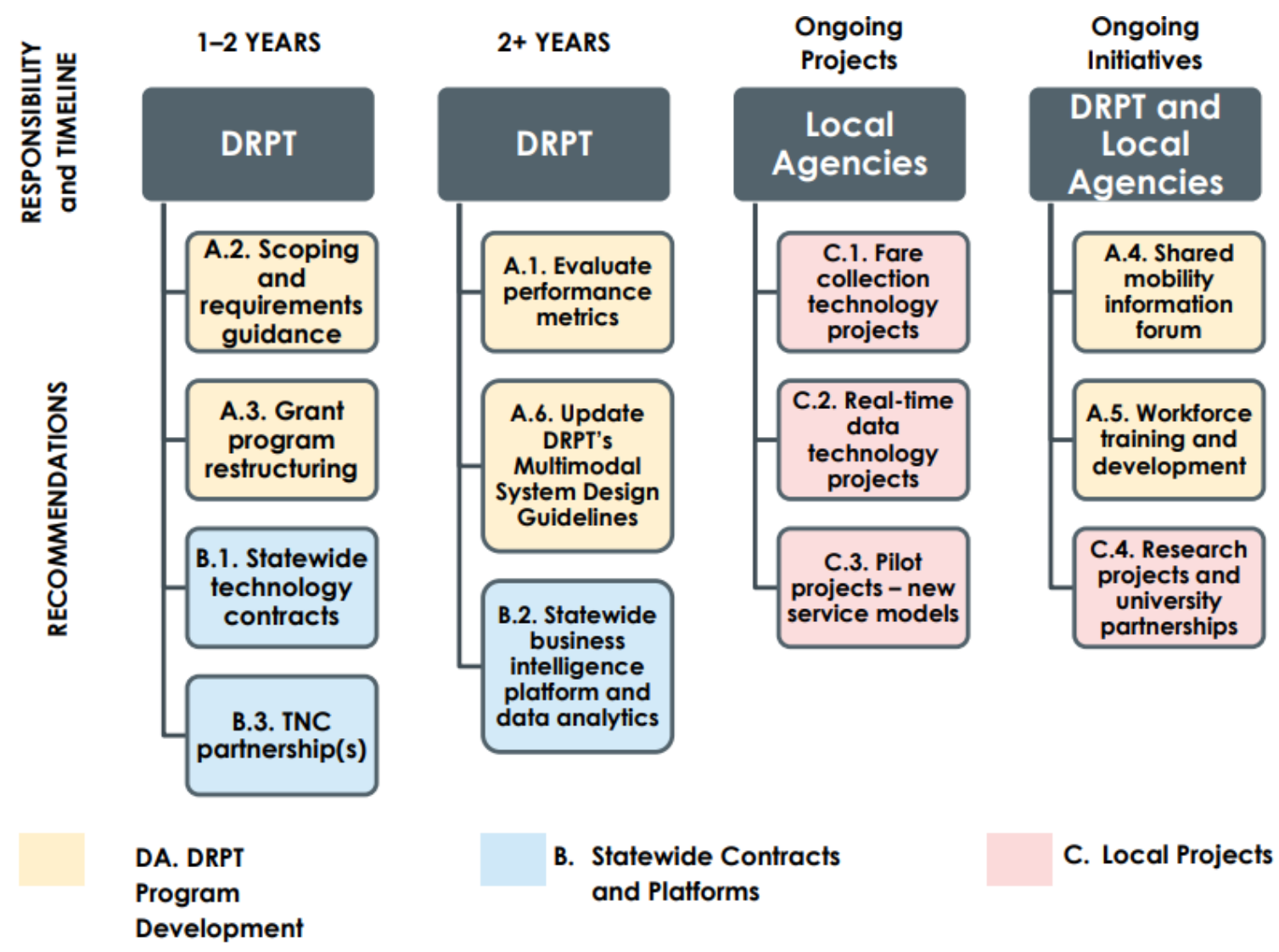

Figure 2. DRPT Near-Term Recommendations 


\section{$\underline{\text { International Experiences }}$}

\section{Barcelona}

Public transportation in Barcelona satisfies the trip demands of residents in one of densest cities in Europe. The Microtransit for Urban Mobility: Analysis, Case Study Proposal and Potential Environmental Impacts report (Werckmeister García, N., 2018) focused in the smaller towns outside Barcelona which needed a solution to their transportation problems. The Associació de Municipis per la Mobilitat i el Transport Urbà (AMTU) grouped 99 municipalities based on their land characteristics and populations size, as follows:

- Group A (population above 100 thousand)

- Group B (population between 50 and 100 thousand)

- Group C (population between 20 and 50 thousand)

- Group D (population between 10 and 20 thousand)

- Group E (population below 10 thousand)

Figure 3 shows, as expected, the reduction in the number of public transportation trips per kilometer as population decreases.

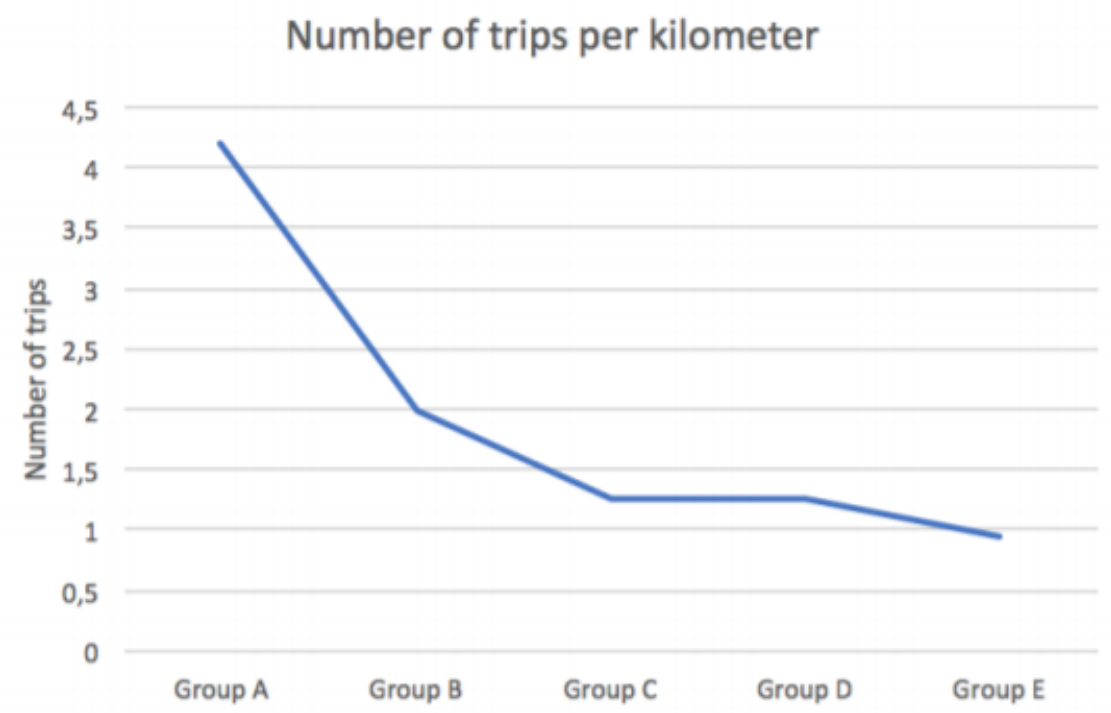

Figure 3. Number of trips per group population

For smaller towns, fixed-route buses cannot offer an efficient service due to low demand and a dispersed population since a large area needs to be covered resulting in the costly maintenance of large buses. Nevertheless, the public transportation services in these towns need to be addressed. For this reason, microtransit is presented as a viable solution for this situation. As stated in the report (Werckmeister García, N., 2018), one of the main goals of this service is to increase the 
transportation coverage and accessibility of these towns. Therefore, in order to implement the best transit service, AMTU completed a survey to identify the reasons for lower performance of public transportation in these areas which were:

- Lack of convenience

- Bad routes or combination of routes

- Lack of public transportation availability

- Inconvenient schedules

AMTU found that the Microtransit service proposal should be implemented along with other means of transportation in order to provide an effective service to these municipalities. The service will be software based allowing customers to book and pay for their rides from their smartphones and booking could be made through traditional phones calls for the people who are not tech savvy. As mentioned before, Microtransit should run as a complement to public transportation service. It will be implemented locally within the municipalities, but it is also important to integrate the services for longer-distance and higher-capacity means of transport such as buses and trains (Werckmeister García, N., 2018). By doing this, microtransit will offer many mobility options to the residents of the towns outside Barcelona.

The vehicles used will be smaller than the buses of fixed-route transit such as microbuses or larger vans that would be able to move on narrow roads reaching the places larger buses cannot serve. For this situation, Microtransit is analyzed as a solution to provide transportation in smaller areas almost as a stand-alone system, therefore, replacing poorly performing fixed-route bus lines. The microtransit service has been proposed using the following principles (Werckmeister García, N., 2018):

- Integration with other means of public transport

- Multi-platform-based service

- Short distance urban travel

- Multimodal

- Flexible routing algorithm

- Small capacity vehicles

\section{Milton}

Another case study presented by RideCo (2019) is the case of Metrolinx in Milton, Canada. Metrolinx is the regional transportation agency in the province of Ontario. When it was first created in 2006, Metrolinx was tasked with working with federal, provincial, municipal agencies, the private sector, and other stakeholders to create an integrated transportation system that would support better quality of life, strong economy, and healthier environment. 
In a partnership between Metrolinx and RideCo, they launched the on-demand Microtransit pilot service "GO Connect" in the Greater Toronto Area (GTA). The one-year pilot project was implemented in the town of Milton, one of the fastest growing communities in Canada. As Milton had congestion and parking issues at its GO station, the objective of the Metrolinx pilot project in Milton was to improve access to the GO Transit station and to reduce the overcapacity of their parking lot. This also helped solve the first mile last mile for Metrolinx. The following bullet points present the key items highlighted by RideCo (2019):

- Customers were given a specific pickup and drop off times when booking a ride.

- Vehicles were dynamically routed based on passenger locations.

- Riders were shared with other passengers going in the same direction.

- The system restricted some of the trip sharing and times to ensure that all riders arrived at their destination on time.

- RideCo developed 240 virtual stops to ensure that the distance riders had to walk to the stop was three minutes or fewer.

- The vehicles selected for the pilot were five-seater vans.

- The frequency of rides during the hours of service was 10 minutes.

- Pricing was set differently for virtual stops versus door stops.

Table 5 highlights some of the findings from the Metrolinx pilot project in Milton, Canada.

\section{Table 5. Milton Pilot Project}

\begin{tabular}{|l|l|l|}
\hline \multicolumn{1}{|c|}{ Levers } & \multicolumn{1}{|c}{$\begin{array}{c}\text { Current transit rider } \\
\text { experience }\end{array}$} & $\begin{array}{c}\text { New transit rider experience } \\
\text { with RideCo }\end{array}$ \\
\hline $\begin{array}{l}\text { Frequency of pickups } \\
\text { and drop offs }\end{array}$ & $\begin{array}{l}\text { 30-minutely frequency and limited } \\
\text { hours of service due to the } \\
\text { prohibitive cost of adding more } \\
\text { buses and routes. }\end{array}$ & $\begin{array}{l}\text { Virtual stop pickups and doorstep } \\
\text { pickups were available every } 10 \\
\text { minutes. }\end{array}$ \\
\hline $\begin{array}{l}\text { Distance to the } \\
\text { virtual stop or use of } \\
\text { door step }\end{array}$ & $\begin{array}{l}\text { Bus stops were well spread out, } \\
\text { leading to long walks for majority } \\
\text { of users. }\end{array}$ & $\begin{array}{l}\text { 240 virtual stops were created to } \\
\text { limit the walking distance to three } \\
\text { minutes or less. }\end{array}$ \\
\hline $\begin{array}{l}\text { Travel Delay versus } \\
\text { driving directly alone }\end{array}$ & $\begin{array}{l}\text { Parking at the transit station was } \\
\text { over-capacity, resulting in no } \\
\text { available parking. }\end{array}$ & $\begin{array}{l}\text { Sharing a ride resulted in an extra } \\
\text { 5-minutes in the vehicle versus }\end{array}$ \\
\hline $\begin{array}{l}\text { Vehicle Type with } \\
\text { the number of seats }\end{array}$ & $\begin{array}{l}\text { Municipal buses were used on fixed } \\
\text { routes. }\end{array}$ & $\begin{array}{l}\text { Used 5-seater vans and rides were } \\
\text { only confirmed when seats are }\end{array}$ \\
\hline $\begin{array}{l}\text { Vehicle Quantity in } \\
\text { the fleet }\end{array}$ & $\begin{array}{l}\text { Cost prohibitive to add buses to } \\
\text { meet fluctuating demand, and } \\
\text { dispersed locations of riders. }\end{array}$ & $\begin{array}{l}\text { A fleet of five to seven vans were } \\
\text { scheduled for dynamic route on- } \\
\text { demand service. }\end{array}$ \\
\hline
\end{tabular}


RideCo (2019) reported that the microtransit pilot in Milton was overwhelmingly positive for Metrolinx, Milton Transit, and the commuters with a rider satisfaction of almost 90 percent. In addition, Metrolinx reported that 45 percent of riders that used the microtransit service switched from driving to the GO transit station.

\section{BRIDJ in Australia}

This case study is based on the trials from Bridj in Inner West Sydney, Australia. Sydney, Australia. The first BRIDJ on-demand service was put in practice in United States, specifically in Boston in 2014. But in 2018, they were acquired by Transit System and the service moved to Australia (Perera, S., Ho, D., and Hensher, D., 2019). One of the main reasons of the acquisition was BRIDJ's technology, as it presented potential solutions for decentralized cities. It started in July 2018 providing transit service to areas that fixed-route buses could not meet the demand of their customers.

BRIDJ services are designed to cover the first and last mile of a resident's trips making easier to move around the local areas. As per the report Resurgence of Demand Responsive Transit services - Insights from BRIDJ trials in Inner West of Sydney, Australia, the main purpose of the service, to be implemented in this region, is to create connections to the train stations especially during peak hours. For the rest of the day and weekends, the service will provide local trips to shopping places and employment centers.

The software used by the BRIDJ allows customers to book and pay for the rides from their smartphones. Vehicles used are smaller with 18 seats offering a fare that varies from $\$ 3.20$ to $\$ 1.60$. The service in Inner West Sydney operates seven days a week with different schedules for weekdays, weekends and public holidays. Changing old mobility habits could take time, but customers were able to try the new demand-responsive transit service, resulting a passenger growth of approximately 30 to $60 \%$ (Perera, S., Ho, D., \& Hensher, D., 2019).

BRIDJ software is on constant evolution. As per data collected from Inner West Sydney, shown in the following figures, pickups are occurring according to their scheduled time and drop-offs are varying from their scheduled and real time. This situation was expected to be the opposite and for that reason, operators are comparing the communication between the service and customers to improve the accuracy of the drop-off and pick-up times. It is also recommended that, in the future software development roadmap, the creation of an optimal service delivery that simulates most common routes used by riders with the purpose of making client's trips more direct and quick savings of time and resources (Perera, S., Ho, D., \& Hensher, D., 2019). Figures 4 and 5 present the actual vs. Scheduled pick-up times and drop-off times of the BRIDJ services, respectively. 


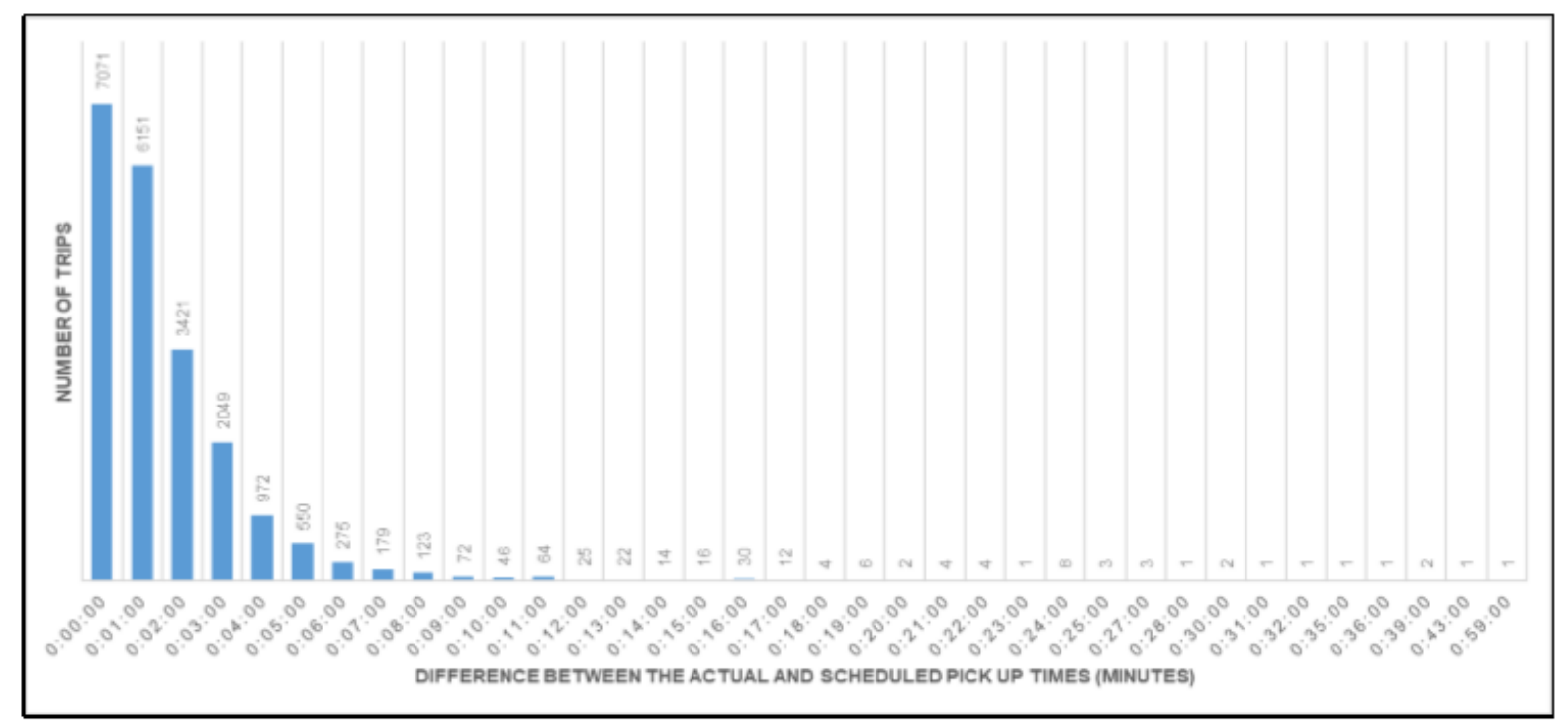

Figure 4. Actual vs. Scheduled Pick-up Times

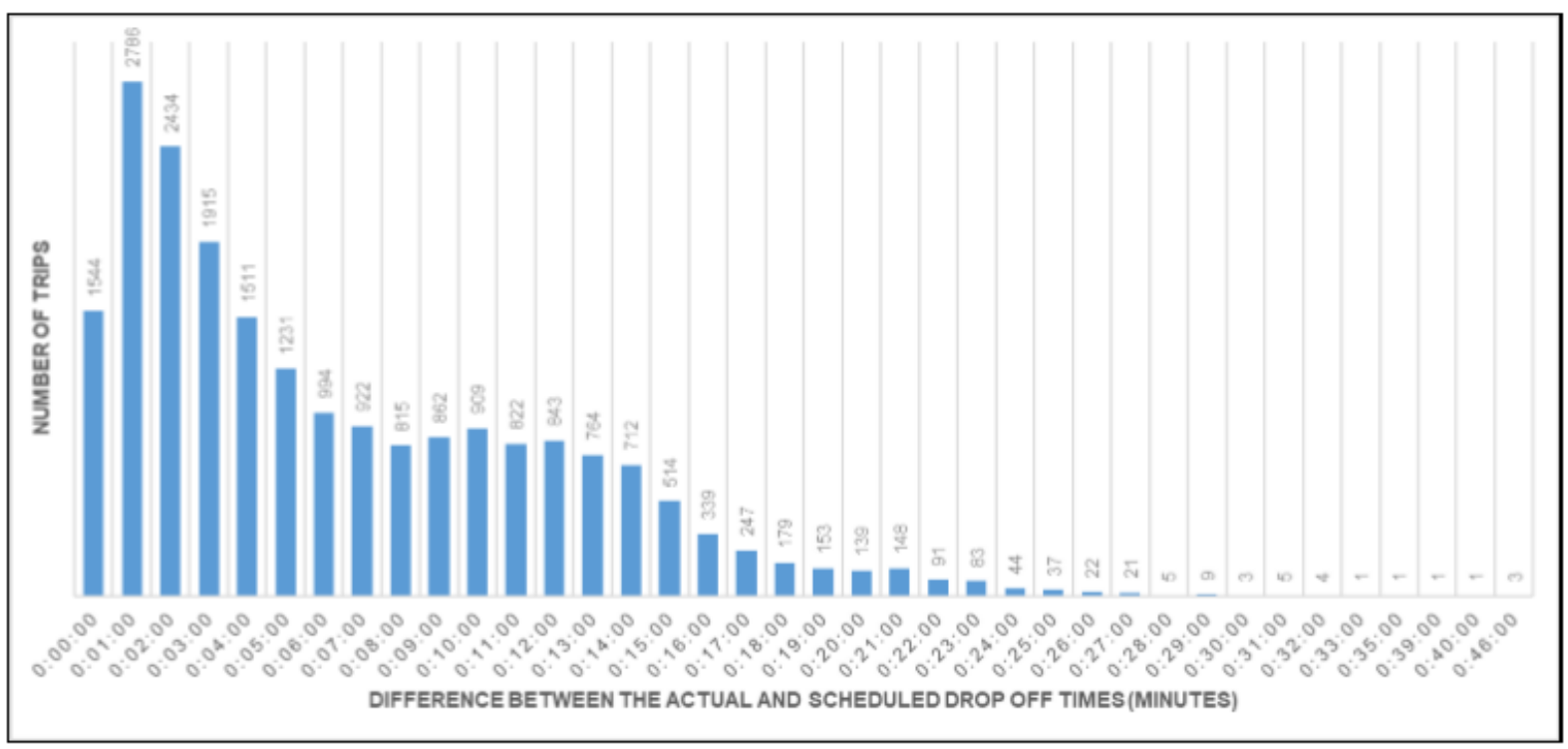

Figure 5. Actual vs. Scheduled Drop-off Times

Even though the service has had a favorable acceptation among people, there are some routes, where BRIDJ service is competing with fixed-route buses fares. The lack of discounted prices for people who are making a connection to the train stations could result in a lower demand of the DRT service. For future service implementations in other areas of the city, it is proposed that the following be considered (Perera, S., Ho, D., \& Hensher, D., 2019):

- Identify the areas where fixed-route buses are not delivering effective service and can be converted to DRT which is a more cost-efficient service 
- Provide discounts fares for riders who are transferring from DRT services to the train station.

- Offer reasonable prices. Establishing a higher fare will make people to consider whether the service is worth the price.

- Analyze the potential performance of DRT service before implementing it.

- Investigate how DRT service could complement the existing public transportation system.

\section{Singapore}

At the Changi International Airport, in Singapore, there are a large number of employees who work on different shifts throughout the day. In this particular case, the fixed-route transit service was not working, because of the employee schedules. Other mobility options needed to be implemented in order to transport these workers to their workplaces. To address this and to increase employee satisfaction, technology was used to improve their commuting experience and reduce costs by using more efficient sharing and vehicle routing. A dynamic on-demand transit service was created, by RideCo and its regional partner Grab, for picking up employees at their homes and taking them to the airport. Now, according to RideCo (2019), the average passenger trip takes around 26 minutes, which is only 10 minutes longer than a direct solo ride.

The vehicles used can be four-seat sedans or six-seat vans, depending on demand. Passengers usually share the ride with three to four coworkers. According to RideCo, 2019, they provide daily service to 200 to 300 employees with a 95 percent on-time performance. As the service quality has improved, so has employee satisfaction, with 80 percent of employees rating their commute very highly. Table 6 presents the five different levers used by the RideCo platform and include Frequency, Distance, Travel Delay, Vehicle Type, and Vehicle Quantity that compares the current with the new transit rider experience. 
Table 6. RideCo Levers and Transit Rider Experience

\begin{tabular}{|c|c|c|}
\hline Levers & $\begin{array}{l}\text { Current transit rider } \\
\text { experience }\end{array}$ & $\begin{array}{c}\text { New transit rider experience } \\
\text { with RideCo }\end{array}$ \\
\hline $\begin{array}{l}\text { Frequency of pickups } \\
\text { and drop offs }\end{array}$ & $\begin{array}{l}\text { Limitations on availability of transit } \\
\text { service due to variety of different } \\
\text { shifts. }\end{array}$ & $\begin{array}{l}\text { Service available to meet employee } \\
\text { needs, regardless of time of day. }\end{array}$ \\
\hline $\begin{array}{l}\text { Distance to the } \\
\text { virtual stop or use of } \\
\text { door step }\end{array}$ & $\begin{array}{l}\text { Doorstep service, with occasional } \\
\text { requirement to walk to stop or taxi } \\
\text { pickup. }\end{array}$ & $\begin{array}{l}\text { Doorstep service and drop off, and } \\
\text { pickup from one of } 4 \text { airport } \\
\text { terminals. }\end{array}$ \\
\hline $\begin{array}{l}\text { Travel Delay versus } \\
\text { driving directly alone }\end{array}$ & $\begin{array}{l}\text { Manual administration of taxis } \\
\text { often resulted in inefficient routes. }\end{array}$ & $\begin{array}{l}\text { Employees spent an extra ten } \\
\text { minutes in the vehicle versus } \\
\text { driving directly. }\end{array}$ \\
\hline $\begin{array}{l}\text { Vehicle Type with } \\
\text { the number of seats }\end{array}$ & $\begin{array}{l}\text { Use of fixed route or manually } \\
\text { scheduled vans and taxis. }\end{array}$ & $\begin{array}{l}\text { A mix of six seat vans and four seat } \\
\text { sedans to meet demand. }\end{array}$ \\
\hline $\begin{array}{l}\text { Vehicle Quantity in } \\
\text { the fleet }\end{array}$ & $\begin{array}{l}\text { Inefficient use of vans and taxis, not } \\
\text { aligned to changing employee } \\
\text { needs. }\end{array}$ & $\begin{array}{l}\text { Dynamic, on demand fleet of } \\
\text { vehicles to efficiently meet } \\
\text { employee needs. }\end{array}$ \\
\hline
\end{tabular}

\section{London}

In 2018, ViaVan launched a microtransit on-demand shared service in London. ViaVan is a jointventure between Via and Mercedes-Benz Vans in Europe and have been granted a renewal for three-years to operate in London by Transport for London (TfL). Since then, ViaV an has expanded to provide service to London city-wide and is collaborating with TfL with the demand-responsive bus pilot in the borough of Sutton. This project is in line and directly related with the city's vision for the future of transport.

According to a Metro Magazine article on July 15, 2019, ViaVan is a company that focuses on the development of on-demand public transportation solutions to reduce single-occupancy vehicles and reduce the impact of increasing congestion and the negative impacts of harmful carbon emissions. By using technology, they have position themselves as a strong private solution provider for transportation services. Since the inception of the pilot project in London, ViaVan provided more than 7 million rides and saved 2 million vehicle miles by transporting multiple passengers into shared vehicles, resulting in saving more than 660 tons of CO2 (Metro Magazine, 2019b). 
In New South Wales, Australia, Via in a partnership with Transport for New South Wales (TfNSW) and Busways launched a new microtransit service for the residents of The Ponds and Schofields. This partnership will provide rides for residents in The Ponds and Schofields areas, addressing the first and last mile problem and connecting more people to the Sydney Metro public transportation system (Via, 2019).

Busways Managing Director, Byron Rowe, said that "Integrated public transport options will alleviate commuter's frustration with congestion on western Sydney roads when they're just trying to get to work and back home each day," "The Ponds and Schofields are growing areas and the Cooee Busways on-demand service provides a crucial first and last mile link to the train and metro." (Via, 2019).

The new shared on-demand microtransit service is called Cooee Busways and will use an app to provide on-demand, dynamic transportation to the suburbs surrounding the two new Sydney Metro stations. The technology used for this service will direct riders to near virtual stops for pickups and drop-offs within a short walking distance. Commuters can download the Cooee Busways smartphone app where they can book their rides between Schofields Train Station, Tallawong Metro station, or Rouse Hill Metro station, and anywhere within the microtransit service area.

\section{Japan}

According to Metro Magazine (2019a), Via announced a strategic partnership with ITOCHU Corp. and Mori Building Co.to provide on-demand service in Japan. This will allow Via to expand its transportation solutions and help Japan with its challenging transportation issues. This builds on a previous partnership between leading Tokyo-based urban developer Mori Building and Via in August 2018 that developed an on-demand mobility solution for travel between Mori Building properties. The success of this program confirmed that Via's solutions can be successfully applied to Japanese business customs and traffic conditions. Therefore, Via will be integrated to the current Japanese transportation system providing mobility options to the places where fixed transit cannot reach.

Using technology, Via aims to provide solutions that can help Japanese transportation companies and drivers improve their productivity and solve social problems related to transportation. The service will be software based and it will be user friendly for people of all ages, including the elderly. The company's technology can efficiently aggregate multiple passengers into shared vehicles, reducing single-occupancy vehicle trips, improving traffic congestion, and reducing carbon emissions (Metro Magazine, 2019a). 


\section{Canada}

The Greater Toronto and Hamilton Area (GTHA) and Greater Montréal Area are exploring the possibility of implementing Microtransit, as a means for reducing greenhouse gases (GHG) in Canada. According to the MaRS Discovery District (2016), the primary influencing factors include the following:

- the magnitude of the travel distances

- the willingness of people to share their journeys

- the rate of occupancy in microtransit vehicles

Transit agencies need to design creative techniques for introducing Microtransit to the community in order to have a successful deployment. For instance, a proactive test-and-learn approach can enable cities to shape the development of microtransit to meet their GHG goals as well as to support reduced congestion, better air quality, transportation, access equity, and greater consumer satisfaction (MaRS Discovery District, 2016).

As presented in MaRS Discovery District, 2016, Table 7 shows a variety of situations, in the Greater Toronto and Hamilton and Greater Montréal, where microtransit can provide attractive alternatives to existing modes of transportation.

Even though the use of the microtransit shared service offers many opportunities, adopting this new mobility method will take some time to overcome the way people are accustomed to travel, like using one car per family working member. For this reason, the service must be reasonably priced relative to the apparent cost of the different alternatives, such as private cars (where the pertrip cost is less apparent) or transit (where the cost per-trip is typically more apparent), MaRS Discovery District (2016).

It is important to create conscience among people about the benefits that this change can bring to the community. Microtransit could be the answer to improve the existing transportation system by offering a convenience and affordable service and this can also help diminish the harmful impacts of traffic to the environment. Figure 6 depicts some microtransit elements important for consumer adoption and potential GHG savings (MaRS Discovery District, 2016). 


\section{Table 7. Microtransit Use Cases in GTHA and Greater Montréal}

\begin{tabular}{|c|c|c|}
\hline$\#$ & Title & Description \\
\hline 1 & $\begin{array}{l}\text { Suburban Rail: Shared dynamic shuttle } \\
\text { services to suburban rail stations }\end{array}$ & $\begin{array}{l}\text { Use of dynamic microtransit to substitute private car use to go to suburban rail and } \\
\text { metro stations }\end{array}$ \\
\hline 2 & $\begin{array}{l}\text { Lower Density Neighbourhoods } \\
\text { Underserved by Transit (trips } \\
\text { originating in suburbs) }\end{array}$ & $\begin{array}{l}\text { Use of dynamically allocated services to aggregate demand, especially at peak } \\
\text { times, from passengers in underserved areas }\end{array}$ \\
\hline 3 & $\begin{array}{l}\text { Off-peak services to mid-density } \\
\text { suburbs }\end{array}$ & $\begin{array}{l}\text { Use of dynamically allocated services to aggregate demand from passengers at off- } \\
\text { peak times to increase cost-effectiveness }\end{array}$ \\
\hline 4 & Busy corridor commutes & $\begin{array}{l}\text { Publicly or privately operated shuttle services based on fixed or dynamic scheduling } \\
\text { to provide an alternative to fixed public transportation and to create additional } \\
\text { capacity }\end{array}$ \\
\hline 5 & $\begin{array}{l}\text { Paratransit: Accessible and special } \\
\text { transport services }\end{array}$ & $\begin{array}{l}\text { Use of on-demand services to aggregate demand from passengers wishing to } \\
\text { use accessible and special transportation services to improve cost-effectiveness, } \\
\text { increase frequency and areas served }\end{array}$ \\
\hline 6 & Downtown circulation & $\begin{array}{l}\text { Substitute use of personal cars in downtown Toronto and Montréal with microtransit } \\
\text { services. } \\
\text { This could also include substitution of transit, walking, cycling with microtransit } \\
\text { (though the data needed was unavailable to quantify the reverse effect). }\end{array}$ \\
\hline 7 & School drop off & $\begin{array}{l}\text { Use of microtransit services to substitute for use of personal cars to drop off and } \\
\text { pick up children at schools. }\end{array}$ \\
\hline 8 & Airport drop off & $\begin{array}{l}\text { Use of microtransit services to substitute for use of personal cars or taxis to drop } \\
\text { off and pick up passengers from airports. This could also include substitution of } \\
\text { transit with microtransit (though more data is needed to quantify the reverse effect) }\end{array}$ \\
\hline 9 & Retail: Suburban malls & $\begin{array}{l}\text { Use of microtransit services to substitute for use of personal cars or taxis to go to } \\
\text { large retail malls, usually located in suburban areas }\end{array}$ \\
\hline 10 & Shift workers & $\begin{array}{l}\text { Use of microtransit services to provide shift workers with more options to go to and } \\
\text { leave work at off-peak hours, where traditional public transit options are scarce. }\end{array}$ \\
\hline 11 & Trip chaining - home-school-work & $\begin{array}{l}\text { Substitute for use of personal cars to drop off children at school and then commute } \\
\text { to work }\end{array}$ \\
\hline 12 & Entertainment: Events & $\begin{array}{l}\text { Use of microtransit services to transport a large number of people to sport and } \\
\text { cultural events, reducing the number of personal cars on the road. }\end{array}$ \\
\hline
\end{tabular}

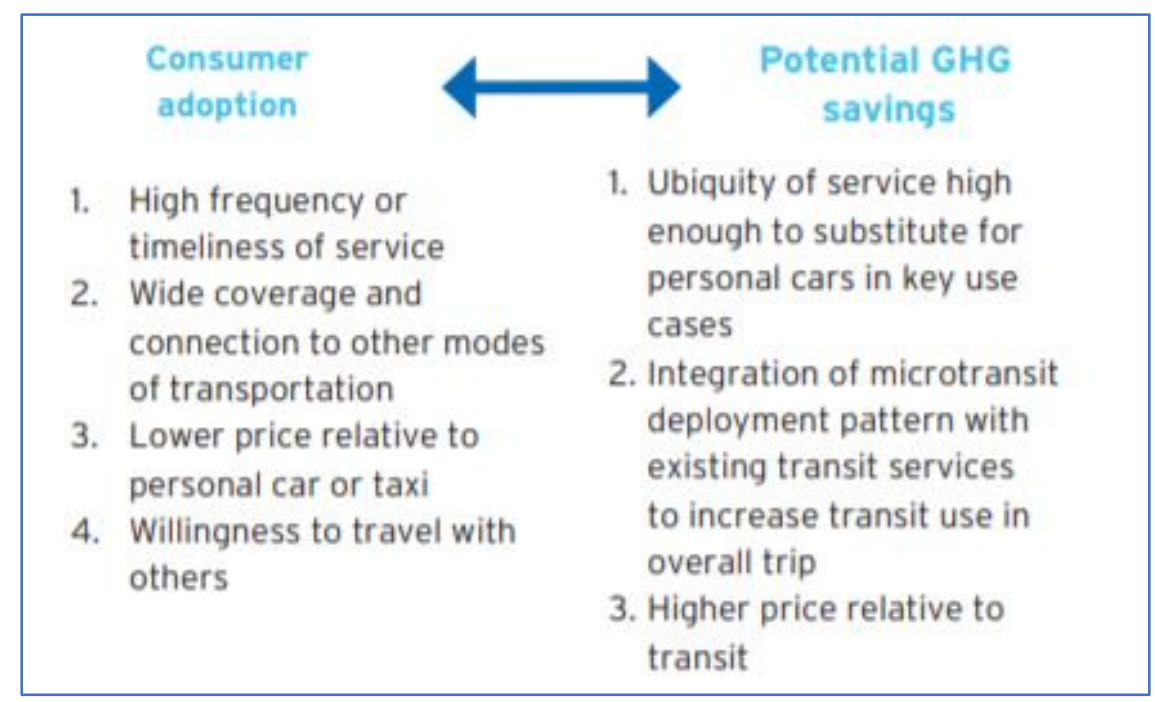

Figure 6. Potential GHG savings 


\section{$\underline{\text { South Florida Considerations }}$}

Transit agencies are exploring, in coordination with private transportation companies, the provision of microtransit services to the local communities. The operators of these services in South Florida include mainly Freebee, Uride, and Circuit. In Miami-Dade County, microtransit services have commenced and more projects continue to be implemented by several municipalities. In Broward and Palm Beach Counties pilot projects are underway, (Cevallos, 2019). In most cases, the on-demand services are being provided by low-speed electric vehicles. Microtransit companies embrace the use of the latest technology such as smartphone apps and real-time tracking information to provide door-to-door service (LCTR, 2019). The on-demand service can provide first mile/last mile connection to transit services as well as provide general transportation within the different municipalities where the service is available.

Free fares for rides are growing in South Florida benefiting its residents and visitors. One of these services, Freebee, provides free short rides in densely populated areas at a maximum speed of 35 mph. Pedestrians in busy sections of Fort Lauderdale, Palm Beach and West Palm Beach can use smartphone apps to request rides. Partnering with local governments and private advertisers, several companies are building fleets of low-speed six-seat electric shuttles to transport people over short distances within congested urban zones (Hurtibise, R., 2019). It is worth mentioning that Freebee also offer larger vehicles that can operate on any roads, without the 35-mph restriction of smaller vehicles. Figure 7 depicts the two types of vehicles currently used by Freebee.

\section{Freebee}

Freebee uses electric transportation that promotes energy efficient service. Their service is currently being used by several municipalities and areas within Miami-Dade County such as Coral Gables, Key Biscayne, Miami, Miami Beach, Wynwood, Downtown, Brickell, Miami Lakes, and Coconut Grove. It is also being tested by other municipalities such Doral and Fort Lauderdale as a means of filling the first and last mile gap by operating as a feeder to the existing regional transit service (LCTR, 2019). The Freebee microtransit service continues to expand in South Florida and some of the municipalities are moving from testing to full operations.

According to Jesse Scheckner with the Miami Today (2019, July 23), Jason Spiegel, Co-Founder and Managing Partner along with co-founder Kris Kimball, started the Freebee service in February of 2012. Initially, the business model of the free on-demand service was different than it is today. Essentially, Freebee began as an ad agency that provided transportation service. The service was provided by a small fleet of electric golf-cart-like vehicles, wrapped with ads from Fortune 500 sponsors like Coca-Cola, T-Mobile and Jack Daniels to transport riders for short distances in South Beach. However, in 2016 the business model changed with the development of Ride Freebee, an app similar to those used by companies like Uber and Lyft that enables customers request door-to- 
door trips using mobile devices. The microtransit service is organized under three models (Hurtibise, R., 2019):

- Cities fund the entire operation as if it was their own.

- Cities pay for the service at a reduced rate when costs are shared with advertising.

- Ad revenues fund the entire operation.
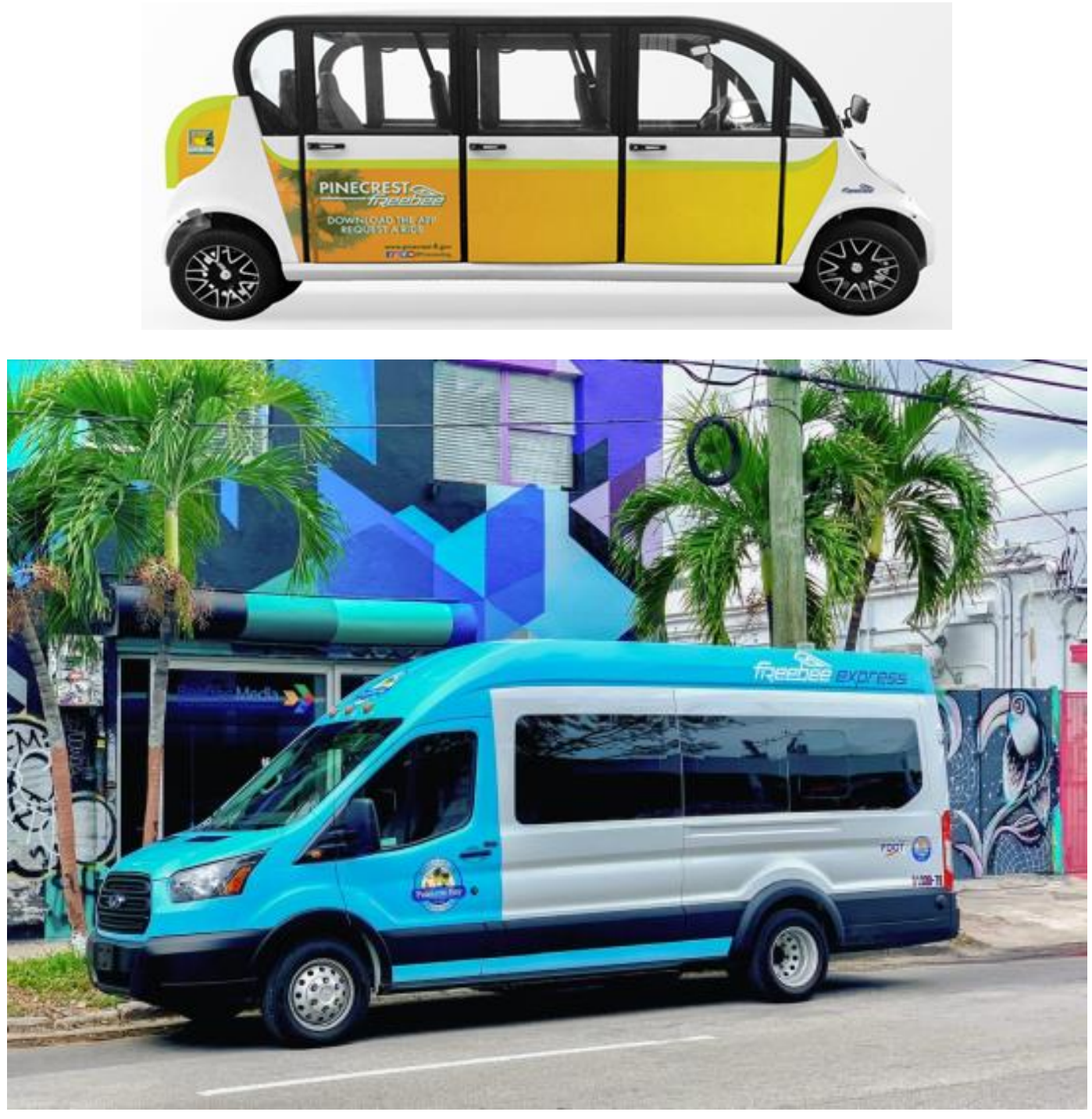

Figure 7 Freebee Microtransit Vehicles

In the FDOT 2018 report, Trolleys, Shuttles, and Community Buses in South Florida: Providing Transit Service to a Special Segment of the Population, a discussion of the Freebee transportation service in Miami-Dade County is presented. As per Spiegel, J., 2018, Freebee could be a solution for Miami-Dade and South Florida to address the lack of connectivity among public transit 
services. In particular, for short distance trips, Freebee can help with the connection to other transit systems or local destinations. The on-demand door-to-door service is free to those requesting a Freebee ride using electric vehicles that move around in their cities and communities.

In Miami-Dade County, Freebee is serving the following cities: Coral Gables, Doral, Key Biscayne, Coconut Grove, Miami Lakes, Miami Beach, North Bay Village, Doral, Palmetto Bay, Pinecrest, and Mainland Miami (includes Downtown, Brickell, Wynwood, Midtown, Design District). There are many benefits that can be obtained from the Freebee services. It offers residents, visitors, and local business a new mode of transportation that contributes with the reduction of traffic and parking congestion and helps provide better quality of life (Spiegel, J. 2018).

\section{Uride}

This company was contacted over the phone and stated that they are currently operating mainly in the Miami Beach area. They use electric vehicles and have advertising which allow the riders to have free service. Uride currently does not have a phone app, and the hours of hours of operation are from 11:00 AM to 11:00 PM.

\section{Circuit}

This company, as per their recording message, does not accept ride requests over the phone. Therefore, customers need to download the Circuit app to request a ride. In the app, they can check the service areas and the hours of operations. Their website shows that they offer service in Miami. However, their app was downloaded and the only cities that appear from South Florida were Fort Lauderdale, Palm Beach, and Hollywood. A request form was sent through their website asking about this discrepancy of information and they answered stating they operate in Miami as a flag down service and their partner is Uride.

South Florida denser areas like Fort Lauderdale, Palm Beach, and Miami are searching for new strategies to enhance their transportation system. Transit agencies have been building partnerships with microtransit companies to provide another mobility option for their residents. Circuit shuttles also offer alternative service and, in some cases, supplement existing transit options. As cofounder of the microtransit company, Alex Esposito says that buses and trains are great in moving people in and out of downtown areas, but not as good at moving people around downtown areas (Stewart, D., 2019). For that reason, Circuit has had great acceptation among residents and visitors because it is covering the first and last mile of their trips thus shortening their walk distance. The service also has free fares which is beneficial for low income families, and their vehicles are electrical, which do not contribute with gas emission into the environment. 
Circuit's goal explained by Esposito is not to eliminate the current infrastructure, but rather to help alleviate the congestion in population hubs by removing individual drivers off the road (Stewart, D., 2019). The service is ideal for seniors and people who travel short distances. Circuit is not competing with taxis or buses, instead it could be complementary to the current transportation system for providing better service to the people.

\section{Swoop}

This company operates in South Beach. The hours of operation are from 12:00 Noon to 12:00 Midnight seven days a week. However, their website shows different hours of operations:

Monday through Saturday from 6:00 PM — 12:00 AM (or later) closed on Sundays.

The service must be requested through a text message using the phone number (305) 9006367.

\section{Impacts on Quality of Life}

U.S. DOT defines livable communities as having transportation options, housing options, and destinations close by. In the vision for transportation for livable communities' conference, it was mentioned that having destinations within the community's limits is more important to its residents than having to take long trips. Furthermore, the definition of isolation is in response to the typical way we develop communities, which keeps land uses separate and is automobile dependent (National Academies of Sciences, 2012).

Transportation options should include not only an effective transit system but also a walkable community, so people can walk or use the bicycle to go to the near places. In addition, this can produce substantial savings to families by reducing the numbers of cars per family. Transportation agencies can also generate awareness and teach people to be more environmentally friendly. It is about making transportation more integrated with land use, housing, and jobs, and about preserving landscapes, the environment, quality places, and the quality of life (National Academies of Sciences, 2012).

Improving the quality of life of a community should be an essential goal of the agencies providing transit service. Local transit services not only provide mobility to segments of the population, but they also connect people to employment, health, educational, and many other destinations (Cevallos, F., 2018). Therefore, local transportation services promote economic development and offer residents, workers, and visitors transportation alternatives that will result in improved quality of life. 
According to the FDOT Report Challenges and Opportunities for Older Adults to Use Public Transportation: A South Florida Perspective report (Cevallos, 2019), the best methods to offer public transportation for the older adult community is to include fixed route, on-demand service, and paratransit. Except for paratransit, this is also applicable to other segments of the population that rely on public transportation. Innovative transportation alternatives, like on-demand microtransit services, can provide effective solutions to local communities.

The idea of microtransit is to offer new mobility options to everybody. It is well known that the current transportation system does not cover a lot of areas in the cities; for that reason, transit agencies are looking for new ways of providing transportation to those regions. Therefore, wideranging studies about Microtransit are taking place using pilot programs acquiring data and information that will be analyzed to design the best approach of this new concept. In designing new transportation options for the community, there are some key goals that must take in consideration (Polzin, S. E., 2018):

1. Provide transportation to enable upward mobility and enhanced quality of life for those unable to provide their own mobility.

2. Provide a resource-efficient means of moving people.

3. Stimulate economic development and influence land use.

Implementing new mobility methods to enhance the current transportation system will positively impact the lives of people because it is critical to health care, education, and employment, and therefore is critical to the quality of life and upward mobility opportunity (Polzin, S. E.). A key advantage of shared mobility is its ability to fill gaps where traditional public transport is absent, inadequate, or ineffective. Lack of access to public transit is all too common in the U.S., especially for many low-income populations (Kimley-Horn and IBI Group, 2019). A well-connected city can be transformed to a successful city not only economically but socially as well because an effective transportation system offers economic growth and improves the quality of life of people.

Several problems can be addressed with the implementation of Microtransit into the transportation system such as congestion mitigation, air quality, and parking management. Microtransit is a shared service and it uses smaller vehicles that can be electric, it helps decrease the number of single owner vehicles and reduce the transmission of $\mathrm{CO} 2$ into the environment.

The implementation of Microtransit services, besides offering the public an improved transportation method, it has many other benefits such as connecting low density areas to main cities and integrating low income families to the society, so they can have equal opportunities and access to be successful.

Livability from transportation is more than capacities, volumes, and levels of service on highways - it is about transportation being more integrated with land use, housing, and jobs and 
about preserving landscapes, the environment, valuable places, and the quality of life (National Academies of Sciences, 2019). Microtransit characteristics allow the service to make the communities more livable because it is designed to connect the areas where fixed-route buses cannot reach and as consequence will integrate the families from these areas into the main cities. It will create a bridge that it was not before creating new opportunities for the people either economically or socially.

U.S. DOT defines livable communities as having transportation options, housing options, and destinations close by. Transportation is a means, not an end (National Academies of Sciences, 2012). Microtransit is a means of enhancing the lives of the residents of low-density areas by giving them an affordable and convenience way of mobility alleviating their lives. Microtransit will contribute to make the communities more livable, sustainable and progressive.

\section{Challenges and opportunities}

In South Florida, the automobile-centric transportation system along with the growth and aging of the population presents serious mobility challenges that impact the quality of life. This requires special attention to be able to provide reasonable mobility for all. As some segments of the population require alternative transportation options, public transportation services need to meet their mobility needs. However, providing public transportation to all communities can be challenging, because fixed-route services cannot reach all areas in a community, in particular those areas that are more dispersed. Therefore, it is critical to identify potential solutions for improving the transit services.

Although they may also be applied to similar areas in Florida or around the country, the following are some of the items that need to be taken into consideration due to the South Florida characteristics:

- Land use - The land use configuration of South Florida makes it difficult for transit agencies to provide coverage to all areas. In addition, poorly connected or lack of connection between residential and commercial land uses makes it difficult for people to travel without their own transportation.

- Automobile dominated - In South Florida, the automobile continues to be the main mode of transportation. Public transportation attempts to provide services on the main arterials and local roads. However, these services cannot compete with the automobile. Nevertheless, within local communities, microtransit presents opportunities for individuals to travel without the need of an automobile.

- Growing and aging of the population - These two issues present a difficult challenge for transit agencies to provide adequate services to the different segments of the population.

- New transportation modes - TNCs and Microtransit present transportation opportunities. 
Another mode is Micromobility which usually refers to the use of scooters and bikes. This mode is still evolving and is more popular with younger persons. Time will tell if it is accepted and under what conditions will it be accepted by the South Florida municipalities.

To address all these issues, agencies must to be prepared to accommodate the needs and demands of the local communities for transportation services. The availability of and accessibility to public transportation can be challenging and this impacts the quality of life of local communities. Therefore, addressing these challenges is critical to ensure that people can continue with their daily activities without affecting their quality of life. Newer microtransit transportation options like Freebee provide solutions for local communities. They can address the first mile and last mile problem by providing connections to community buses and regional transit services and can provide door-to-door services to many other destinations.

\section{MICROTRANSIT IN MIAMI-DADE COUNTY}

This section presents the current situation of the microtransit services in Miami-Dade County. Microtransit commenced operating in Miami-Dade County in 2012 by a new company named Freebee which provided mobility service in South Miami Beach. Since then, Microtransit has been implemented in eleven communities in Miami-Dade County and continues to grow as several other municipalities are seriously considering implementation of this environmentally friendly kind of transit service. Existing Microtransit service in several Miami-Dade County municipalities has become so popular that accessible electric vehicles with a higher passenger capacity are being assigned to the service.

For this project, the research team investigated the available information on the microtransit services in the County. The information of these services was found in the websites of those municipalities with Microtransit and from the websites of microtransit service providers, in particular Freebee. A description of the available information is presented in Appendix B. In addition, the research team collected data and information from Freebee, the main microtransit service provider in Miami-Dade County, that were used to assess the services provided in five municipalities.

\section{Case Studies}

To better understand the microtransit services and their impacts on the community, five municipalities were investigated in Miami-Dade County. These municipalities are Coral Gables, Doral, Key Biscayne, North Bay Village, and Pinecrest. They were selected to study the effectiveness of Freebee in improving the mobility and quality of life of these communities.

A description of each municipality with information from their websites is provided along with data from the U.S. Census Bureau to understand the demographics of each municipality. In 
addition, data from the American Community Survey (ACS) were used to assess the number of cars per household to gain a better understanding of the mobility options for each of the five selected communities. The microtransit data used for this study was provided by Freebee. They provided detailed information on ridership of their vehicles including average boardings as well as riders age, gender, and other operational information.

To prepare the overall findings and the creation of tables and figures, the microtransit datasets were reviewed, processed, and analyzed. This includes the ridership data and the passenger origins and destinations of the Freebee trips for the five municipalities. The analysis allowed for a reasonable way to ascertain the microtransit ridership and the most common starting and ending points of Freebee riders in each city. The information allowed to assess the microtransit usage level and to determine the main trip purposes of the Freebee service as well.

\section{Coral Gables}

Coral Gables called the "City Beautiful" was incorporated in 1925. Coral Gables which is directly west of the City of Miami has a Mediterranean architectural style and is a well-planned and very desirable place to live. Coral Gables is considered an international city with more than 20 consulates and foreign offices as well as greater than 140 multinational corporations. The City is a major employment center with as many people working there as those who live there. Coral Gables is also the home of the University of Miami, a top tier educational institution with over 17,000 students.

According to the U.S. Census Bureau, in 2019, the City of Coral Gables had an estimated population of 49,700. Persons who are 65 years and older makeup $18 \%$ of the estimated population. The median household income is $\$ 100,000$ which is among the highest in Miami-Dade County. In addition, according to the American Community Survey data (U.S. Census Bureau, 2018), the weighted average of number of cars per household is 1.65 and that $5.3 \%$ of the Coral Gables households do not have a car. In addition, Coral Gables has a fairly low population density of 3,621 per square mile. However, when those who work in the City are included, the impact on transportation is significant.

\section{Freebee and Other Transit}

Coral Gables has been served by several Metrobus routes and Metrorail for decades and the City implemented a trolley system in 2003 funded by the half-penny surtax in Miami-Dade County. The Coral Gables Trolley has two fixed routes with approximately 500 riders per day according to the City's website.

Freebee provides rides around Downtown Coral Gables thanks to a partnership between the City of Coral Gables and Freebee, an environmentally friendly transportation service that provides free 
fare on-demand, door to door service to many downtown destinations. Freebee commenced service in June 2017 to alleviate traffic due to construction on Miracle Mile. In February 2019, the Freebee span of service was expanded to 12 hours a day, seven days a week. More stops were added to the route within Coral Gables for first mile/last mile connectivity including the Douglas Road Metrorail Station. In general, Freebee has improved mobility in a city with high motor vehicle traffic and limited number of parking space. Table 8 presents the information provided by Freebee for the most recent two months prior to the Pandemic concerning Coral Gables service, average age and gender of the riders, average trip length, and average riders per hour and month.

\section{Table 8 Coral Gables Microtransit Service}

\begin{tabular}{|c|c|c|c|c|c|c|c|}
\hline Zones & $\begin{array}{c}\text { Number } \\
\text { of } \\
\text { Vehicles } \\
\text { in Service }\end{array}$ & $\begin{array}{c}\text { Hours of } \\
\text { Operation }\end{array}$ & $\begin{array}{c}\text { Average } \\
\text { Age of } \\
\text { Riders }\end{array}$ & Gender & $\begin{array}{c}\text { Average } \\
\text { Trip } \\
\text { Length } \\
\text { (Minutes) }\end{array}$ & $\begin{array}{c}\text { Average } \\
\text { Passengers } \\
\text { per Hour }\end{array}$ & $\begin{array}{c}\text { Average } \\
\text { Passengers } \\
\text { per Month }\end{array}$ \\
\hline $\begin{array}{c}\text { Coral } \\
\text { Gables }\end{array}$ & 5 & $\begin{array}{c}10 \mathrm{am}-10 \mathrm{pm} \\
\text { (7 days/week) }\end{array}$ & 41.09 & $\begin{array}{c}\text { M 34\% } \\
\text { F 66\% }\end{array}$ & 6 & 25.00 & $7,368.00$ \\
\hline
\end{tabular}

\section{Ridership}

Since Freebee started in June 2017, ridership has continually increased especially when service was expanded in February 2019. The average monthly ridership prior to the expansion of service was 5,435. Since the February 2019 service expansion until the end of February 2020, the monthly average of boardings jumped to 8,160 which is a $50 \%$ increase in ridership. The last two months, January and February 2020 averaged 7,368 passengers per month. Figure 8 shows the microtransit monthly ridership for the City of Coral Gables since the inception of the service. 


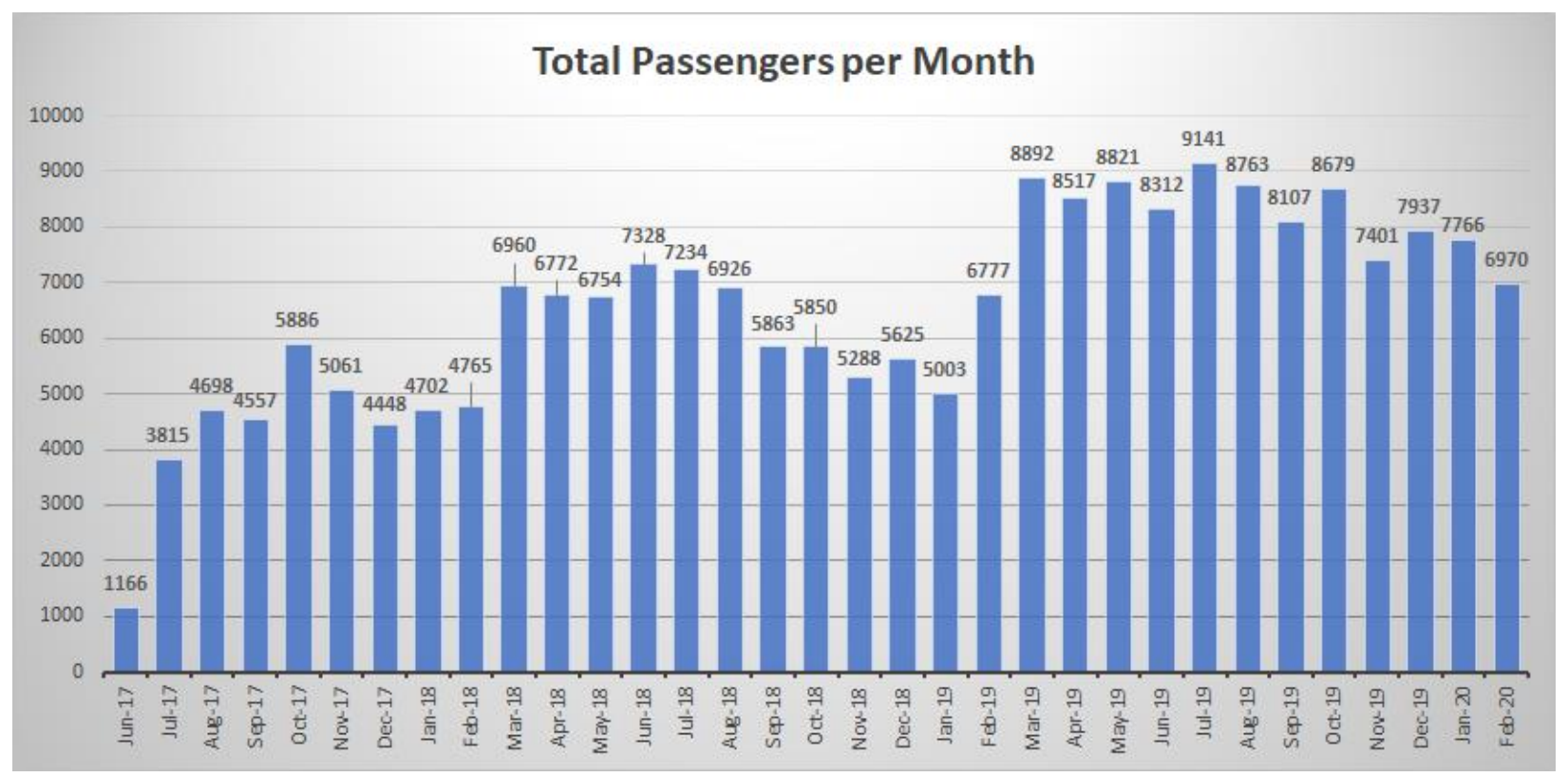

Figure 8 Coral Gables Microtransit Ridership

\section{Origin/Destination}

Freebee provides feeder service to the Miami-Dade County Douglas Road Metrorail Station and approximately $21 \%$ of all Freebee origins and destinations or about 700 trips per week are to and from the Metrorail Station. Freebee provides vital mobility for Gables residents who shop at a major Publix grocery store near Miracle Mile with 20\% of all Coral Gables Freebee riders travelling to or from this Publix. Besides Publix, Freebee serves the shops and restaurants along Miracle Mile and the Shops of Merrick Park on the south side of the city. High-rise condominiums line Biltmore Way on the west side of downtown Coral Gables. Nearly 1,000 passengers per week or $30 \%$ of all Freebee trips start or end at these condos along Biltmore Way.

\section{$\underline{\text { Doral }}$}

The City of Doral, located in west Miami-Dade County just one mile away west of the Miami International Airport, has many residential and business developments throughout the City. Incorporated in 2003, has a population of approximately of 66,000 in 2019 according to the U.S. Census Bureau (2019). According to the City of Doral website, the City can have more than 100,000 people working within the City. Those 65 years old and over comprise just $7.2 \%$ of the population which is likely being a city with a large workforce. The population per square mile for Doral is 3,293.5 and it is well known that Doral and surrounding west Miami-Dade have some of the worst traffic in the County. 
The City of Doral Trolley which started in 2008 has expanded to operates a robust trolley circulator system with four fixed routes serving the City and connecting to Metrorail and Florida International University. In addition to the City run Trolley service, Miami-Dade Transit provides two all day fixed routes and three peak hour services. Freebee on-demand service started as a demonstration project in April 2019 and, after a six-months, it was approved by the City in October 2019 to continue with contracted service. Three Freebee electric vehicles are assigned with the following span of service: Monday - Thursday $11 \mathrm{am}-7 \mathrm{pm}$, Friday and Saturday 10 am to 12 am, and Sunday $12 \mathrm{pm}-7 \mathrm{pm}$.

Freebee has free fares and one of the three vehicles is wheelchair accessible. The Freebee ondemand service area is in a section of the city roughly bounded by NW 58 Street, NW 33 Street, NW 79 Avenue, and NW 87 Avenue. Table 9 presents the information provided by Freebee for the most recent months prior to the Pandemic showing the service in Doral, average age and gender of the riders, average trip length, and average riders per hour and month.

\section{Table 9 Doral Microtransit Service}

\begin{tabular}{|c|c|c|c|c|c|c|c|}
\hline Zones & $\begin{array}{c}\text { Number } \\
\text { of } \\
\text { Vehicles } \\
\text { in } \\
\text { Service }\end{array}$ & $\begin{array}{c}\text { Hours of } \\
\text { Operation }\end{array}$ & $\begin{array}{c}\text { Average } \\
\text { Age of } \\
\text { Riders }\end{array}$ & Gender & $\begin{array}{c}\text { Average } \\
\text { Trip } \\
\text { Length } \\
\text { (Minutes) }\end{array}$ & $\begin{array}{c}\text { Average } \\
\text { Passengers } \\
\text { per Hour }\end{array}$ & $\begin{array}{c}\text { Average } \\
\text { Passengers } \\
\text { per Month }\end{array}$ \\
\hline Doral & 3 & $\begin{array}{c}11 \mathrm{am}-7 \mathrm{pm} \\
\text { Mon to Thurs } \\
\text { 10am-12am (Fri } \\
\text { and Sat) 12pm- } \\
7 \mathrm{pm} \text { (Sunday) }\end{array}$ & 29.44 & F 65\% & 3.52 & 14.75 & $4,400.00$ \\
\hline
\end{tabular}

\section{Ridership}

During the six-month demonstration project from April to September 2019, Freebee carried an average of 1,117 riders per month. With the new agreement, Freebee ridership from October 2019 to February 2020 jumped to an average of 3,634 per month, a 225\% increase. Figure 9 shows the microtransit monthly ridership for the City of Doral since the inception of the service. 


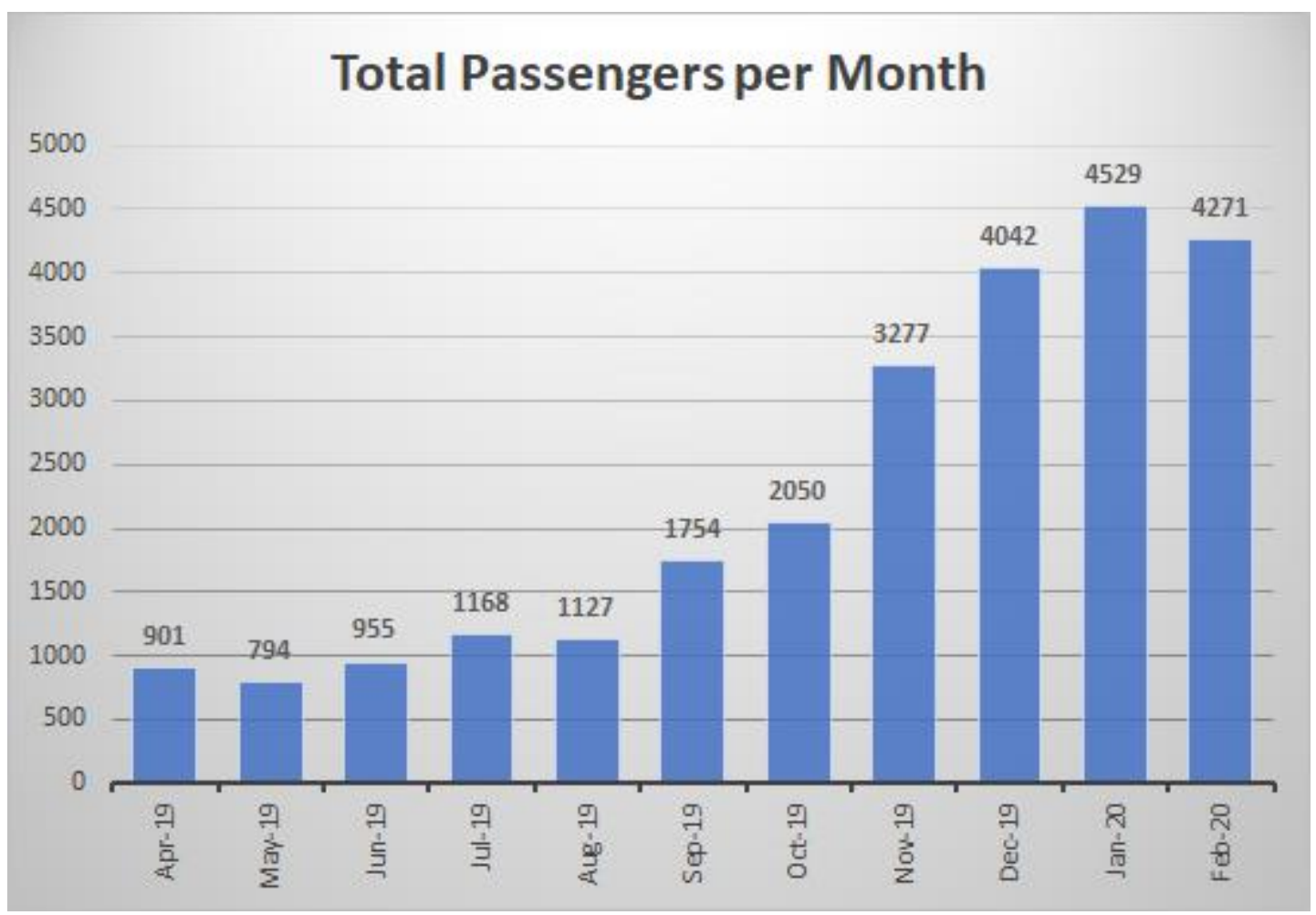

Figure 9 Doral Microtransit Ridership

\section{Origin/Destination}

Freebee continues to provide on-demand service to a slightly larger area to that in the 2019 demonstration. This area includes new developments such as Downtown Doral which continues to expand with residential, shopping, restaurants, and Doral City Hall. NW 53 Street, between NW 87 and 79 Avenues, is the Main Street of the City. According to information provided by Freebee, $58 \%$ of the Doral Freebee ridership is to and from Downtown Doral. About 1/3 of the trips to Downtown Doral are going to the Publix Supermarket. Those residents living within the Freebee service area and close to Downtown are the ones using Freebee to travel to Downtown Doral, Publix, as well as Downtown Doral Charter Elementary School and City Hall.

The growth of Downtown Doral along with excellent public transportation provided by the Trolleys and Freebee makes this area a highly desirable place to live.

\section{$\underline{\text { Key Biscayne }}$}

Key Biscayne is an Island town on the southeast side of Miami-Dade County is accessible only via the Rickenbacker Causeway. The Village is surrounded by Biscayne Bay and has many recreational resources such as Crandon Park, Bill Baggs State Park, and the Key Biscayne Tennis 
Center. According to the U.S. Census Bureau Quick Facts for 2019, Key Biscayne had a population of 12,846 in 2018 . Those 65 years and older comprise $17 \%$ of the population. The median income per household is very high at $\$ 133,958$. In addition, according to the American Community Survey data (U.S. Census Bureau, 2018), the weighted average of the number of cars per household is 1.79. The population density is high with 10,068 persons per square mile since the Village is only 1.23 square miles and many high-rise condominium complexes have been constructed in the last two decades on the east side of the island.

\section{Freebee and Other Transit}

Miami-Dade County operates a single Metrobus route on Key Biscayne which connects the Village with the mainland and the Brickell Metrorail Station. Freebee on the Key, which commenced in December 2016, uses electric vehicles that provide free on-demand service throughout the Village. Hours of the on-demand operation are from 8:00 a.m. - 8:00 p.m. Sunday-Thursday, 8:00 a.m. 10:00 p.m. Friday and 10:00 a.m. - 10:00 p.m. Saturday. Residents of Key Biscayne can request a ride with an app on their smart phone or to call by phone. In addition, Freebee operates a fixed loop throughout the Village with designated bus stops. The loop route operates every 20 to 30 minutes. Hours of operation are from 11:00 a.m. - 7:00 p.m.

In Table 10, Freebee provided information for the most recent months prior to the Pandemic concerning Key Biscayne service. The average age and gender of the riders shows mostly females and a younger average age then the other four municipalities being highlighted in this study. The average trip length and average riders per hour are based on the last months before the Pandemic (January and February 2020).

\section{Table 10 Key Biscayne Microtransit Service}

\begin{tabular}{|c|c|c|c|c|c|c|c|}
\hline Zones & $\begin{array}{c}\text { Number } \\
\text { of } \\
\text { Vehicles } \\
\text { in } \\
\text { Service }\end{array}$ & $\begin{array}{c}\text { Hours of } \\
\text { Operation }\end{array}$ & $\begin{array}{l}\text { Average } \\
\text { Age of } \\
\text { Riders }\end{array}$ & Gender & $\begin{array}{c}\text { Average } \\
\text { Trip } \\
\text { Length } \\
\text { (Minutes) }\end{array}$ & $\begin{array}{c}\text { Average } \\
\text { Passengers } \\
\text { per Hour }\end{array}$ & $\begin{array}{c}\text { Average } \\
\text { Passengers } \\
\text { per Month }\end{array}$ \\
\hline $\begin{array}{c}\text { Key } \\
\text { Biscayne }\end{array}$ & 3 & $\begin{array}{c}\text { 8am-8pm } \\
\text { (Sun-Thurs) } \\
\text { 8am-10pm } \\
\text { (Fri) } \\
\text { 10am-10pm }\end{array}$ & 33.45 & $\begin{array}{l}\text { M 20\% } \\
\text { F 80\% }\end{array}$ & 4.17 & 22.37 & $6,593.00$ \\
\hline
\end{tabular}

\section{Ridership}

Freebee on the Key shows healthy growth with an average of 4,618 boardings per month in 2017 which increased to 6,094 riders per month in 2019 through February 2020. Comparing the third 
year of service with the first, ridership is climbed by $32 \%$. Figure 10 shows the microtransit monthly ridership for the Village of Key Biscayne since the inception of the service.

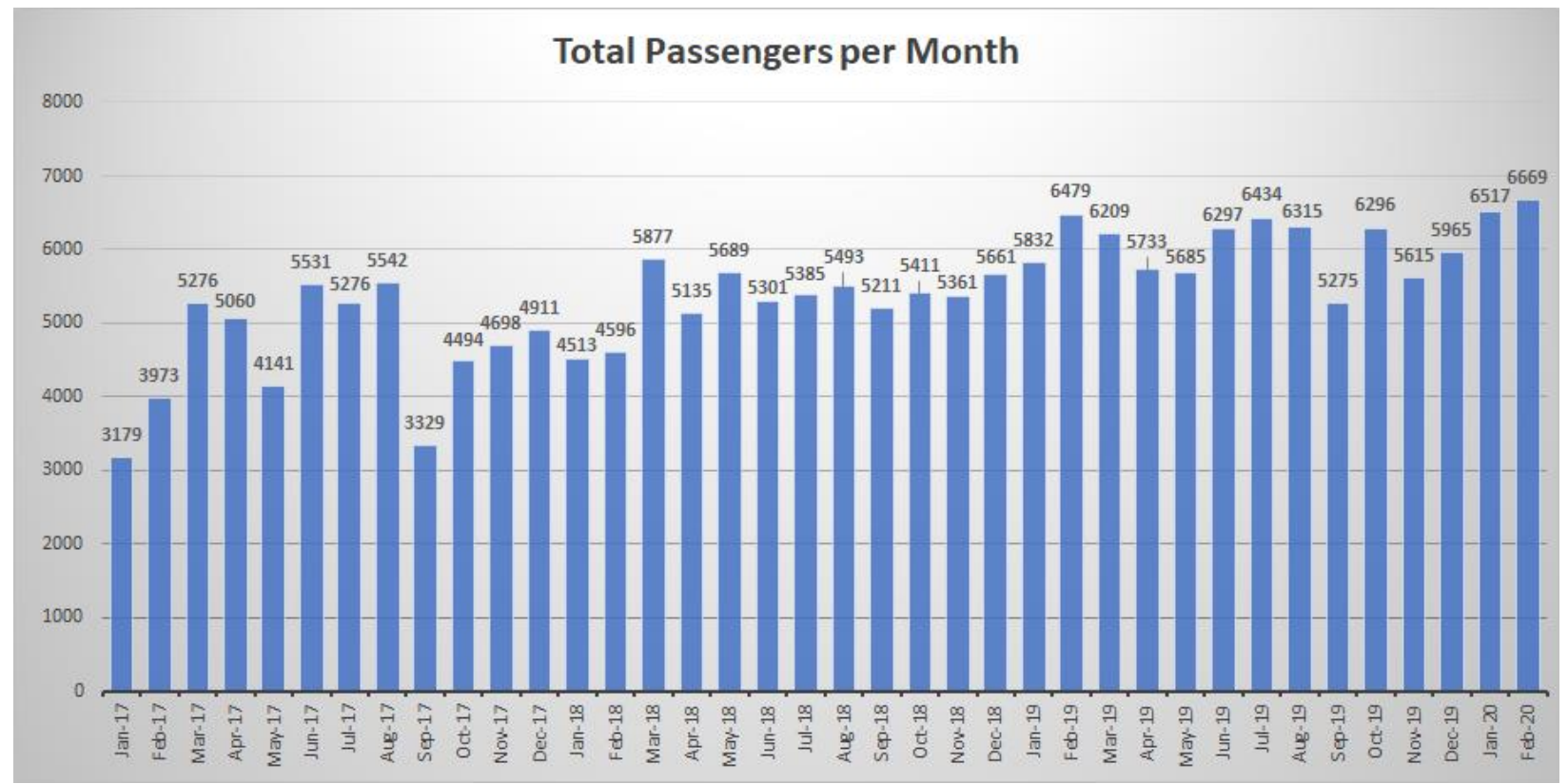

Figure 10 Key Biscayne Microtransit Ridership

\section{Origin/Destination}

There are several major events on Key Biscayne and the Rickenbacker Causeway that have limited parking and Freebee provides a connection from the Village to these events. Although this is not reflected in Figure 10, it is estimated that a large number of people also use the Freebee services to the Miami Boat Show event in February. With normal Freebee service on the Key, popular destinations are the CVS Pharmacy and the Key Biscayne Community Center each having about 350 trips or $15 \%$ of the weekly Freebee trips.

Other important destinations served by Freebee are St. Agnes Church and School, Winn Dixie, and the Arcade Shopping Center on Crandon Boulevard. Freebee serves most residential areas including several large condominiums and hotels on the east side of the Island such as Key Colony, the Towers of Key Biscayne, and the Ritz-Carleton Hotel. This enables residents and visitors to travel to Crandon Boulevard for groceries, pharmacy, and community services.

\section{North Bay Village}

North Bay Village, incorporated in 1945, consists of three islands that straddle the John F. Kennedy ( $79^{\text {th }}$ Street) Causeway between Miami and Miami Beach. These three islands are the North Bay 
Island, Harbor Island, and Treasure Island. One of the smallest municipalities in Miami-Dade County, the population estimate in 2019 was 8,057 according to the U.S. Census Bureau Quick Facts (2019). Persons 65 years or older make up $11.7 \%$ of the population of the Village. The median household income is $\$ 55,000$ according to the Census Bureau. In addition, according to the American Community Survey data (U.S. Census Bureau, 2018), the weighted average for the number of cars per household is 1.33 and many residents depend on public transportation as $9.5 \%$ of the Village households do not have a motor vehicle. The land area of North Bay Village is only 0.37 square miles which results in the Village having a high population density of 19,289.2 per square mile.

\section{Freebee and Other Transit}

Public transportation for North Bay Village includes a trolley service provided by the Village on a fixed route for their residents. Routes L and 79 MAX are operated by Miami-Dade County and travel along the 79 Street Causeway between the Miami Beach and mainland Miami with stops in North Bay Village. The North Bay Village Freebee, which commenced in November 2019, complements the fixed service by providing door to door service for all residents. Freebee started operations four months before the Pandemic commenced. Table 11 shows information provided by Freebee concerning service, rider characteristics, and ridership performance for the North Bay Village.

\section{Table 11 North Bay Village Microtransit Service}

\begin{tabular}{|c|c|c|c|c|c|c|c|}
\hline Zones & $\begin{array}{c}\text { Number } \\
\text { of } \\
\text { Vehicles } \\
\text { in } \\
\text { Service }\end{array}$ & $\begin{array}{l}\text { Hours of } \\
\text { Operation }\end{array}$ & $\begin{array}{c}\text { Average } \\
\text { Age of } \\
\text { Riders }\end{array}$ & Gender & $\begin{array}{l}\text { Average } \\
\text { Trip } \\
\text { Length } \\
\text { (Minutes) }\end{array}$ & $\begin{array}{c}\text { Average } \\
\text { Passengers } \\
\text { per Hour }\end{array}$ & $\begin{array}{c}\text { Average } \\
\text { Passengers } \\
\text { per Month }\end{array}$ \\
\hline $\begin{array}{c}\text { North } \\
\text { Bay } \\
\text { Village }\end{array}$ & 1 & $\begin{array}{c}\text { 7am-7pm } \\
\text { (Mon-Fri) } \\
\text { 10am-6pm } \\
\text { (Sat) }\end{array}$ & 33.753 & $\begin{array}{l}\text { M 35\% } \\
\text { F 65\% }\end{array}$ & 8.61 & 8.60 & $1,190.00$ \\
\hline
\end{tabular}

\section{Ridership}

Data is available for the first four months of service by the North Bay Village Freebee and there was growing ridership for each month. Comparing February 2020 ridership with November 2019 showed a $65 \%$ increase in ridership. Figure 11 shows the microtransit monthly ridership for the Village of North Bay since the inception of the service in November of 2019. 


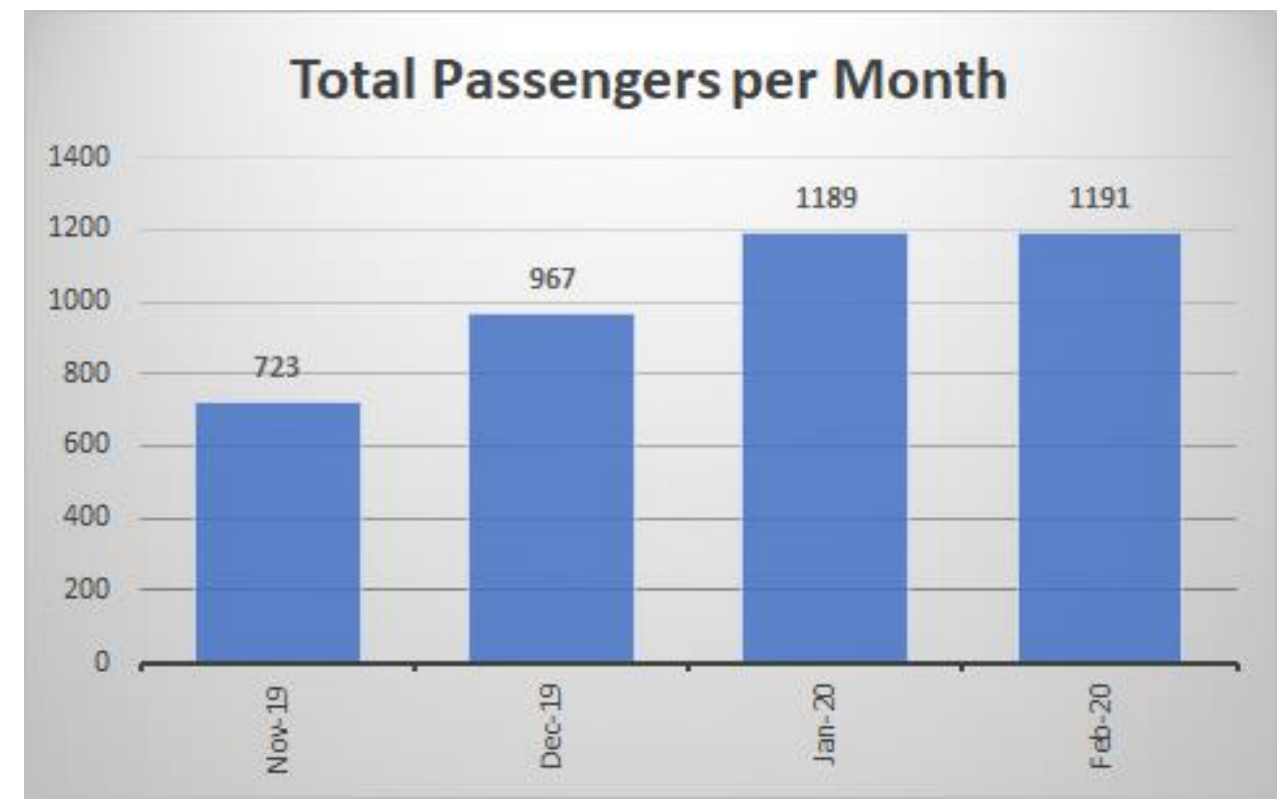

Figure 11 North Bay Village Microtransit Ridership

\section{Origin/Destination}

Major destinations of the Freebee service are mostly in Miami Beach with $60 \%$ of the 1,190 monthly passenger trips in February. A transfer point is at Harding Avenue and 72 Street for Freebee riders wishing to catch the Miami Beach Trolley or Miami-Dade Metrobus. Nineteen percent of the Freebee riders travel to mainland Miami and have the option to transfer to several Metrobus routes on Biscayne Boulevard.

Multi-family condominiums are located mostly on North Bay Island and Treasure Island. Fifty five percent of Freebee trip origins or about 600 of weekly boardings are from the North Bay Village multi-family condominium and apartment locations. Residents of these condominiums use Freebee to the three grocery stores in North Bay Village and to the plethora of shopping and restaurants on Miami Beach.

\section{Pinecrest}

The Village of Pinecrest, located in the southeast segment of Miami-Dade County, was incorporated in 1996. It is recognized as a very desirable place for a good quality of life. Pinecrest is home to an estimated 19,115 residents according to the 2019 U.S. Census Bureau Quick Facts. Fifteen percent of the population of Pinecrest are 65 years and older. Pinecrest encompasses approximately 7.44 square miles and is recognized as one of the most beautiful residential areas 
in South Florida. The median income is $\$ 153,417$ per household, however, there are $5.5 \%$ of the households below the poverty line according to Pinecrest demographic information on their website. According to the American Community survey data (U.S. Census, 2018), the weighted average of the number of cars per household is 1.94 and that $6.2 \%$ of the households do not have a motor vehicle.

\section{Freebee and Other Transit}

Freebee commenced free on-demand rides for the Village of Pinecrest effective January 2019. Pinecrest is participating in a three-year demonstration program as part of the Miami-Dade SMART Plan. Freebee provides door-to-door access for residents to destination in the Village and also provides feeder connections to Metrorail and the South Dade Transitway. The service operates from 7:00 a.m. to 7:00 pm on weekdays and 10:00 a.m. to 10:00 p.m. on Saturday. Table 12 shows information provided by Freebee of various measures of the service in Pinecrest. As shown in the other four cities, the percentage of female riders are much higher than males.

\section{Table 12 Pinecrest Microtransit Service}

\begin{tabular}{|c|c|c|c|c|c|c|c|}
\hline Zones & $\begin{array}{c}\text { Number } \\
\text { of } \\
\text { Vehicles } \\
\text { in Service }\end{array}$ & $\begin{array}{c}\text { Hours of } \\
\text { Operation }\end{array}$ & $\begin{array}{c}\text { Average } \\
\text { Age of } \\
\text { Riders }\end{array}$ & Gender & $\begin{array}{c}\text { Average } \\
\text { Trip } \\
\text { Length } \\
\text { (Minutes) }\end{array}$ & $\begin{array}{c}\text { Average } \\
\text { Passengers } \\
\text { per Hour }\end{array}$ & $\begin{array}{c}\text { Average } \\
\text { Passengers } \\
\text { per Month }\end{array}$ \\
\hline Pinecrest & 2 & $\begin{array}{c}7 \mathrm{am}-7 \mathrm{pm} \\
\text { (Mon-Fri) } \\
1 \mathrm{pm}-10 \mathrm{pm} \\
\text { (Sat) }\end{array}$ & 34.29 & $\begin{array}{c}\text { M 18\% } \\
\text { F 82\% }\end{array}$ & 8.61 & 8.46 & $2,171.50$ \\
\hline
\end{tabular}

\section{Ridership}

Freebee ridership has consistently increased since it commenced in January 2019. Comparing the first seven months of service with the most recent seven months found that ridership increased from an average of 1,522 boardings to 1,979 boardings per month, a $30 \%$ increase. February 2020, which was the last full month of operation, had the highest ridership with 2,183 boardings. Recent ridership numbers significantly declined like all transit systems due to the Pandemic. Figure 12 shows the microtransit monthly ridership for the Village of Pinecrest since the inception of the service. 


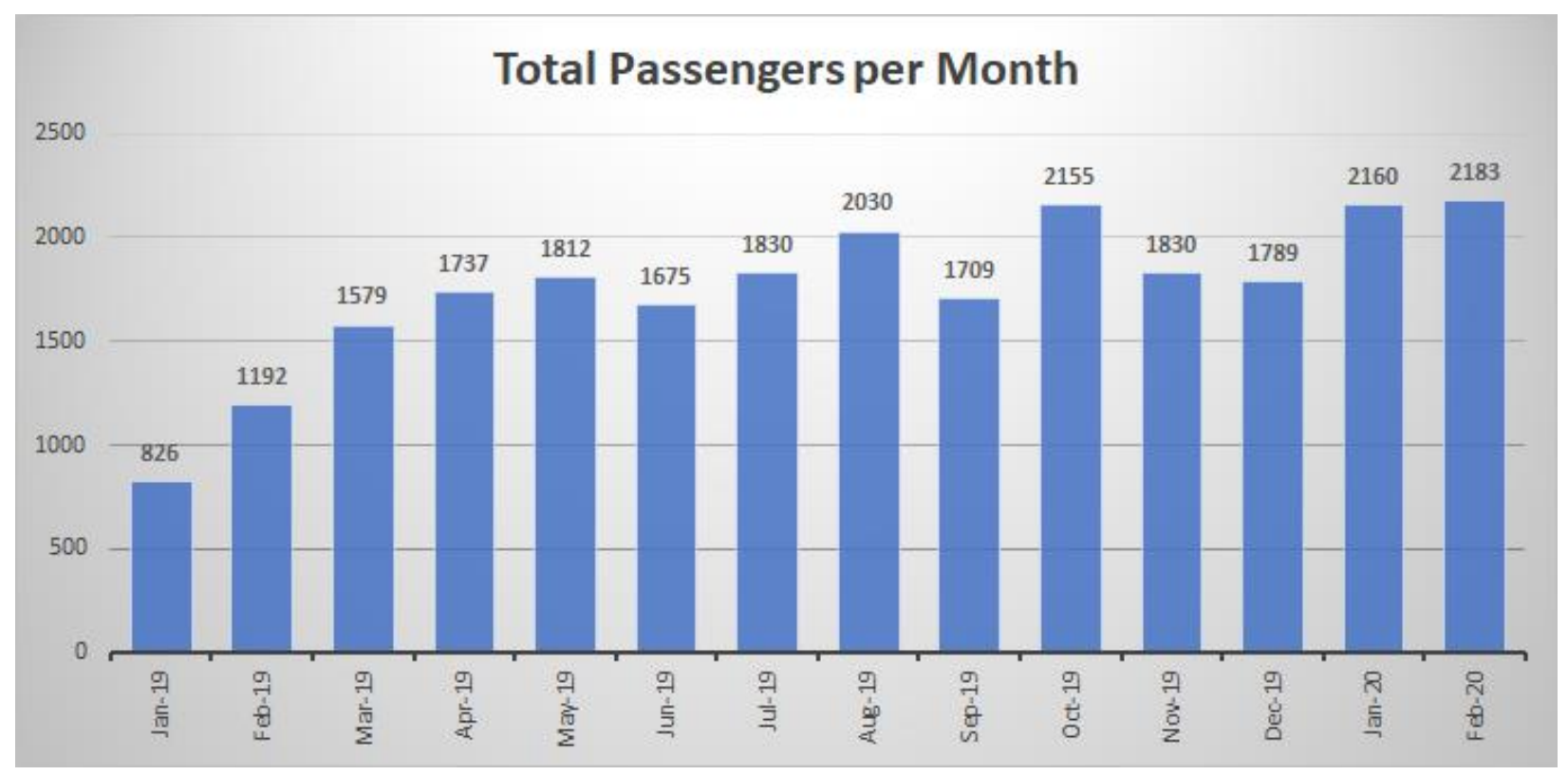

Figure 12 Pinecrest Microtransit Ridership

\section{Origin/Destination}

The major destination of the Pinecrest Freebee service is the Dadeland North Metrorail Station. A smaller number of riders also travel to the Dadeland and South Dade Transitway Station. Overall, $50 \%$ of all Freebee trips or an average of 870 per week were destined to both Metrorail Stations. Retail and commercial areas near both Metrorail Stations on South Dixie Highway were also popular destinations with $35 \%$ of the weekly Freebee trips. Within the Village, residents used Freebee to travel to the Pinecrest Community Center, Palmetto Middle School, and Pinecrest Elementary School. Residential areas which were frequent users of Freebee for commuting and shopping were along SW 67 Avenue and in the SW 94 Street neighborhood.

\section{County Ordinances and State Safety Rules}

With the implementation of microtransit services, legislative items and safety rules are likely to be implemented, modified, or enforced to promote the new service and ensure safe operations. Therefore, it is worth mentioning that in 2018, Miami-Dade County adopted an ordinance that authorized the use of surtax funds for On-Demand transportation services. The amendment of section 29-124 of the Miami-Dade County Code attempts to coordinate on-demand transportation services with existing transit services to augment and increase solutions and mobility. Below are some excerpts from the adopted Miami-Dade Legislative Item (File Number: 181216):

ORDINANCE RELATING TO THE CITIZENS' INDEPENDENT TRANSPORTATION TRUST, THE PEOPLE'S TRANSPORTATION PLAN AND CHARTER COUNTY 
TRANSPORTATION SYSTEM SURTAX FUNDS; AMENDING SECTION 29-124 OF THE CODE OF MIAMI-DADE COUNTY, FLORIDA, BY A TWO-THIRDS VOTE OF THE COMMISSION MEMBERSHIP; AUTHORIZING THE USE OF CHARTER COUNTY TRANSPORTATION SYSTEM SURTAX FUNDS FOR ON-DEMAND TRANSPORTATION SERVICES; PROVIDING SEVERABILITY, INCLUSION IN THE CODE, AND AN EFFECTIVE DATE [SEE ORIGINAL ITEM UNDER FILE NO. 180267]

The use of surtax proceeds for on-demand transportation services shall be limited to providing transportation services where the trip is no greater than 5 miles in distance and (1) where the origination or destination of the trip is solely within city boundaries; (2) where the origination of a trip is within city boundaries and the destination is the nearest Metrorail station or South Dade Transitway bus shelter; (3) where the origination of a trip is the Metrorail station or South Dade Transitway bus shelter closest to the city boundary of the city where the intended destination of the trip is located; or (4) where the origination or destination of the trip is a public transit park-and-ride facility. Each city that uses surtax proceeds for on-demand transportation services shall provide an annual report to the County describing the city's implementation of the on-demand transportation services in accordance with this paragraph.

In addition, the municipalities are ensuring that the microtransit operators comply with the applicable elements of the Florida Administrative Code (FAC) Rule Chapter 14-90. It is a common practice that municipalities request transit service providers to comply with the provisions of Florida law that includes the requirements of Rule 14-90: Equipment and Operational Safety Standards for Bus Transit Systems. Further, as stated by Freebee, in all service areas where FDOT provides funding to the municipality, they have complied with all operational standards of Florida Rule 14-90. Drivers undergo FDOT Medical Exams and FDOT Drug Screening, while Freebee's organization has adopted its own System Safety Program Plan (SSPP). Besides the safety compliance, Freebee employs their drivers and provides the vehicles. Therefore, they follow similar rules as agencies or organizations that provide mobility services for municipalities like Trolleys, Shuttles, or Buses.

\section{CONCLUSIONS}

In Miami-Dade County, local services are provided by trolleys, community buses, and shuttles that are supported by a major regional transit system that includes rail and bus services. This study concentrates on the microtransit services in Miami-Dade operated with electric vehicles used within several local communities. Microtransit can provide service as fixed-route or on-demand and typically relies on technology and dynamic routing. In addition, microtransit can be useful to address the first mile/last mile problem and provide mobility to areas not reached by conventional public transportation. 
The services provided by public transportation systems increase the mobility and accessibility options of a community. They enhance livability by offering affordable transportation alternatives that not only help reduce traffic congestion, but also provide access to employment, health, educational, and other services. These benefits are shown in the five case studies of Microtransit in Miami-Dade County. The five municipalities that were studied disclosed continuous growth in ridership of the Microtransit service despite having established transit service of regional bus and community shuttles. With rising ridership, it is expected that the number of vehicles and overall service provided will increase in the future as more municipalities in Miami-Dade explore this relatively new transportation service. For most municipalities, there are no fares, thus providing a viable transportation option that improves the quality of life. Continued implementation of Microtransit services in the County should foster economic development and offer residents, workers, and visitors a full range of transportation choices for an improved quality of life.

The main objective of this research was to conduct a study of microtransit service using low-speed electric vehicles in Miami-Dade County and the impact they have on the quality of life of the community. Microtransit provides an answer to the first mile/last mile concern as demonstrated in Coral Gables and Pinecrest with door to door service to Metrorail stations. Access to shopping including supermarkets and pharmacies are revealed by Microtransit service in North Bay Village, Key Biscayne, and Coral Gables. Microtransit continues to evolve with the assignment of larger electric vehicles that can provide more capacity and operate on those roadways with higher speed limit than what is required (35 $\mathrm{mph})$ of smaller vehicles.

\section{Lessons Learned}

Public transportation services can enhance the quality of life of local communities. However, local communities have particular needs. They require transportation options that are accessible and readily available that cannot be easily provided by regular fixed-route services. Therefore, ondemand services in particular Microtransit can fill the void in areas that are not well covered by fixed-route transportation services. The following are a collection of important issues reported by others that are relevant to microtransit:

- The transportation system in the United States needs a change to efficiently address people's needs and demands.

- Transportation agencies should identify existing problems and provide solutions, with customers' needs being a priority.

- Public transportation in local communities can be improved with the use of mobility options like new on-demand services.

- Public transportation should provide mobility and to enhance the quality of life for those who are unable to provide their own transportation. 
- The efficient movement of people stimulates economic development.

- Transportation agencies should focus on how to encourage commuters to using public transportation.

- New transportation options are being created to offer people an alternative means of mobility.

- Improving the transportation system will provide a series of changes along with time and money savings that will have an impact on economic activity and quality of life.

- Improving public transit services can make the service more attractive to the general public.

- Potential benefits of improving transit service can also help improve mobility, reduce costs, decrease energy use, diminish environmental impacts, and provide a better quality of life.

- Transit agencies around the country are looking for solutions to enhance their current transportation system.

- Partnerships are being created and explored with private mobility companies such as TNCs and Microtransit to provide efficient mobility to the community.

- Microtransit is a new concept offering innovative ways of mobility to people. It can use small vehicles with dynamic routing and scheduling for door-to-door on-demand services.

- The term Microtransit is still a vague term and sometimes even applied to nearly any shared ride service in vehicles larger than a sedan, but smaller than a bus. U.S. DOT defines microtransit as "a privately owned and operated shared transportation system that can offer fixed routes and schedules, as well as flexible routes and on-demand scheduling. The vehicles generally include vans and buses."

- Programs are being designed to either replace an entire route in low-ridership areas or a complement to fixed-route buses. Many challenges can be faced by microtransit. If the goals and objectives are not well set, these partnerships can be problematic.

- Microtransit is still in a probationary phase, but thus far, the results are promising on how it can be implemented to enhance public transit services and attract more riders.

The capability of using a phone application for requesting and paying for this service is changing the way people use public transportation. The community usage of microtransit on-demand services is becoming very popular these days, with fixed-route bus service being used for longer distance travel along the main arterials. Microtransit describes the type of services offered by transportation providers from the private sector. Its name can vary from one community to another, for instance, microtransit can be referred as Flex service, call n'ride, dial-a-ride, on-demand service, and on-call service. This type of service is mainly used in areas not fully covered by fixedroute transit. In some cases, microtransit can be more expensive to the rider than fixed route, but less than paratransit. However, in other cases, they can also be free. This depends on the business model of the private company (e.g., sell advertisement) or the support from the local municipalities.

It appears that microtransit is more convenient in less dense cities rather than crowded ones, because in big cities the fixed-route services are usually more efficient. In particular, microtransit 
can be very useful where distances to the nearest transit stop are more that $1 / 4$ of a mile, which is the distance most people are willing to walk. The experiences of several public transportation providers provide important lessons to be applied to the future public operation of flexible route, on-demand microtransit:

- Agencies willing to test microtransit should prioritize customers' needs and plan how to design, develop, and implement pilot projects.

- Agencies should empower those most familiar with the pilot to make quick decisions outside of the standard procedures to be able to quickly react to potential issues.

- The success or failure of a microtransit project should be determined based on performance metrics that go beyond ridership and revenue parameters, such as improved mobility, increased safety, and enhanced customer experience.

- Agencies should establish their goals and objectives and work with potential vendors to design the microtransit project that meet those parameters.

- Agencies should utilize aggressive marketing strategies to ensure that current and potential customers understand how to use the new service.

Public transportation can be improved with the use of microtransit on-demand services as an additional mobility option. Therefore, agencies should first identify the existent transportation problems in order to provide better solutions, keeping the needs of customers as a priority. Transportation services like microtransit, that are being provided in many communities, seem to the filling the gap of existing public transportation services. As microtransit gets accepted as a new transportation mode, its scope of services and coverage area is likely to evolve.

There are a few key factors that have contributed to the interest of implementing demand-response public transit service or microtransit by transit agencies (National Academies of Sciences, 2019), as presented below:

- Transit ridership has decreased for most transit agencies since 2014. One of the reasons for this trend can be attributed to the competition from transportation network companies that provide an attractive and convenient demand-response mobility service.

- Suburban development continues to grow, but these areas cannot be easily or economically served by fixed-route transit services.

- The transportation system should be designed to provide an equitable level of transportation services for all populations.

- Transit agencies seek to provide equitable transportation services to the different communities.

- New technology gives transit agencies the opportunity to provide demand-response service to the general public in a more economical and efficient way. 
- Transit agencies have been historically supply-oriented, focusing on their operations and requiring people to adjust to the service they provide. Nowadays, the public expectations are a lot higher. With the advance of technology, such as used by DRT or microtransit services, the transit vehicle can easily find the person instead of the person finding the transit service.

In summary, the following is a list of key items that have been identified by the review of the literature on microtransit and can provide some guidance in the deployment of this transportation mode:

- First mile / Last mile issue - microtransit services could work as a complement of fixedroute buses.

- Areas with poor or no fixed-route service - microtransit can fill some of the gaps in public transportation coverage.

- Low demand for public transportation - microtransit can provide service in locations where the demand or expected demand for public transportation is relatively low to justify a more expensive fixed-route service.

- Total costs - capital and operating costs can be less expensive than conventional public transportation. This may be adequate in areas with low ridership demands.

- New mode of transportation - the actual niche for microtransit service is yet to be fully determined. However, it can be more efficient than fixed route under certain conditions.

- Social interaction - services like microtransit that use smaller vehicles and serve neighborhoods lend themselves to create a more social environment in the vehicle.

- Driver personal assistance - as drivers get to know their customers, they can provide additional assistance to riders that need them. Drivers can assist with the groceries, front door drop-off and pickup, etc. This can be particularly beneficial to older adults and people with disabilities that use the service.

- Marketing - some microtransit expenses can be covered with advertising or marketing campaigns such as making a passenger ride fun, vehicles with splashy colors, discounts with restaurants etc.

- Environmentally friendly - since the microtransit vehicles are mainly small and electric, the carbon footprint is very low compared to automobiles of larger gas or diesel buses.

- Use of technology - The ease to use technology facilitates the rides requests and allows efficient operations of this type of service.

- Mobility provider - microtransit can be a connector service between small towns and main cities, reduce traffic, and improve the mobility within cities.

- Improved quality of life - the convenience of microtransit services and the transportation savings to the riders promotes economic activity and is likely to improve the quality of life to those who cannot afford an automobile or prefer using this mode of transport. 
Microtransit services appear to have an appeal to many population groups. People use this service to connect to local and regional transit services, take residents to shopping, health care, recreational facilities, allow students to take a ride to schools, or provide access to many other activities. The microtransit capital and operating costs in lower ridership areas can be more affordable than other transit services like community buses or regional fixed-route services. This can help reduce the dependence of subsidies to provide transit services or the cost savings can be used to provide additional hours of service at the same cost of other transit services.

\section{Miami-Dade County}

Based on this research, it is clear that microtransit is here to stay and has found a place among the available transportation and transit alternatives in Miami-Dade County. Microtransit services present a viable solution, so it continues to be explored and implemented throughout South Florida. From the available information available from the municipalities' websites and data collected from the different municipalities in Miami-Dade County, the following items present the key findings of this research study:

Microtransit ridership is increasing. What is interesting is that, unlike public transit that usually takes a year or two for ridership to mature, the microtransit data show that ridership starts to materialize after a couple of months of operation and continues to increase with time. The origins and destinations vary according to the municipality or community they serve. For instance, some connect to rail stations (first mile/last mile) while others connect residents to different local destinations.

The future of microtransit in Miami-Dade County and South Florida in general seems promising. So, it is expected that more municipalities will be exploring and implementing microtransit to provide transportation services in their communities. Nevertheless, more research is needed to establish the parameters needed for decision making to assist local communities with the assessment of the best mode to select for providing transit services that will best address the needs of the community.

\section{Future Considerations}

Local communities have specific needs and demand better transportation service. Having a transit system that efficiently addresses the needs of the communities should be a priority goal for transit agencies. Transit services provided by regional and local agencies need to be enhanced by additional service that can reach all members of the community. Microtransit can help fill this gap in neighborhoods and areas that are not or difficult to reach with other transit services. 
Microtransit could help areas with lower density and demand with an efficient and reliable service that can connect people to other places. It can help move people from their home to their destinations, encouraging economic development, reducing the impact on the environment, and improving social activity and quality of life in general. The following items present a list of issues that have been identified for future consideration:

- As a transportation mode, where does Microtransit fit? - As microtransit is a relatively new mode of transportation, more research is needed to place microtransit in the larger scheme of current transportation modes.

- Operation considerations - what is the best way to deliver microtransit services? Should microtransit be operated as on-demand, fixed-route, or flex service? Answers to these questions can help local municipalities provide the best possible transit service to the community they serve.

- Accessibility and Safety - ADA compliance and local and state safety regulations need to be taken into consideration in the planning, design, and implementation of microtransit services.

- Service Standards and Performance Measures - as the scope of services provided by microtransit is still evolving, this is an area that needs to be investigated to ensure that these services can be efficiently monitored and managed.

- Guidelines - General microtransit guidelines are needed to help municipalities who are exploring the implementation of microtransit services.

- Government regulation - Government agencies can assist in this effort by providing leadership in this effort. Policymakers and planners must develop innovative approaches and prioritize resources to meet the challenging transportation needs for good mobility and an improved quality of life.

- Partnership and coordination with transit agencies - As the demand for transportation services is expected to increase, coordination among transit agencies and service providers is needed to provide services that efficiently cover all members of a community.

- Technology or not? - Microtransit services use technology for their riders' request and to manage the service. However, there are some segments of the population that may not have access to technological devices like computers or smart phones or people that are not technically savvy. Therefore, keeping the traditional booking methods, through phones calls should be part of the microtransit services.

- Education - Educating the community about the service and how to use it is required for success. Agencies also need to explore the use non-traditional communications or media channels to ensure that all members of a community are reached. If a communication channel is found to reach these individuals, it can save an agency's time and resources when it comes to educating people on the use of microtransit.

- Funding - The funding of transportation services is always a challenge. However, funding 
sources need to be identified for providing microtransit services. Funding can come from local, state, or federal sources. Additional revenue can come from advertising. In South Florida, Miami-Dade and Broward counties have implemented a sales tax to fund transit projects, so they can be used to fund microtransit projects.

- Fares and Subsidies - Agencies need to explore if using the same fares as fixed-route buses is beneficial to attract customers. Should microtransit services be subsidized and offered to the community free of charge? In South Florida, most of the microtransit services are provided to passengers free of charge. 


\section{REFERENCES}

Alonso-Gonzalez, M. J., Liu, T., Cats, O., Van Oort, N., \& Hoogendoorn, S. (2018). The Potential of Demand-Responsive Transport as a Complement to Public Transport: An Assessment Framework and an Empirical Evaluation. Transportation Research Board, 2672(8), 879-889. doi: https://doi.org/10.1177/0361198118790842

American Public Transportation Association (APTA). (2010). Public Transportation: Moving America Forward.

Anaheim Resort Transportation (ART). (2017). Anaheim Ctr City Microtransit Conceptual Plan: Working paper. Anaheim, CA. http://rideart.org/wp-content/uploads/2014/12/ART-CTR-CityAnaheim-Microtransit-Plan.pdf

Anaheim Resort Transportation (ART). (2018). MicroTransit Service CtrCity Anaheim: Project Description. Anaheim, CA. http://rideart.org/wp-content/uploads/2018/08/CtrCity-AnaheimMicrotransit.pdf

Beverly Foundation. (2001). On the Road to Senior Friendly Transportation: The 5 A's. Pasadena, CA.

Bliss, L. (2017, May 3). Bridj Is Dead, But Microtransit Isn't. Retrieved from https://www.citylab.com/transportation/2017/05/bridj-is-dead-but-microtransit-isnt/525156/

Cevallos F., J. Skinner, A. Joslin, \& T. Ivy. (2010, January). FTA Report: Attracting Senior Drivers to Public Transportation: Issues and Concerns. Miami, FL: Florida International University, Lehman Center for Transportation Research.

Cevallos, Fabian. (2018). FDOT Report: Trolleys, Shuttles, and Community Buses in South Florida: Providing Transit Service to a Special Segment of the Population. Miami, FL: Florida International University, Lehman Center for Transportation Research.

Cevallos, Fabian. (2019). FDOT Report: Challenges and Opportunities for Older Adults to Use Public Transportation: A South Florida Perspective. Miami, FL: Florida International University, Lehman Center for Transportation Research.

Feigon, S. and C. Murphy. (2018) TCRP Research Report 195: Broadening Understanding of the Interplay Among Public Transit, Shared Mobility, and Personal Automobiles. Washington, DC: The National Academies Press. 
Freebee. (2020). Retrieved February 4, 2020 from https://ridefreebee.com/

Georgia Planning Association. (2019). Micro-Transit Feasibility Study Hall County, Georgia. Georgia, GA.

Hansen, T. (2019). Innovation in Accessible Transportation and Demand Response Service. Texas A\&M Transportation Institute.

Hurtibise, R. (2019, May 11). They're like Uber but free: New electric shuttles popping up all over South Florida. Retrieved October 9, 2019, from https://www.sun-sentinel.com/business/flbz-free-electric-shuttles-fill-urban-commuting-need-20190510-hugx4xf5ljfpvnnbb7ovxme66astory.html.

Kimley-Horn and IBI Group. (2019). DRPT Statewide Integrated Mobility Initiative. Prepared for Virginia Department of Rail and Public Transportation. Virginia.

KFH Group. (2019). Demand Response Transit / Microtransit: A Guide for Implementing Flexible Transportation Services. Arlington County, VA.

Kortum, K. (2016). Between Public and Private Mobility: Examining the Rise of TechnologyEnabled Transportation Services. Washington DC: The National Academies of Sciences, Engineering and Medicine.

LA Metro. (2017). Industry Forum on Micro Transit Pilot Project. Los Angeles, CA.

Lehman Center for Transportation Research (LCTR). (2019). Town of Surfside, Bal Harbour Village, and Bay Harbor Islands Interlocal Shuttle System. Transit Program Lehman Center for Transportation Research (LCTR), Florida International University (FIU). Miami, FL.

Li, H. (2018). SacRT Community/Neighborhood Shuttle Program. SacRT

Community/Neighborhood Shuttle Program. Sacramento, CA.

Mackie, P. (2018, April 26). Is microtransit actually focused on providing "first mile" to transit? Retrieved January 16, 2020, from https://mobilitylab.org/2018/04/25/first-mile-may-be-code-forwhitewashing-by-microstransit-companies/

MaRS Discovery District. (2016). Microtransit: An assessment of potential to drive greenhouse gas reductions. Canada. 
Mass Transit magazine (2019, June 11). MetroLINK begins pilot microtransit program. Retrieved February 27, 2020, from https://www.masstransitmag.com/alt-mobility/shared-mobility/pressrelease/21084187/metrolink-metrolink-begins-pilot-microtransit-program

Metro Magazine. (2019a) Via bringing on-demand services to Japan. Retrieved February 28, 2020, from https://www.metro-magazine.com/mobility/news/733770/via-bringing-on-demandservices-to-japan

Metro Magazine (2019b). Transport for London renews ViaVan microtransit service for 3 years. Retrieved February 27, 2020, from https://www.metro-magazine.com/mobility/news/734872/ transport-for-london-renews-viavan-microtransit-service-for-3-years

National Academies of Sciences, Engineering, and Medicine. 2012. Transportation Systems for Livable Communities. Washington, DC: The National Academies Press. https://doi.org/ $10.17226 / 22778$.

National Academies of Sciences, Engineering, and Medicine. (2019). Microtransit or General Public Demand Response Transit Services: State of the Practice. Washington, DC: The National Academies Press. https://doi.org/10.17226/25414

NelsonlNygaard. (2019). Transit \& Emerging Technologies. San Francisco, CA.

Perera, S., Ho, D., \& Hensher, D. (2019). Resurgence of Demand Responsive Transit services Insights from Bridj trials in Inner West of Sydney, Australia. Sydney, Australia: Institute of Transport and Logistics Studies.

Polzin, S. E. (2018). Just Around the Corner: The Future of U.S. Public Transportation. Journal of Public Transportation, 21, 43-52. doi: http://doi.org/10.5038/2375-0901.21.1.5

RideCo. (2019, January 3). How transit operators are getting on board with microtransit. Retrieved February 26, 2020, from https://blog.rideco.com/how-transit-operators-are-getting-on-boardwith-microtransit-b0e65540f476

Sacramento Regional Transit. (2020, January 14). SacRT expands microtransit service to six additional communities. Retrieved January 28, 2020, from https://sizzles.org/us/business/sacrtexpands-microtransit-service-additional-communities-40082686

SamTrans. (n.d.). SamTrans. San Mateo County, CA. Retrieved March 11, 2020, from http://www.samtrans.com/schedulesandmaps/timetables/OnDemand.html 
Schaller, B. (2018). The New Automobility: Lyft, Uber and the Future of American Cities. Brooklyn, NY. Retrieved from http://www.schallerconsult.com/rideservices/automobility.pdf

Scheckner, Jesse. (2019, July 23). Jason Spiegel: Driving Freebee local transit into many communities. Miami Today, Miami, FL.

Stewart, D. (2019, July 18). Circuit's Free Shuttle Service Expands to Hollywood; Points to a Growing Transportation Trend. Retrieved February 25, 2020, from https://www.browardpalmbeach.com/news/circuit-the-free-ride-shuttle-service-in-hollywoodflorida-10267122

Schwieterman, J. P., Livingston, M., \& Van Der Slot, S. (2018). Partners in Transit: A Review of Partnerships Between Transportation Network Companies and Public Agencies in the United States. Chicago, IL: Chaddick Institute for Metropolitan Development.

Spiegel, J. (2018, September 28). OI Engine, an Innovation Management Software Built on Design Thinking. Retrieved January 3, 2019, from https://challenges.cityoftomorrow.com/challenge/ miami/propose/freebee-innovative-and-proven-first-and-last-mile-transportation

The Eno Foundation. (2018). UpRouted: Exploring Microtransit in the United States. Retrieved from https://www.enotrans.org/wp-content/uploads/2018/01/UpRouted-18.pdf

U.S. Census Bureau (2019). Quick Facts. Retrieved from https://www.census.gov/quickfacts/ fact/table/US/PST045219.

U.S. Census Bureau (2018). Selected economic and housing characteristics, 2014-2018 American Community Survey 5-year estimates data profiles. Retrieved from https://www.census.gov/acs/www/data/data-tables-and-tools/data-profiles/

Via. (2019. Via and Busways launch microtransit service connecting The Ponds and Schofields residents to public transit. Retrieved February 27, 2020, from https://ridewithvia.com/2019/06/viaand-busways-launch-microtransit-service-connecting-the-ponds-and-schofields-residents-topublic-transit/

Werckmeister García, N. (2018). Microtransit for urban mobility: analysis, case study proposal and potential environmental impacts. Barcelona, Spain.

Weinreich, D., Skuzinski, T., Hamidi, S., \& Reeves, S. M. (2020). Transit in Flex: Examining Service Fragmentation of New App-Based, OnDemand Transit Services. Arlington, TX:

Department of Transportation Research and Innovative Technology Administration. 


\section{APPENDIX A}

\section{(List of Acronyms/Abbreviations)}

APTA American Public Transportation Association

ADA Americans with Disabilities Act

DOT Department of Transportation

DRT Demand-responsive transport

FDOT Florida Department of Transportation

FIU Florida International University

FTA Federal Transit Administration

GHG Greenhouse Gases

LCTR Lehman Center for Transportation Research

NCTR National Center for Transit Research

TCRP Transit Cooperative Research Program

TNC Transportation Network Companies

USF University of South Florida

ATN Anaheim Transportation Network

ART Anaheim Resort Transportation

SOV Single-Occupancy Vehicle

LYNX Central Florida Regional Transportation Authority

RTD Regional Transportation District

RideCo Inc.

SacRT Sacramento Regional Transit District

DRPT Department of Rail and Public Transportation

AMTU Associació de Municipis per la Mobilitat i el Transport Urbà (Association of Municipalities for Mobility and Urban Transport) 


\section{APPENDIX B}

\section{Freebee Microtransit Service in Miami-Dade County}

\section{COCONUT GROVE}

The Freebee service in Coconut Grove is provided by the City of Miami for the Coconut Grove community. According to their website, to use this service, users can call ahead or download the app and ride for free. In addition, in partnership with the Business Improvement District (BID), drivers serve as Grove Ambassadors and can provide information to riders. Users of the Freebee app can also find deals and specials submitted by local businesses.

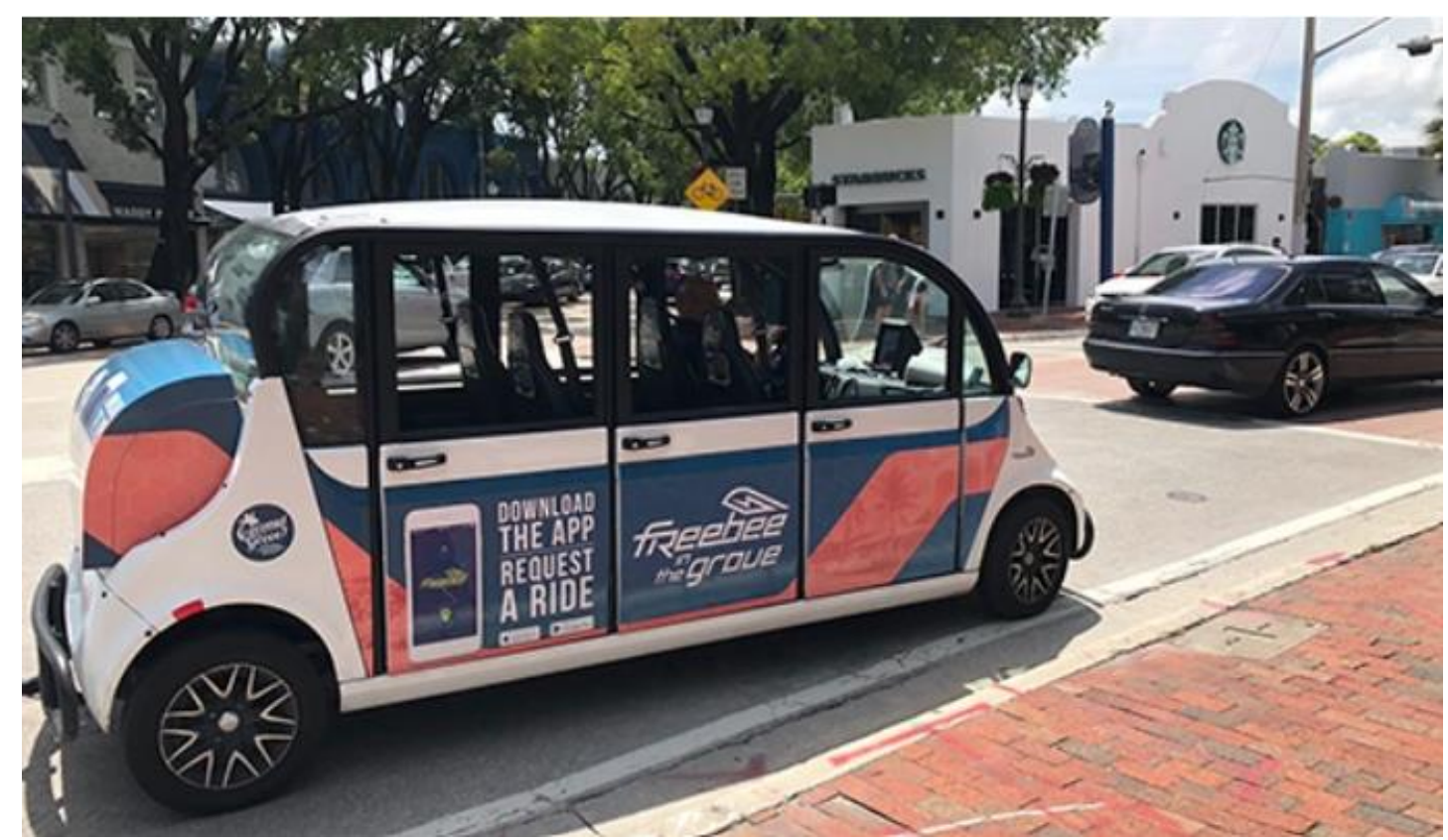

Hours of Operation

11am-8pm (Sun-Wed)

$11 \mathrm{am}-11 \mathrm{pm}$ (Thurs-Sat)

The service provided for Coconut Grove is free. The following figures depict the coverage area of the Freebee service. 


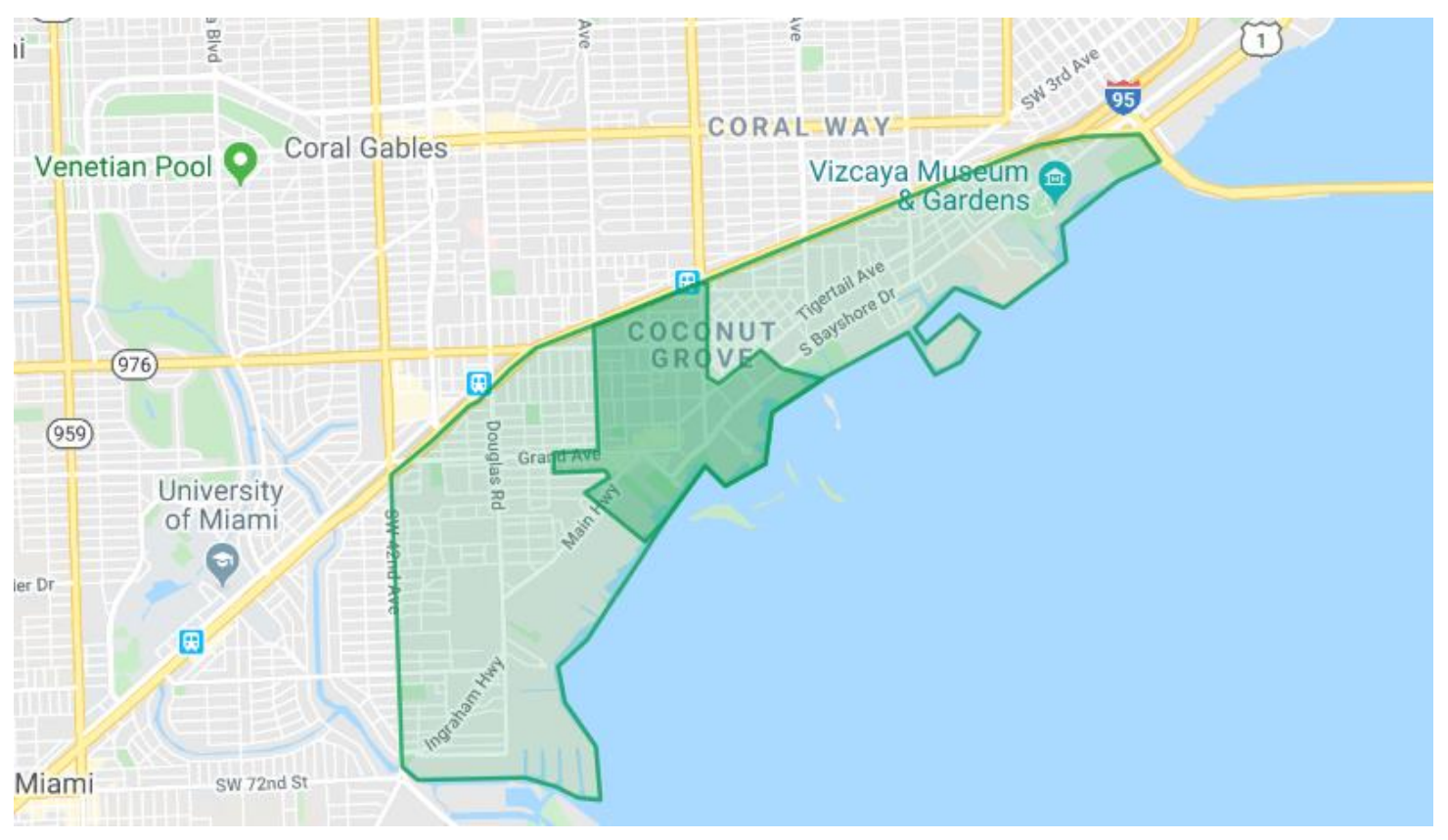

\section{COVERAGE AREA}

PICK-UP / DROP-OFF ANYWHERE WITHIN THESE BOUNDARIES

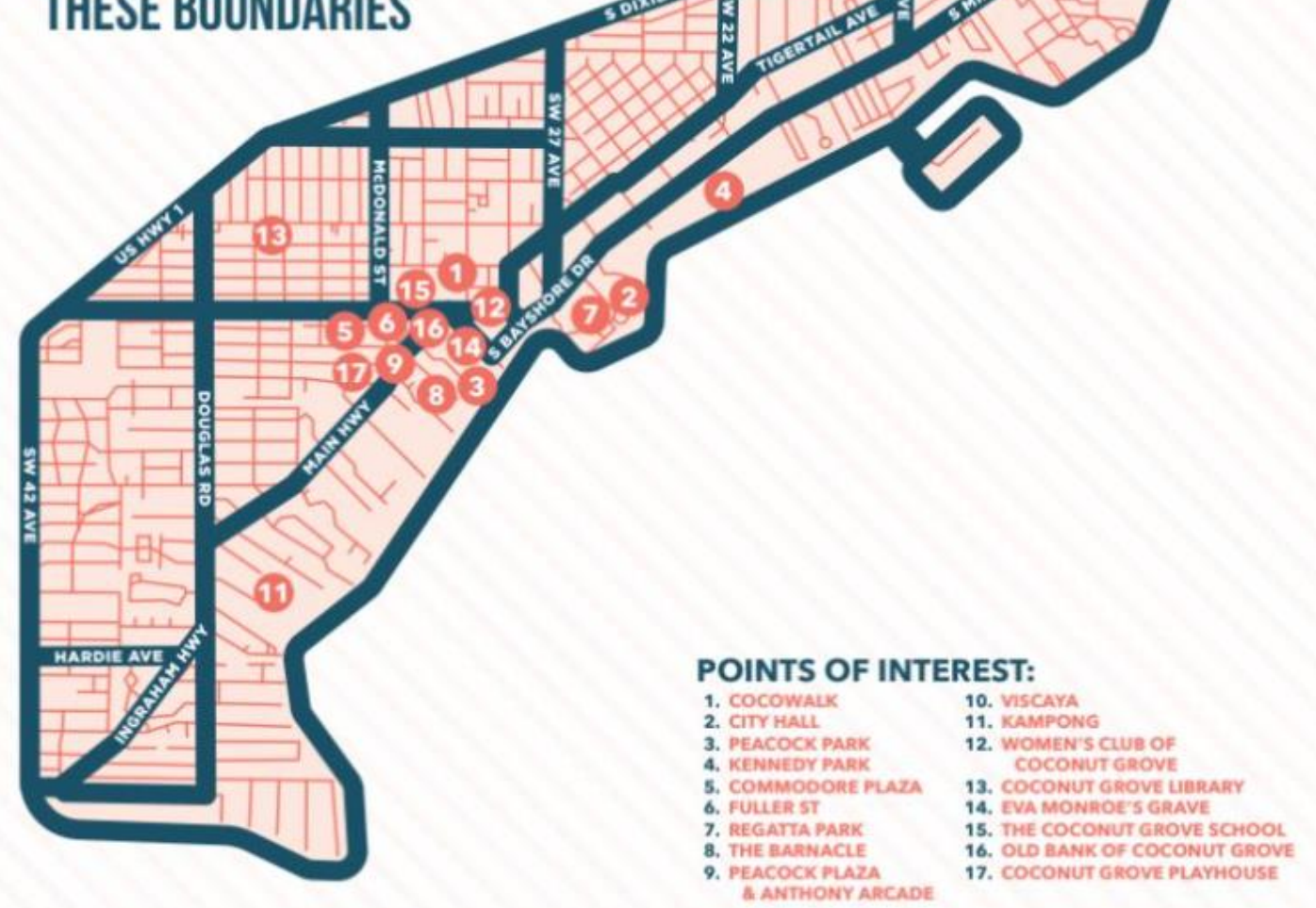




\section{CORAL GABLES}

The City of Coral Gables offers rides around Downtown Coral Gables thanks to a partnership between the City of Coral Gables and Freebee, a green transportation service that offers free doorto-door rides around your favorite destinations. Friendly drivers in sleek electric vehicles are on the street from 10 a.m. to 10 p.m. seven days a week. According to the City of Coral Gables website, to use the service riders can request this service on your smart phone through the Ride Freebee app by following these steps:

a) Download the app at www.ridefreebee.com

b) Use the app to Request a Ride

c) Select your Destination

d) Confirm your Pickup, and

e) Enjoy the Ride!

Hours of Operation

10am-10pm (Mon-Sun)

The service provided by the City of Coral Gables is free. The following figure depicts the coverage area of the Freebee service.

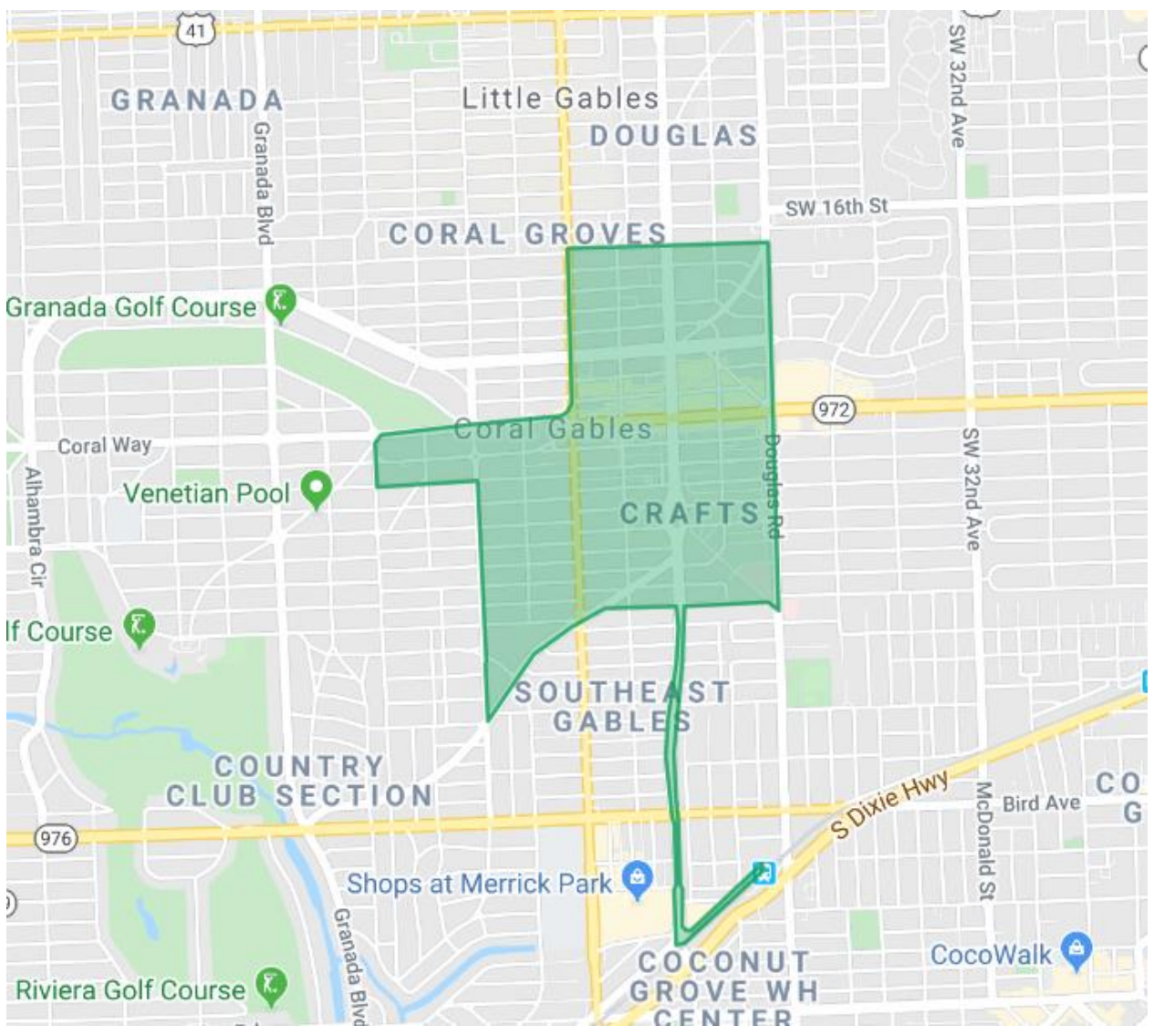




\section{DORAL}

The City of Doral offers a door-to-door, on-demand, transportation service to its citizens and visitors. The Freebee vehicles are 100\% electric and emission-free. In addition, the Freebee guide shares with users the latest and greatest happenings in the City of Doral. This service caters all ages, from children to seniors, and all types of pets. It provides booster seats as appropriate for children who exceed the size requirements to travel in a car seat. Smaller children and infants are required to be secured in a federally approved car seat, provided by their parent or guardian. If ADA assistance is needed, users can contact Freebee in Doral at 305-216-9819.

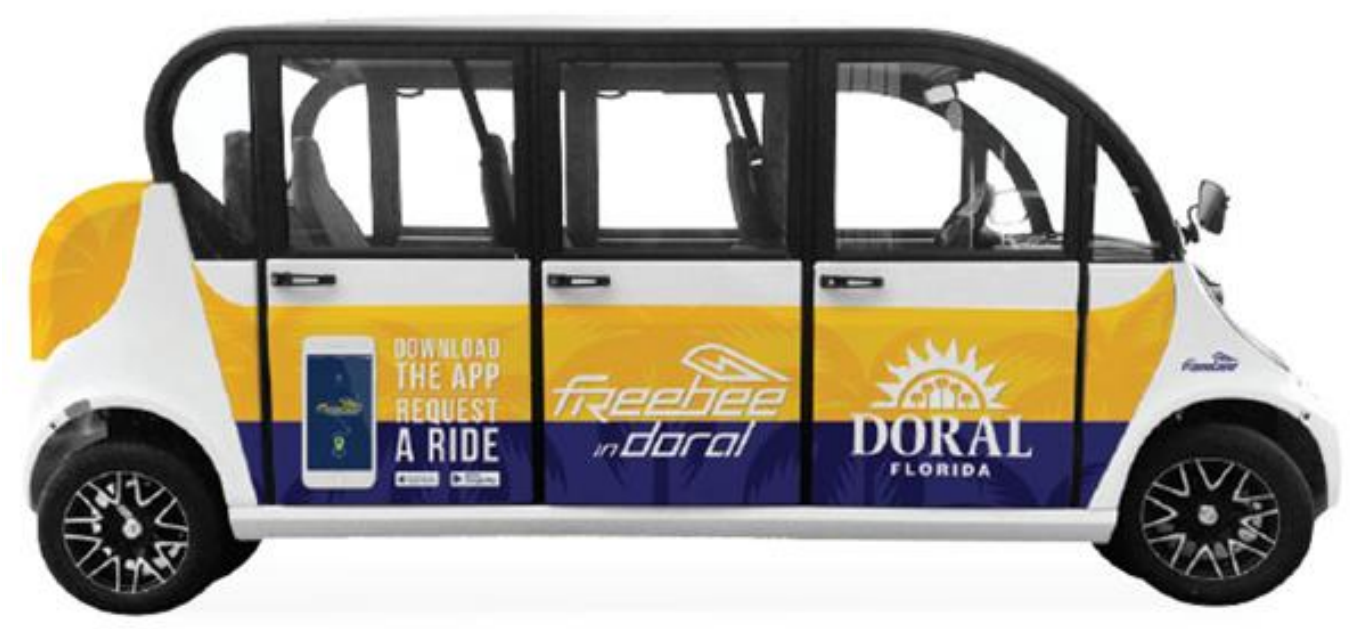

Hours of Operation

$$
\begin{gathered}
\text { Monday - Thursday 11am - 7pm } \\
\text { Friday - Saturday 10am - 12am } \\
\text { Sunday 12pm - 7pm }
\end{gathered}
$$

The service provided by the City of Doral is free. The following figures depict the Freebee service coverage area, points of interest, and connections to their local Trolley and county MetroRail transit systems. 


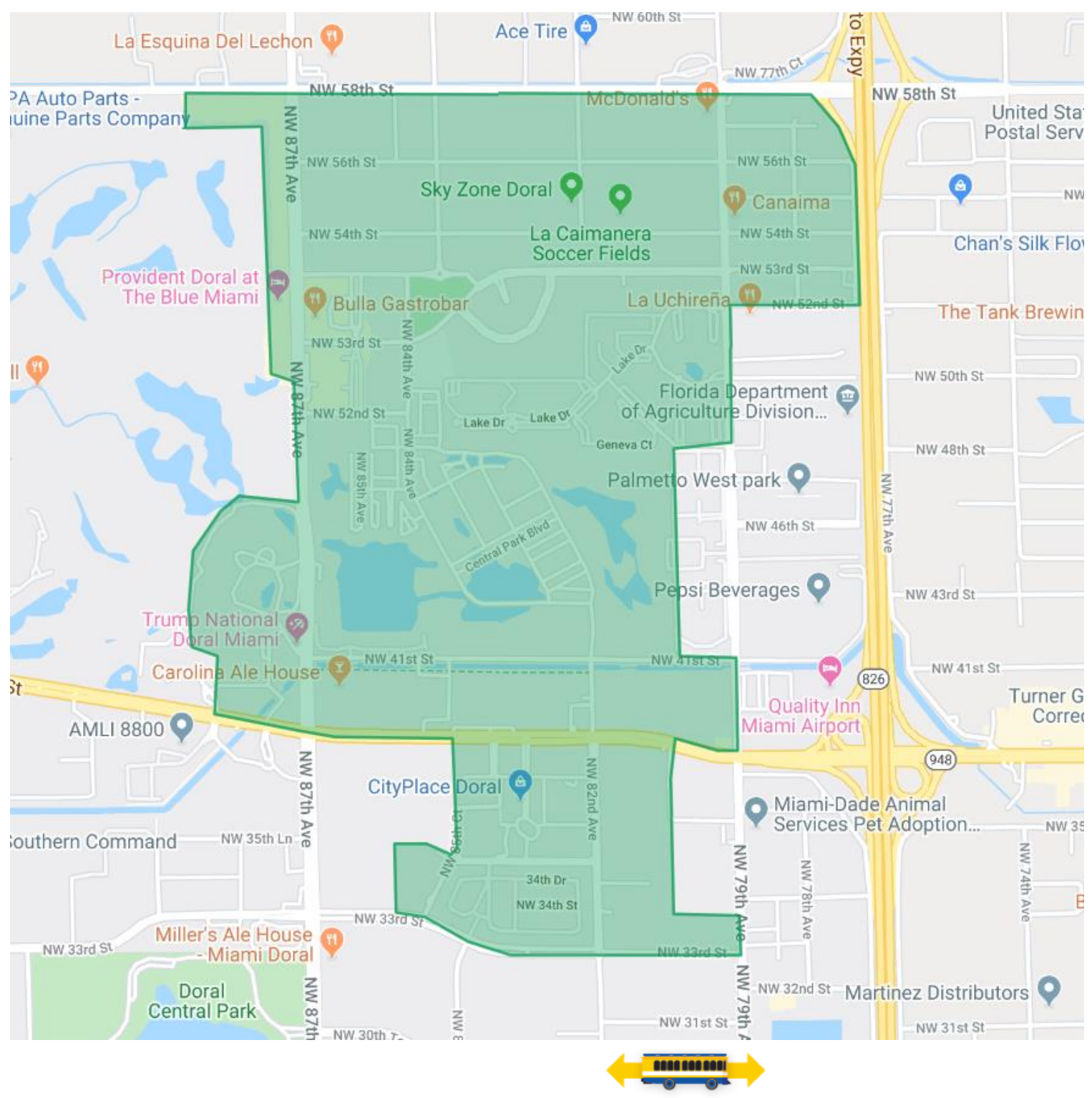

POINTS OF INTEREST

1. City of Doral - Government Center

2. Downtown Doral Park

3. Downtown Doral Charter Elementary School

4. Downtown Doral Charter Upper School

5. Downtown Doral

6. Trump National Doral

7. The Provident

8. CityPlace Doral
CITY OF DORAL TROLLEY CONNECTION TO METRORAIL STATION AND CITY PLACE

Route 1 SERVICE HOURS

Weekdays 6:00 am to 10:07 pm

Saturdays 7:00 am to $8: 03 \mathrm{pm}$

Sundays 7:00 am to $8: 03 \mathrm{pm}$

ROUTE 2 SERVICE HOURS

Weekdays 6:00am to $9: 38 \mathrm{pm}$

Saturdays 6:50am to 7:53pm

No Service on Sundays

For easy connections to the Palmetto Metrorail Station and City Place, Freebee will connect you to the closest City of Doral trolley stop along 53rd St. 


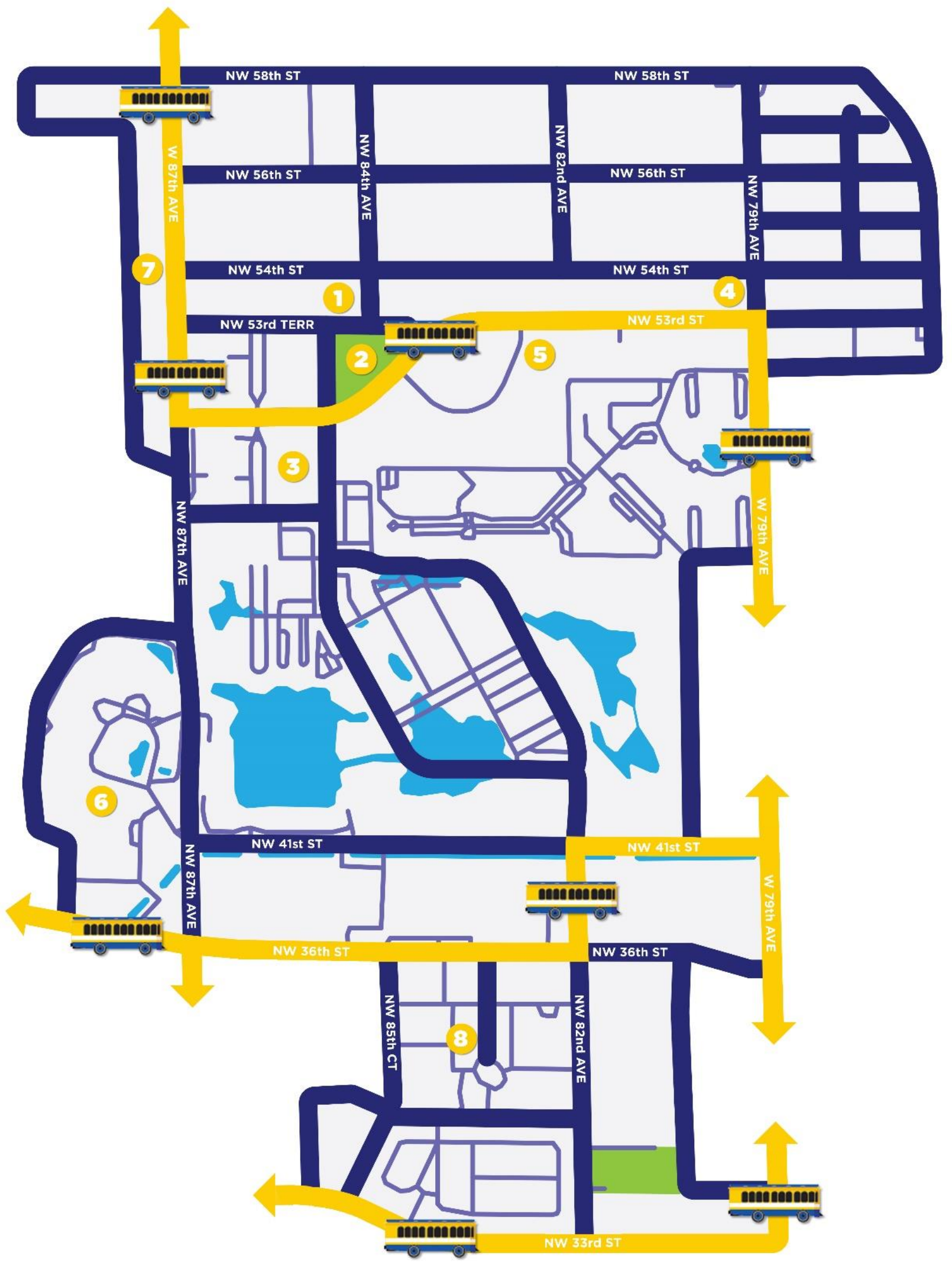


Freebee on the Key is the Village's on-demand ride service. The service started on December 15, 2016. Freebee can be requested via the app available for iOS devices at the App Store or for Android devices and the Google Store. Information on how to use the service is also available through flyers.

In addition to the on-demand service, users can also ride Freebee using its continuous KB Loop service along Village streets at stops marked by signs. Several vehicles circulate from 11:00 a.m. to 7:00 p.m. daily, enabling service every 20-30 minutes. Users can track the vehicles on the app or on a web browser at http://kbloop.ridefreebee.com/

\section{Hours of Operation \\ 8am-8pm (Sun-Thurs) \\ 8am-10pm (Fri) \\ 10am-10pm (Sat)}

The service provided by the Village of Key Biscayne is free. The following figures depict the Freebee service coverage area, points of interest, and information about the KB Loop Route.
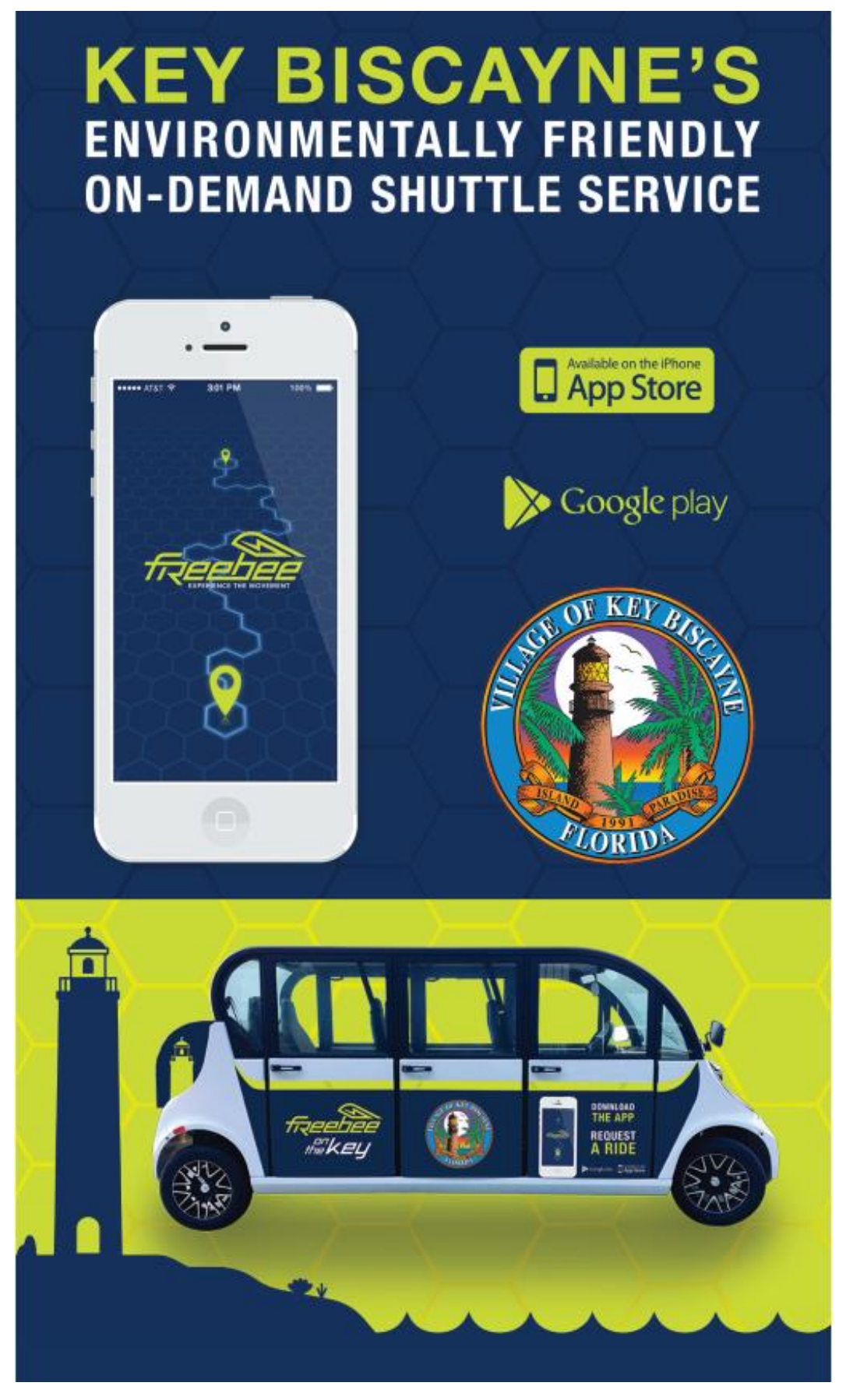


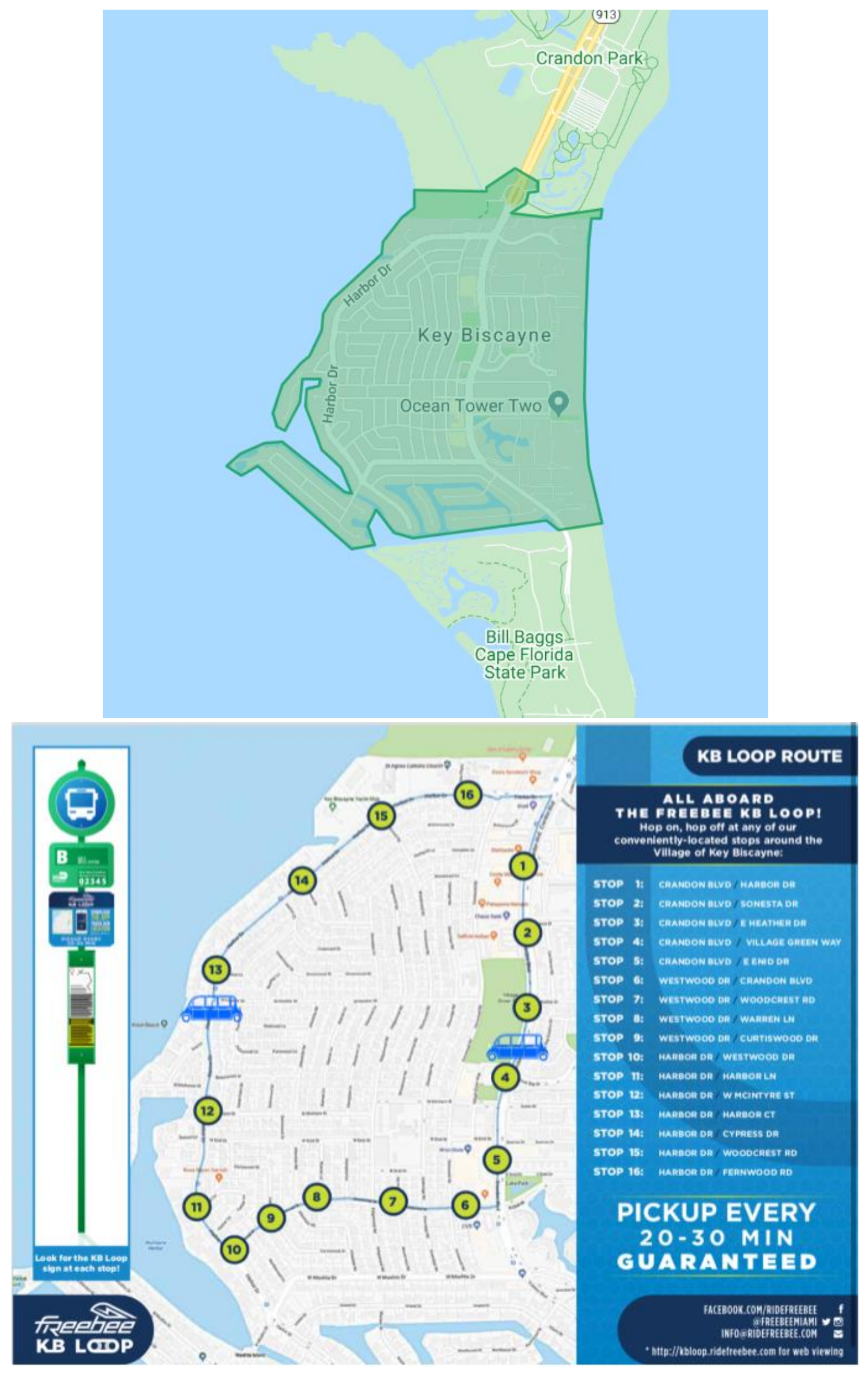


This service directly by Freebee. It covers Brickell, Downtown, Wynwood, Edgewater, Midtown, and the Design District. The operating costs are covered by advertising.

\section{Hours of Operation}

\section{1am-11pm (Sun-Thurs) \\ 11am-2am (Fri-Sat)}

The service provided in Miami is free. The following figure depicts the Freebee service coverage area in Miami.

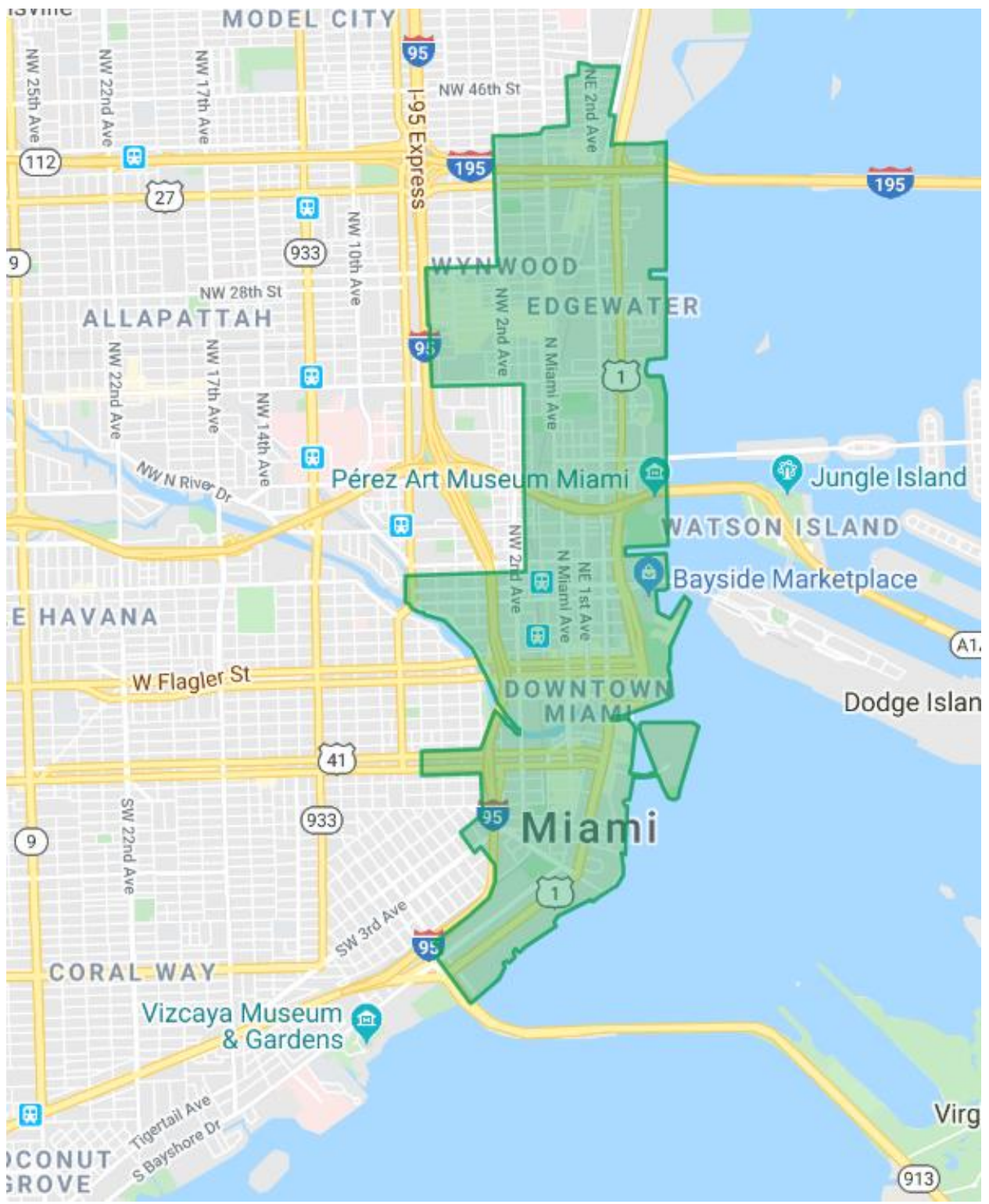




\section{MID BEACH (Miami Beach)}

The City of Miami Beach, in partnership with Freebee, offers a free on-demand service to riders throughout Mid-Beach. The on-demand service provides first mile/last mile service connecting to the existing Miami Beach Trolley and Miami-Dade County Bus service within the geo-fenced service area and door-to-door service for trips originating and ending within the geo-fenced service area. The service operates as a continuous vanpool, dynamically adjusting vehicle routing to appropriately meet ridership demand and service needs within the service area.

Important Information \& Tips

- Due to limited number of vehicles in operation, we suggest requesting service approximately 20 minutes in advance of your desired departure time MB Freebee vehicles are $100 \%$ electric, emission-free and ADA accessible.

- Smaller children and infants are required to be secured in a federally approved car seat, provided by their parent or guardian.

- Booster seats are available if needed for children. If needed, please request booster seat from your driver.

- Available transit connections are: Washington Avenue/17 Street, Alton Road/Lincoln Road, West Avenue/19 Street (Publix), Indian Creek Dr/41 Street, Indian Creek Drive/63 Street, Indian Creek Drive/65 Street (Shane Center), and Collins Avenue/69 Street (Publix).

If you don't have access to a smart phone, you can call 786.598 .9870 or hail a Freebee street side.

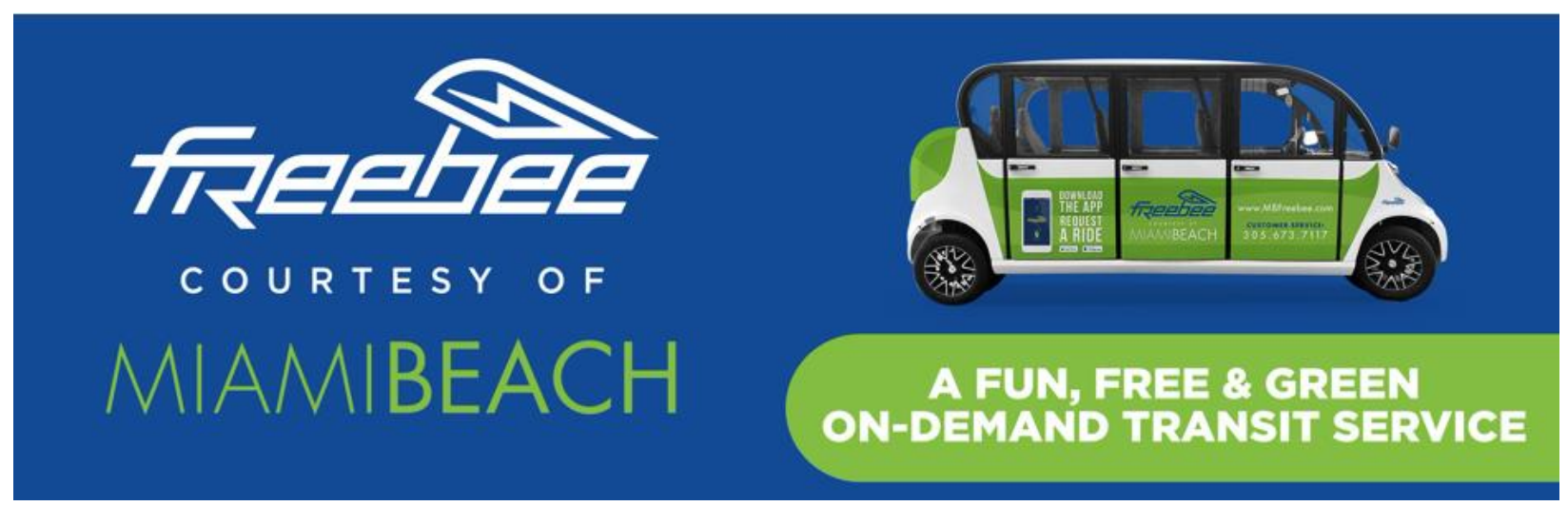

Hours of Operation

6:30am-10pm (Mon-Fri)

8am-10pm (Sat)

8am-8pm (Sun) 
The service provided by the City of Miami Beach is free. The following figure depicts the Freebee service coverage area in Miami Beach.

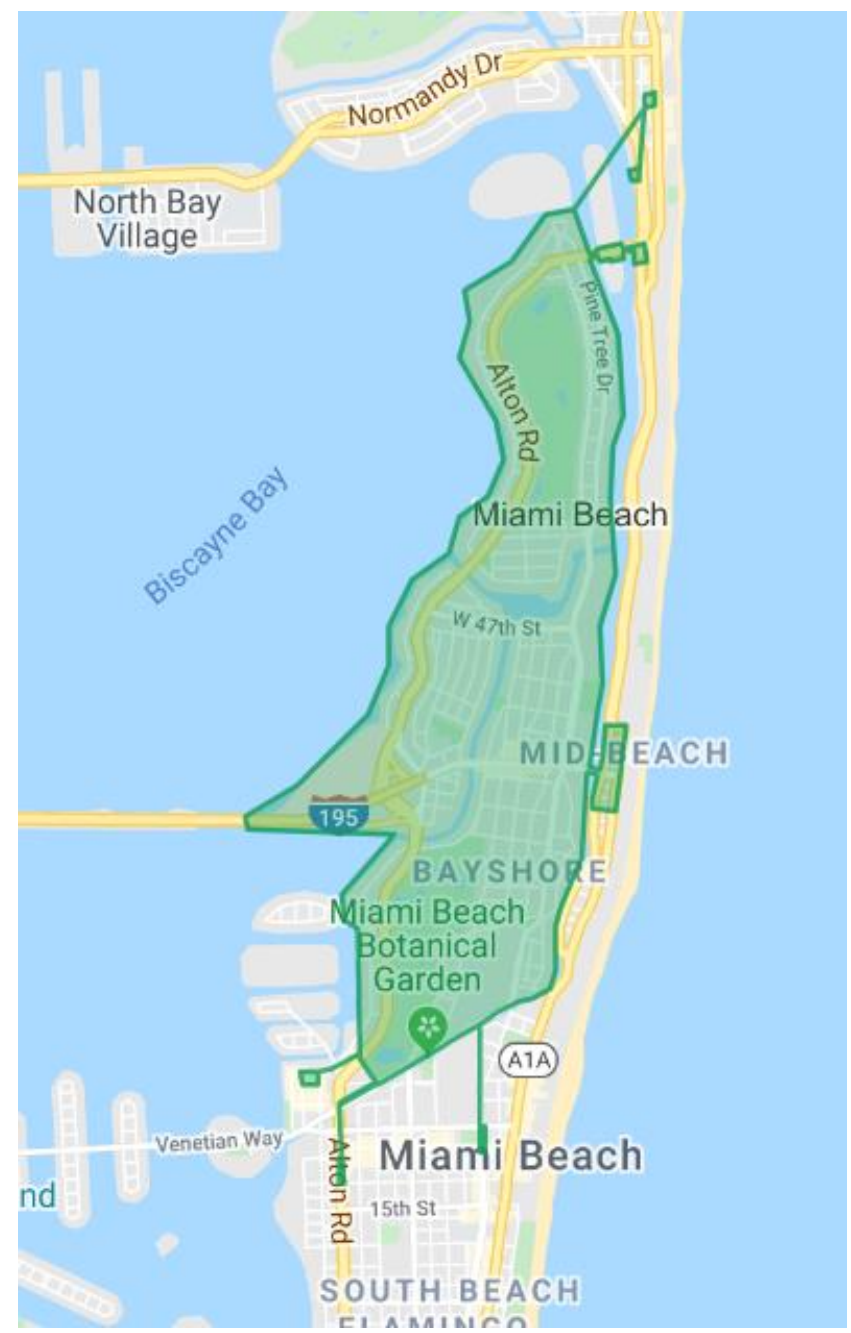




\section{SERVICE AREA}

ON.DEMAND

SERVICE AREA:
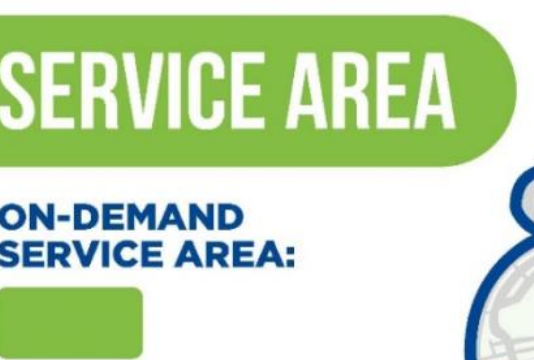

Publix on

Publix on
Collins Ave / 69 St

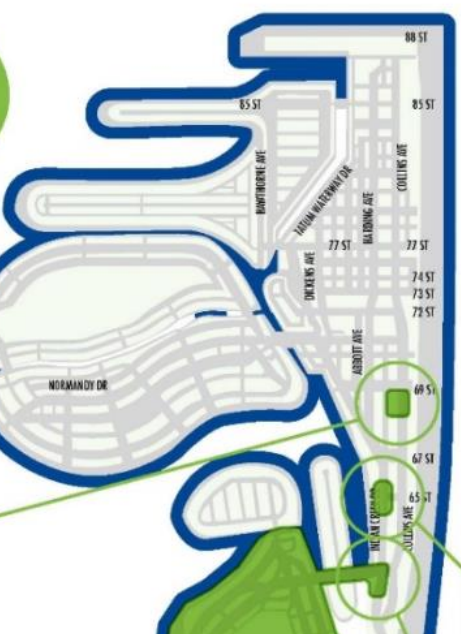

Shane Center
Indian Creek Dr/65 St

Transit Hub on

Indian Creek Dr / $63 \mathrm{St}$

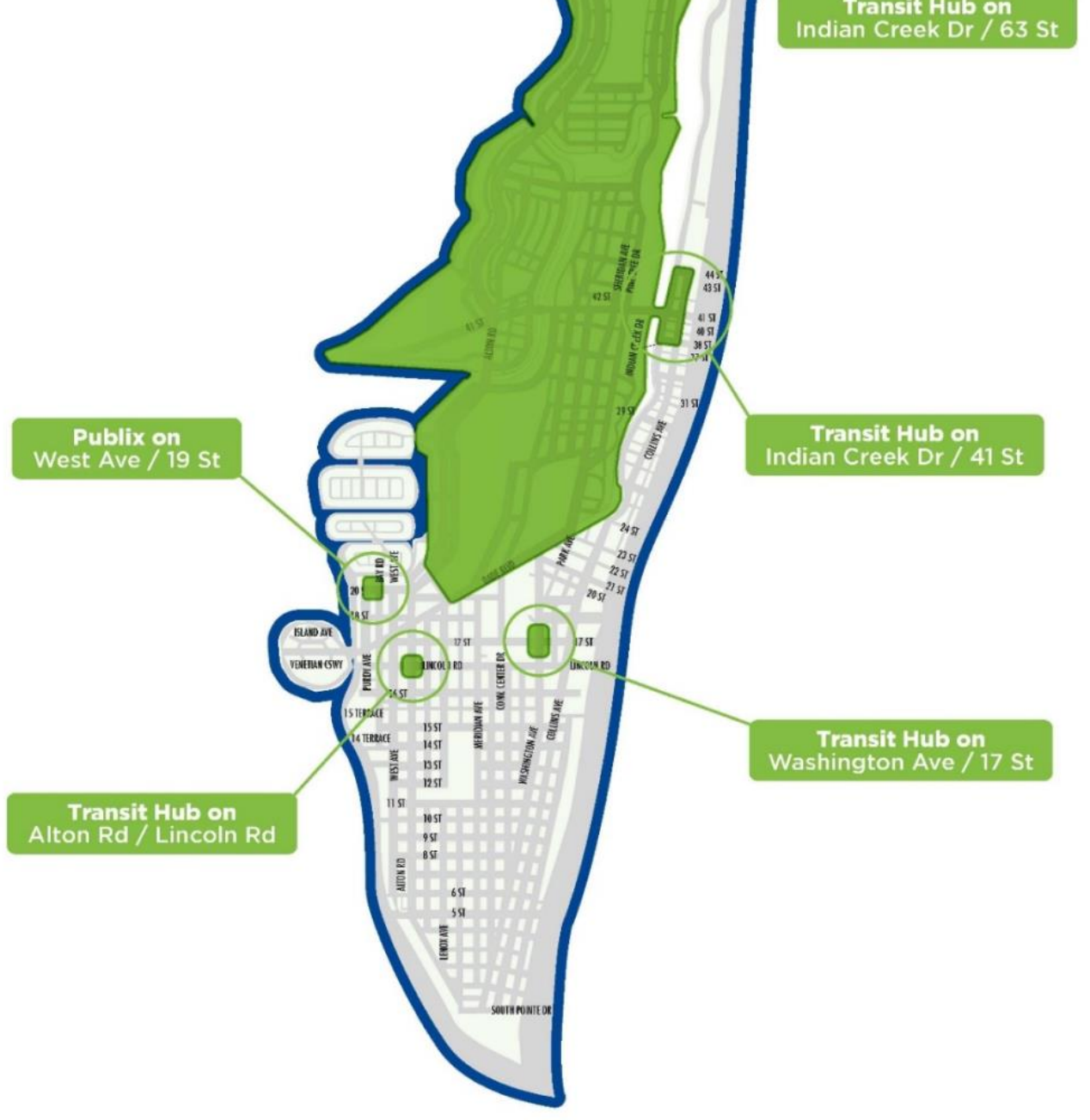


According to website, the Town of Miami Lakes switched from the Moover fixed-route system to the on-demand Freebee service. Here are the key changes:

- Switching from fixed-route service to full on-demand ridesharing service

- Added a new larger ADA accessible vehicle to the Freebee fleet that holds up to 10 passengers, so now the Town have three vehicles s circulating.

- The larger bus will be able to access the parts of the town that are currently not serviced due to the speed limit restrictions. These areas are NW 67th Ave north of Miami Lakeway to NW 167th Street and the NE business district by Costco and Miami Lakes Education Center.

- $\quad$ Rides can request via the RideFreebee app or by calling (305) 901-9500.

Freebee offers a green and free travel options using the branded electric Freebee cars. Users can request this service on smartphones through the Ride Freebee app following these easy steps:

Step 1: Download the app at www.ridefreebee.com

Step 2: Use the app to Request a Ride

Step 3: Select your Destination

Step 4: Confirm your Pickup, and

Step 5: Enjoy the Ride!

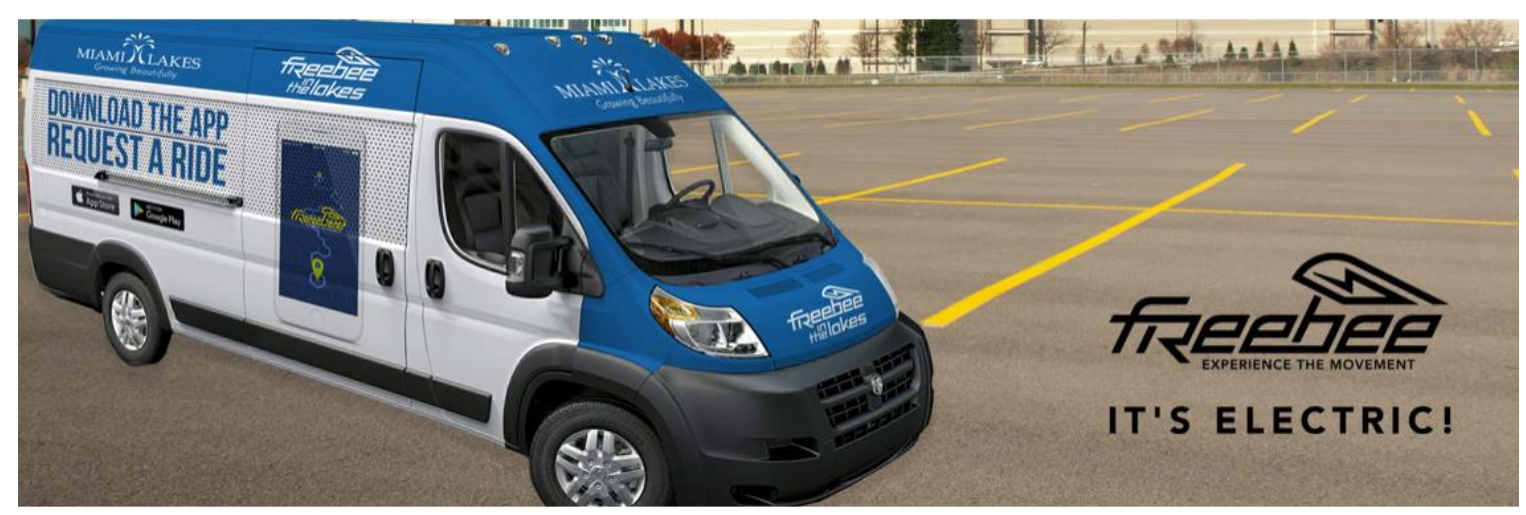

Hours of Operation

Monday- Thursday 9:00 am to 6:30 pm

Friday 9:00 am to 10:00 pm

Saturday 9:00 am to 9:00 pm

Sunday 10:00 am to 2:00 pm 
The service provided by the Town of Miami Lakes is free. The following figure depicts the Freebee service coverage area in Miami Lakes.

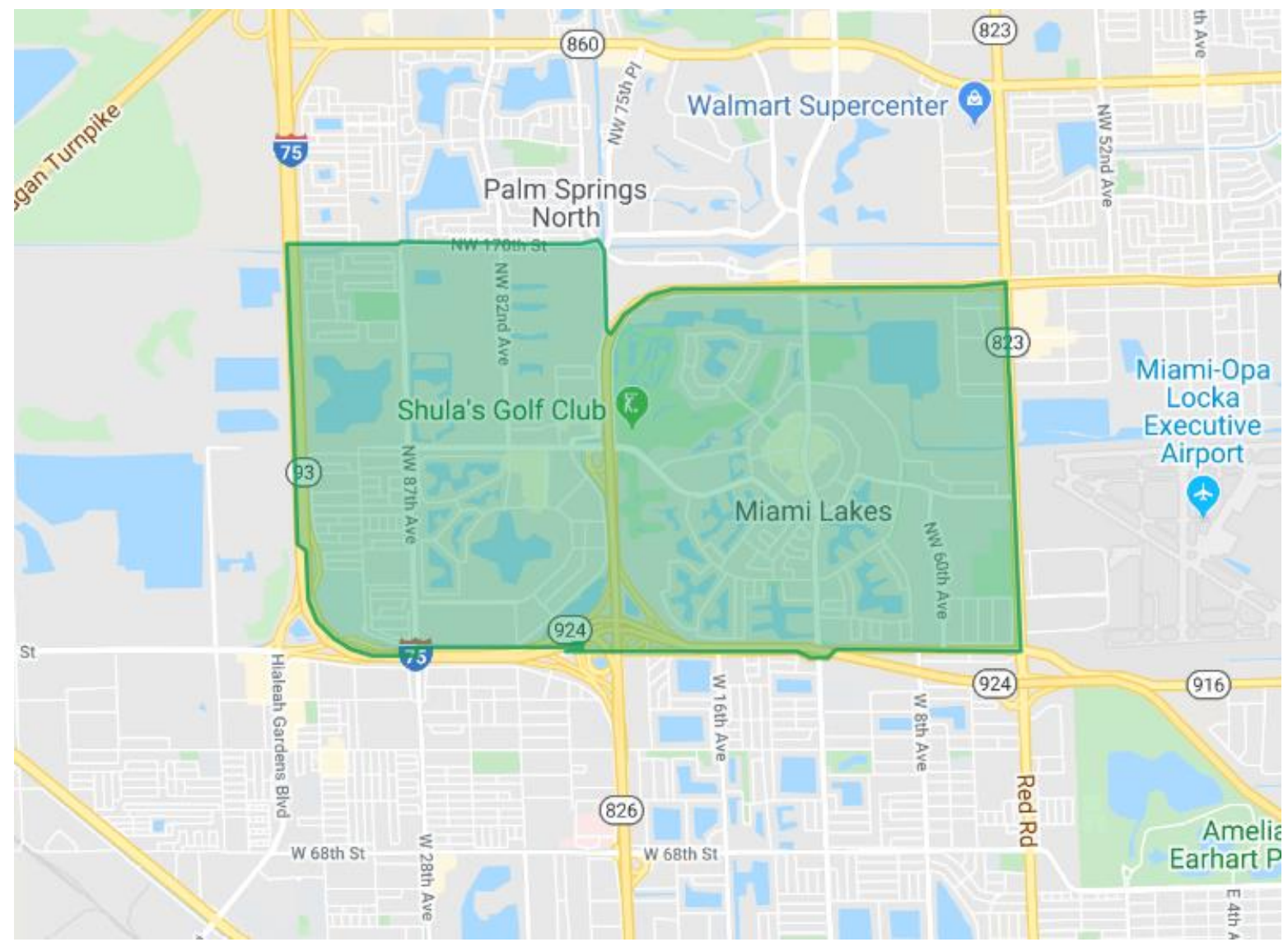


North Bay Village, FL - Freebee is all the buzz around North Bay Village. Since its inception in early November 2019, the Freebee ridership program has more than doubled in ridership, from 130 passengers in its first week to 283 during the week of January 20, 2020.

Residents and visitors, alike, can catch a ride from anywhere within the Village with a few clicks using the Freebee app or by calling 305-397-5015.

Freebee helps residents easily navigate the islands for a quick shopping trip, an easy way to and from school or a boost getting to the beach. Even in a pinch, the ride-hailing app can help reduce anxiety in a stressful situation.

Freebee North Bay Village is available to anyone, free of charge, Monday through Friday from 7 a.m. -7 p.m. and Saturday from 10 a.m. to 6 p.m. For more information on Freebee, visit ridefreebee.com.

\author{
Hours of Operation \\ $7 \mathrm{am}-7 \mathrm{pm}$ (Mon-Fri) \\ $10 \mathrm{am}-6 \mathrm{pm}$ (Sat) \\ Closed (Sun)
}

The service provided by the Village of North Bay is free. The following figure depicts the Freebee service coverage area in North Bay.

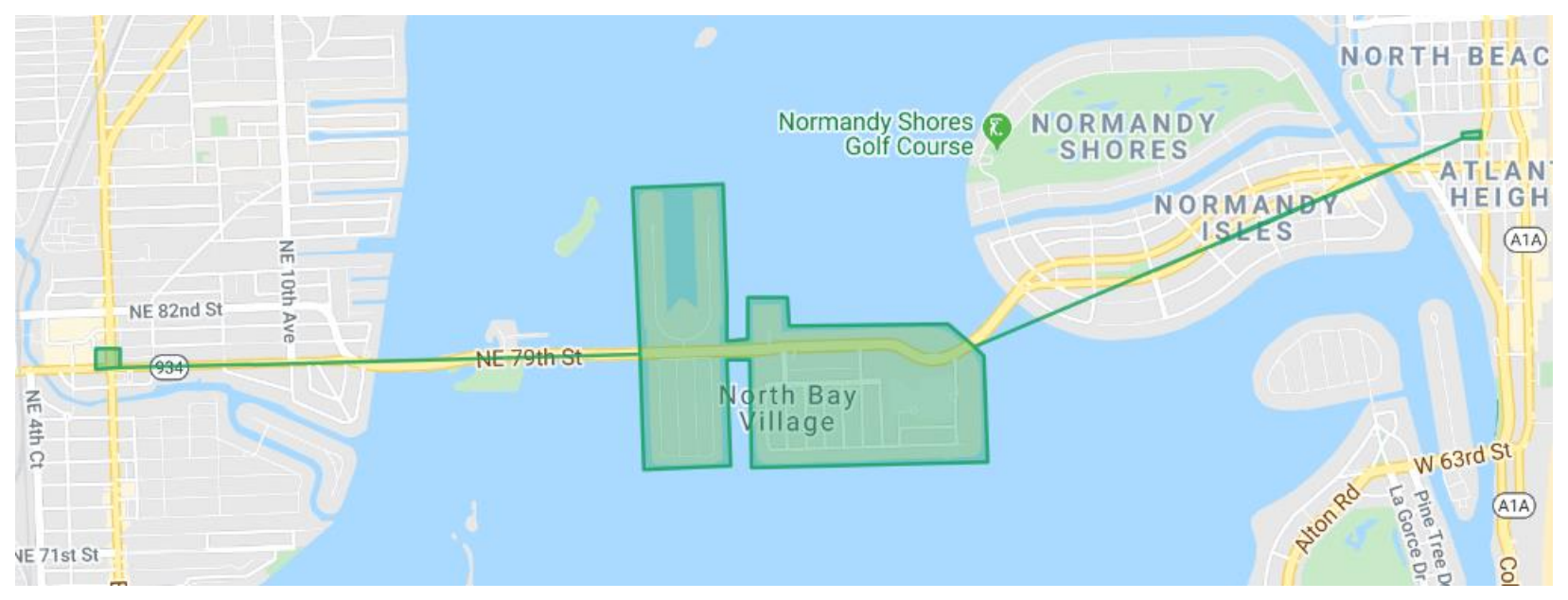


In July 2019, the Village of Palmetto Bay introduced the Freebee on-demand service. Users can ride the service for free anywhere within Palmetto Bay. Two Freebee vans are available to passengers out of the Village's second Park and Ride location in the rear parking area of Palmetto Bay Park. A one-seat ride will allow passengers to travel from and to the Dadeland South Metrorail Station on the Miami-Dade County Transitway. Users can download the "Ride Freebee" app to request a pickup to go to any point in the Village. People who don't use smartphones, they can request a ride by calling 305-397-5002.

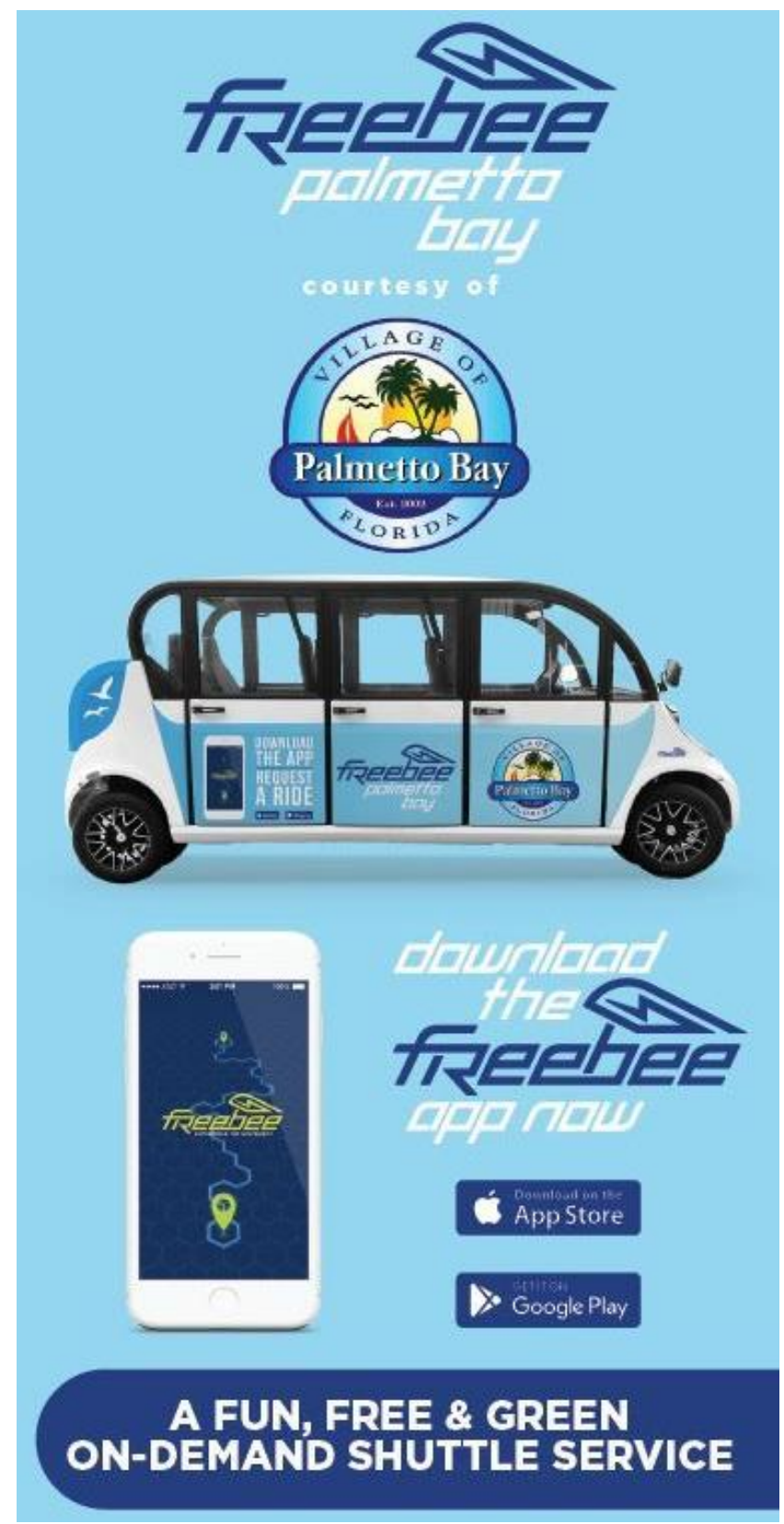




\section{Hours of Operation}

\section{6:30am-10am / 3pm-7pm (Mon-Fri) 1pm-10pm (Sat) \\ Closed (Sun)}

The service provided by the Village of Palmetto Bay is free. The following figure depicts the Freebee service coverage area in Palmetto Bay.

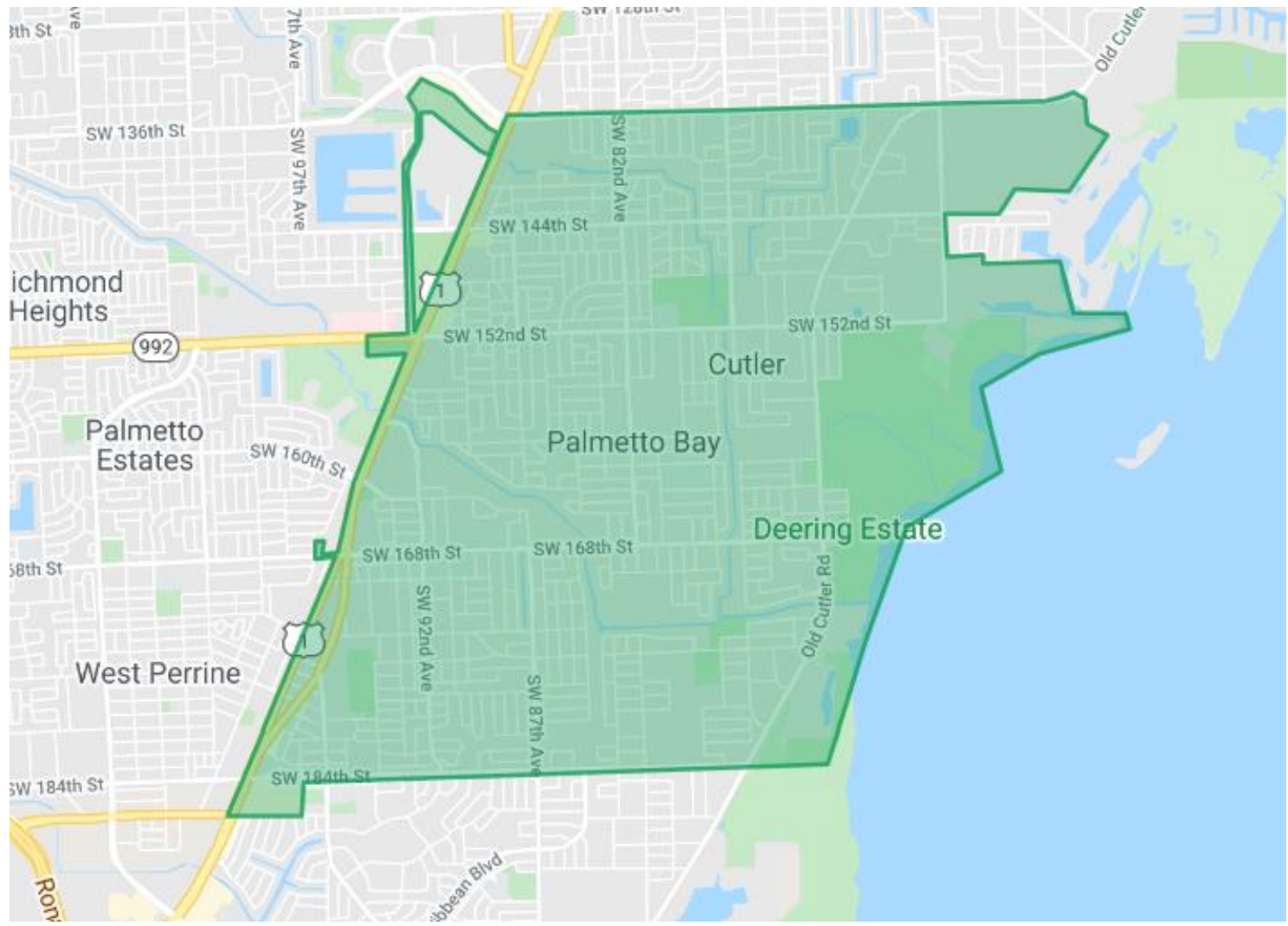




\section{PINECREST}

The Village of Pinecrest offers a free on-demand rides. According to their website, the service launched the Freebee service on January 16, 2019. This service is thanks to a partnership between the Village of Pinecrest, Miami-Dade County's TPO, and Freebee. They provide a green transportation service that offers free on-demand rides around favorite destinations in the Village and also connect to the South Dade Transitway and Metrorail station.

Users can request this service on smartphones through the Ride Freebee app following these easy steps:

- Download the app at www.ridefreebee.com

- Use the app to Request a Ride

- Select your Destination

- Confirm your Pickup, and

- Enjoy the Ride!

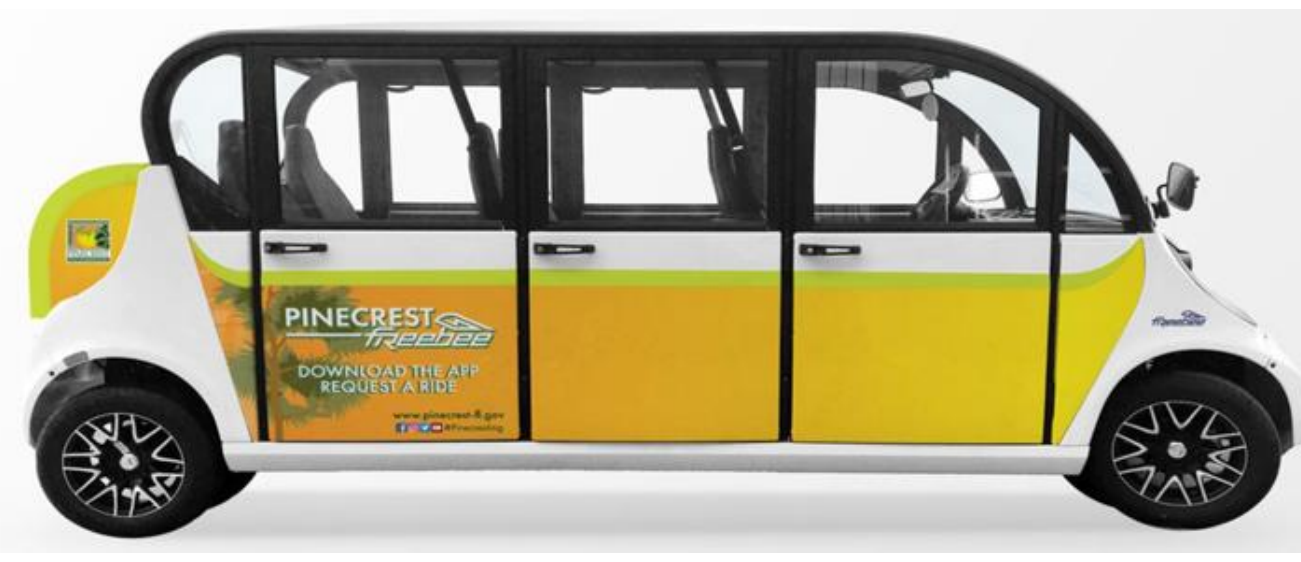

Hours of Operation

7am-7pm (Mon-Fri)

10am-10pm (Sat)

Closed (Sun)

The service provided by the Village of Pinecrest is free. The following figure depicts the Freebee service coverage area in Pinecrest. 


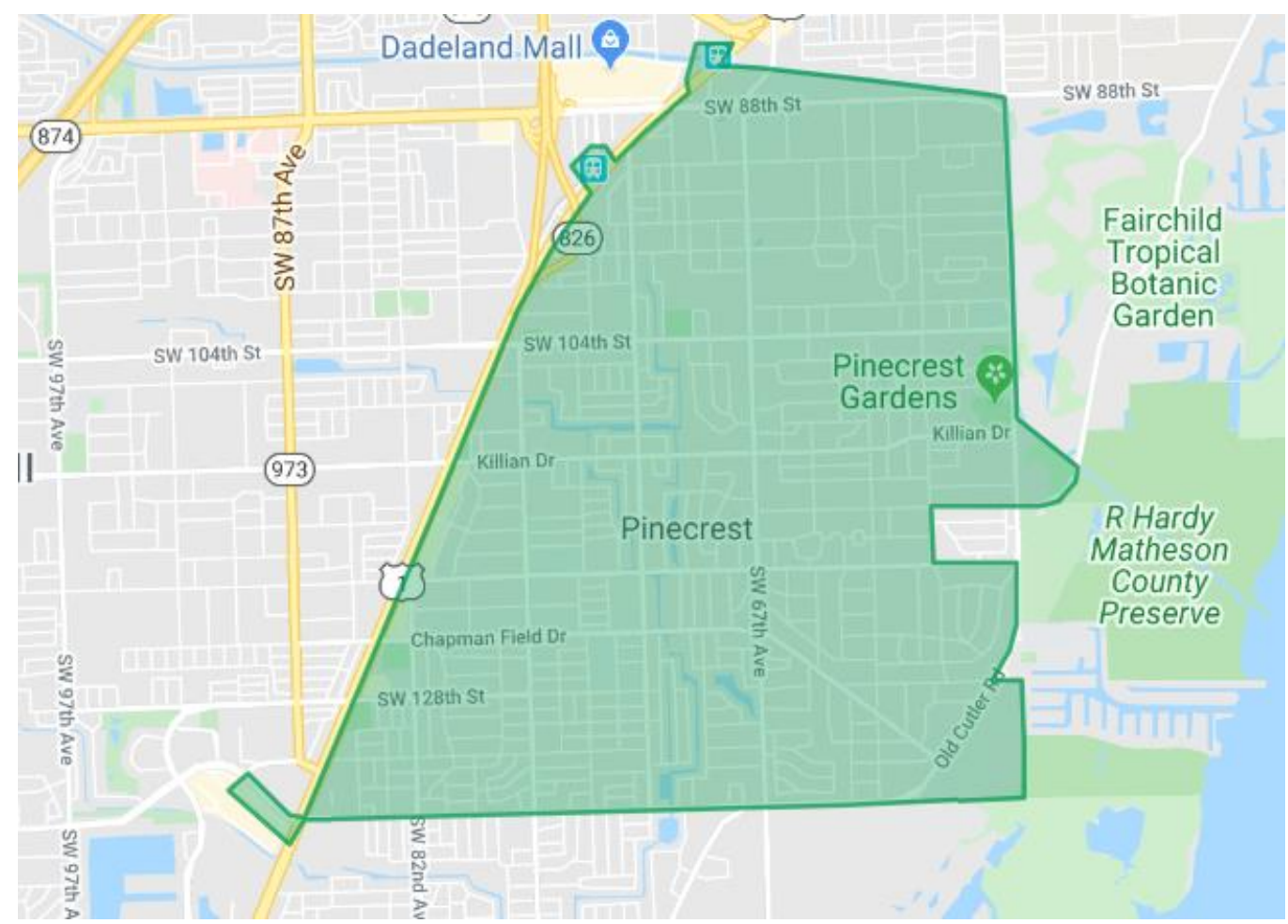


This service is provided for free by Freebee. The operating costs are covered by advertising.

\section{Hours of Operation}

\section{2pm-12am (Mon-Wed) \\ 12pm-2am (Thurs-Sun)}

The following figure depicts the Freebee service coverage area in South Beach.

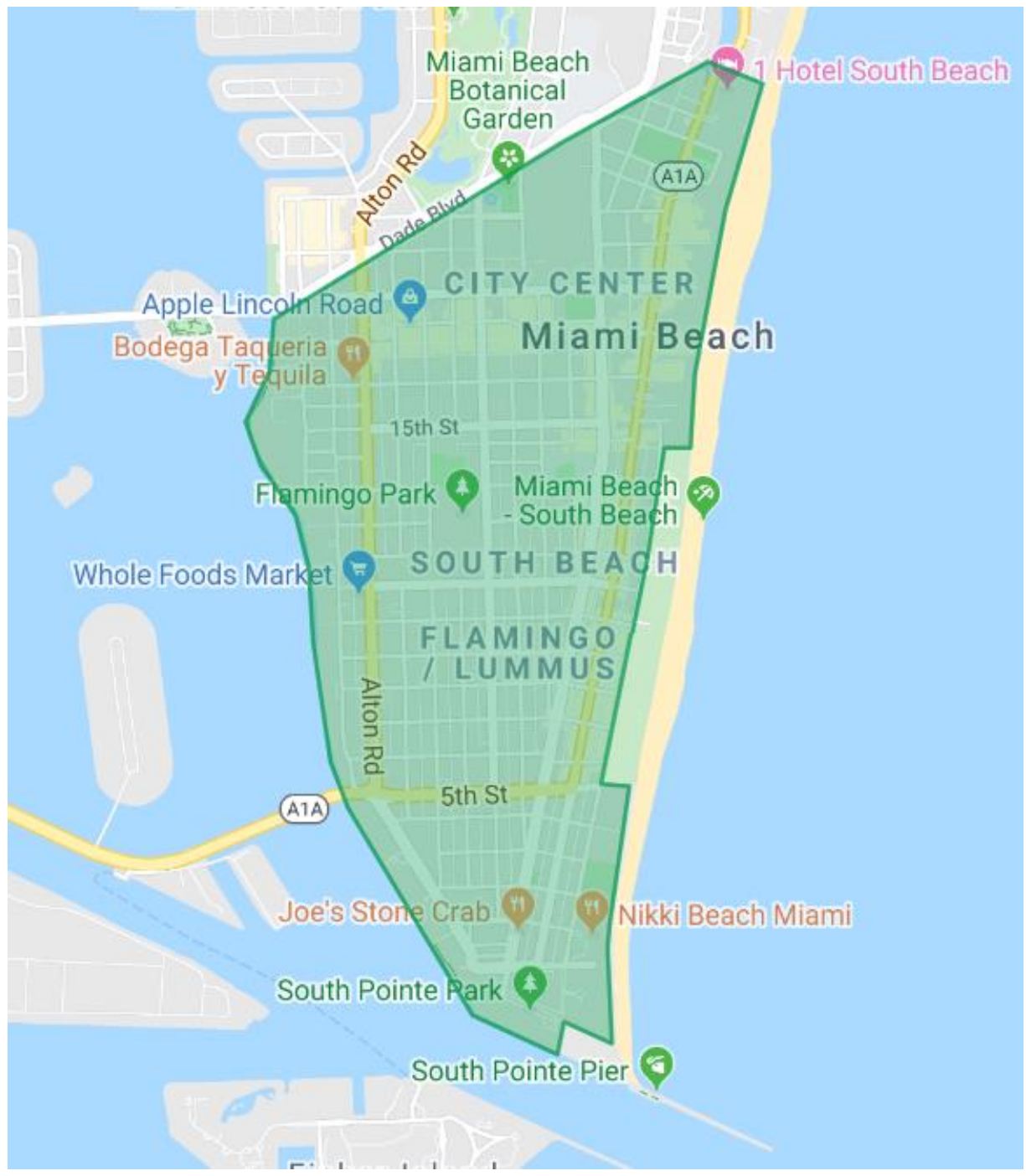

